\title{
THE ROLE OF PERSONALITY AND CURRENT MOOD IN PREDICTING BEHAVIOUR AND SELF-REPORTED AFFECTIVE FORECASTS FOR SOCIAL EVENTS
}

\author{
A thesis submitted to \\ the Faculty of Graduate Studies and Research \\ in Partial Fulfillment of the requirements for the degree \\ Master of Arts
}

by

Christina M. Besner

Department of Psychology

Carleton University

August 2009

(C)2009 Christina M. Besner 


$\begin{array}{ll}\begin{array}{l}\text { Library and Archives } \\ \text { Canada }\end{array} & \begin{array}{l}\text { Bibliothèque et } \\ \text { Archives Canada }\end{array} \\ \begin{array}{l}\text { Published Heritage } \\ \text { Branch }\end{array} & \begin{array}{l}\text { Direction du } \\ \text { Patrimoine de l'édition }\end{array} \\ \begin{array}{l}\text { 395 Wellington Street } \\ \text { Ottawa ON K1A ON4 } \\ \text { Canada }\end{array} & \begin{array}{l}\text { 395, rue Wellington } \\ \text { Ottawa ON K1A ON4 } \\ \text { Canada }\end{array}\end{array}$

Your file Votre référence

ISBN: 978-0-494-60296-6

Our file Notre reférence

ISBN: 978-0-494-60296-6

NOTICE:

The author has granted a nonexclusive license allowing Library and Archives Canada to reproduce, publish, archive, preserve, conserve, communicate to the public by telecommunication or on the Internet, loan, distribute and sell theses worldwide, for commercial or noncommercial purposes, in microform, paper, electronic and/or any other formats.

The author retains copyright ownership and moral rights in this thesis. Neither the thesis nor substantial extracts from it may be printed or otherwise reproduced without the author's permission.
AVIS:

L'auteur a accordé une licence non exclusive permettant à la Bibliothèque et Archives Canada de reproduire, publier, archiver, sauvegarder, conserver, transmettre au public par télécommunication ou par l'Internet, prêter, distribuer et vendre des thèses partout dans le monde, à des fins commerciales ou autres, sur support microforme, papier, électronique etlou autres formats.

L'auteur conserve la propriété du droit d'auteur et des droits moraux qui protège cette thèse. $\mathrm{Ni}$ la thèse ni des extraits substantiels de celle-ci ne doivent être imprimés ou autrement reproduits sans son autorisation.
In compliance with the Canadian Privacy Act some supporting forms may have been removed from this thesis.

While these forms may be included in the document page count, their removal does not represent any loss of content from the thesis.
Conformément à la loi canadienne sur la protection de la vie privée, quelques formulaires secondaires ont été enlevés de cette thèse.

Bien que ces formulaires aient inclus dans la pagination, il n'y aura aucun contenu manquant.

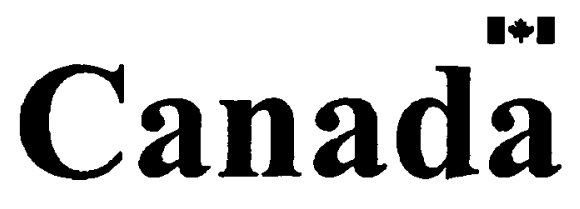




\begin{abstract}
Although trait extraversion is one of the best predictors of happiness (Diener \& Seligman, 2002), research has shown that acting extraverted, regardless of disposition, increases positive affect (McNeil \& Fleeson, 2006). Thus, why don't introverts tend to act extraverted in order to reap potential hedonic benefits? One possible explanation is that introverts, when predicting future affect, forecast differently than extraverts, and in such a way that leads them to be less likely to choose extraverted behaviours. Results demonstrated that, when compared to extraverts, introverts 1) predict less positive emotions in social situations and 2) make predictions about acting extraverted which are, in some ways, less optimistic. These differences may account, at least in part, for why introverts may not choose extraverted-type behaviours/situations. The study generally failed to show, however, that affective forecasts and a related behavioural choice can be modified through the manipulation of mood.
\end{abstract}




\section{Acknowledgements}

Thank you to my advisor John Zelenski, whose patience, support and encouragement has been infinitely appreciated. Your positivity throughout this whole process made all the difference. Also much appreciated was the support of my fellow labmates, especially the senior members of our lab, whose expertise and guidance cannot be undervalued. Added thanks to Kelly Lyon and Serene Mann, your commitment to the lab has been such an asset. Special thanks to Colin Vincent, recruiting from such a small pool of extreme extraverts and introverts was quite the challenge and without your diligent phone calling, we would not have had nearly as many recruits. Finally, thanks to the wonderful administrative staff in the psychology department (especially Etelle Bourassa) for your guidance and support

Thank you to all my friends who constantly asked me the nagging question "how is your thesis going?" in order to keep me on track and motivated. Added thanks to Adam Jones, not only did you push me to succeed, but you were there to encourage me when the task seemed insurmountable. A most special thanks to Adrienne Foster, your constant support throughout these past two years, in all domains of life, has been incredible.

Finally, great thanks are also owed to my family and the Ouimet family, for supporting me in my education since the very beginning. I know how proud you are, and it means so much to me. 


\section{Table of Contents}

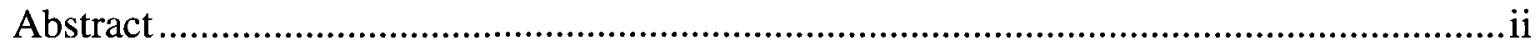

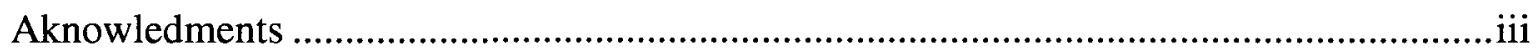

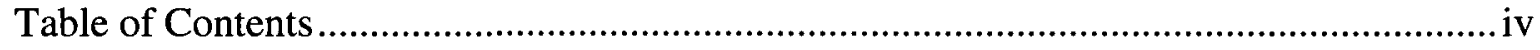

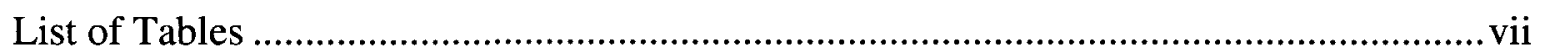

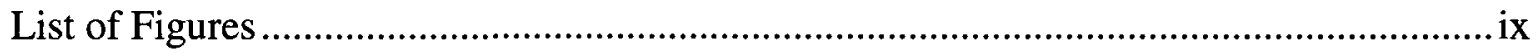

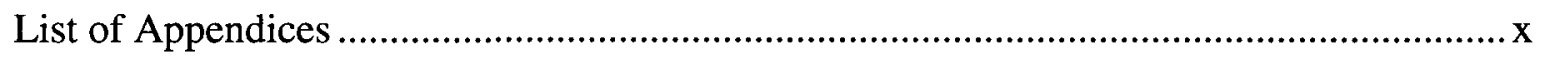

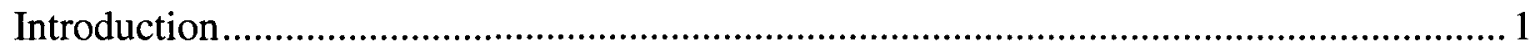

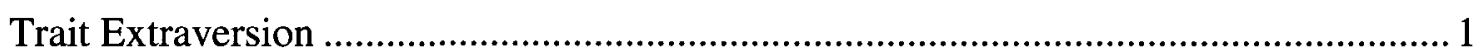

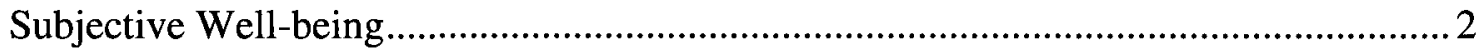

Subjective Well-being and Personality ............................................................... 3

Explaining the Link between Extraversion and Subjective Well-being ....................... 4

State Extraversion and Subjective Well-being ...................................................

Affective Forecasting: Why don't Introverts act Extraverted more Often .................. 12

Personality and Affective Forecasts: Individual Differences in Affective Forecasts .... 17

Interaction between Personality and the Details of the Forecasted Situation ............... 22

Mood States and Affective Forecasts ............................................................... 23

Habitual Mood States and Affective Forecasts..................................................... 27

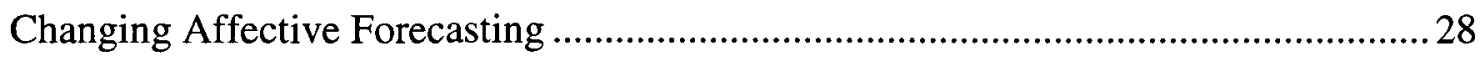

Predictions and Aims of the Current Investigation............................................. 30

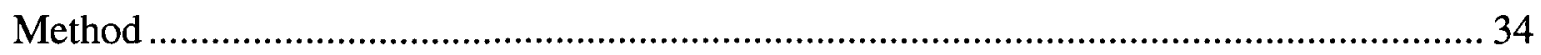

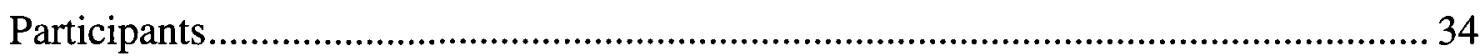

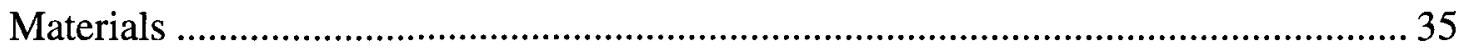


Goldberg's Mini-Markers for Extraversion

Mood Manipulation

Hypothetical Group Discussion Task ............................................................... 37

Hypothetical Group Discussion Affective Forecasting Questionnaire .................... 38

Scoring of the hypothetical Group Discussion Questionnaire ............................. 39

Social Situations Questionnaire ............................................................................. 40

Imagination Questionnaire ................................................................................ 41

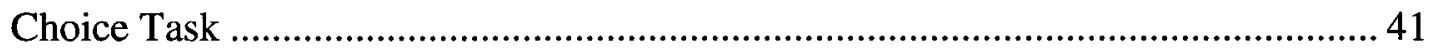

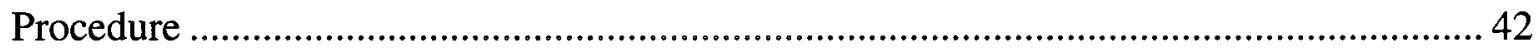

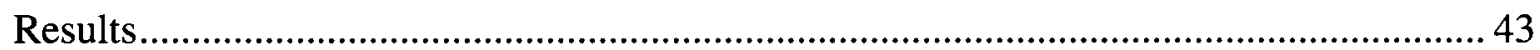

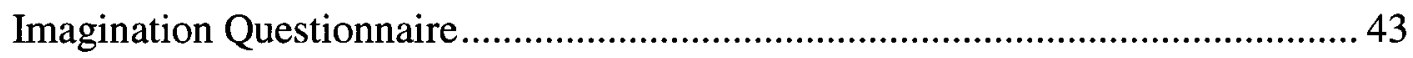

Dispositional Differences in Forecasts for Extraverted/Introverted

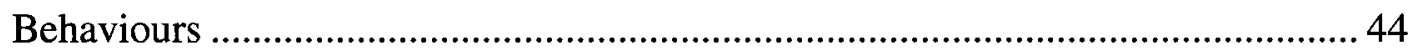

2x2x2 ANOVA: Main Dependant Variables of Interest........................................... 46

Affective Forecasts for Positive Affect......................................................... 46

Positive Attitudes towards Acting Introverted and Acting Extraverted ..... 49

Affective Forecasts for Negative Affect ................................................... 51

2x2x2 ANOVA: Affective Forecasts of Low Activation Positive and

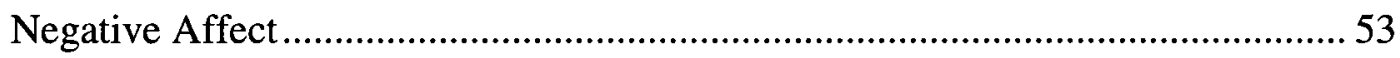

Affective Forecasts for Social and Non-Social Situations.......................................6

Extraverted Behaviours: Choice Task ...................................................................63

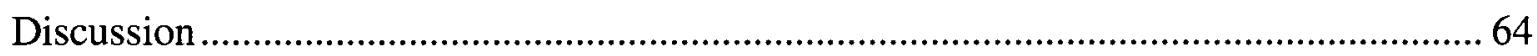

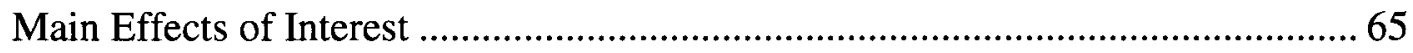

Disposition and Affective Forecasting.................................................................6 
Disposition, Mood, and Affective Forecasting .................................................... 72

Affective Forecasts and Behavioural Choices ....................................................... 75

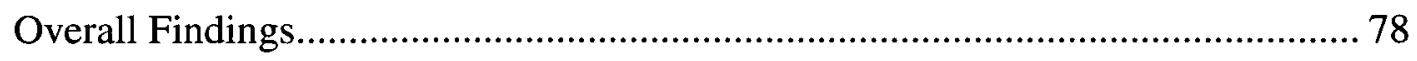

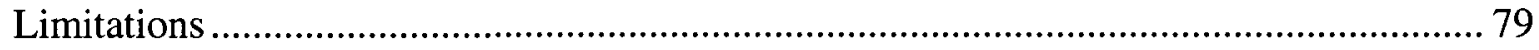

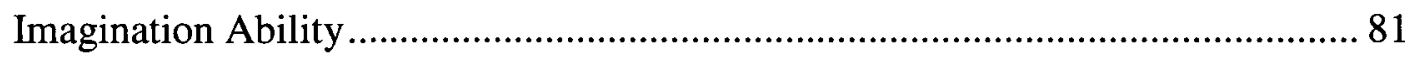

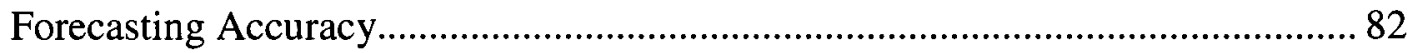

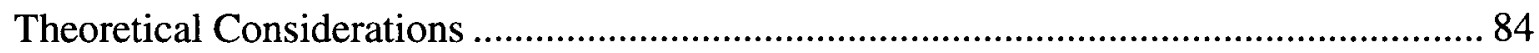

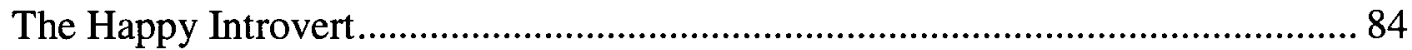

Authenticity and Being True to Traits .............................................................. 85

The Goal of Happiness and Changing Levels of Happiness.................................... 87

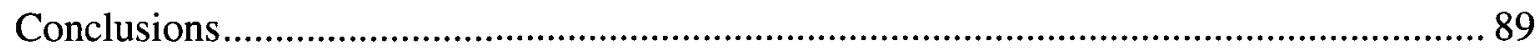

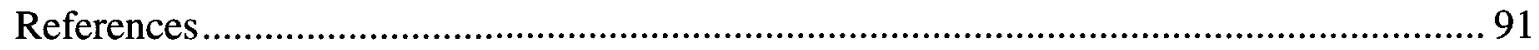




\section{List of Tables}

Table 1 Number of Participants in each Condition Group.......................................... 35

Table 2 Comparison of Affect by Mood Condition ................................................... 36

Table 3 Mean Predicted Positive Affect (neutral mood manipulation only) .................... 44

Table 4 Mean Predicted Positive Attitudes (neutral mood manipulation only) ............... 45

Table 5 Mean Predicted Negative Affect (neutral mood manipulation only).................. 45

Table 6 Mean Anticipated Positive Affect ................................................................. 47

Table 7 PA ANOVA Table: Disposition X Acting Condition X Mood

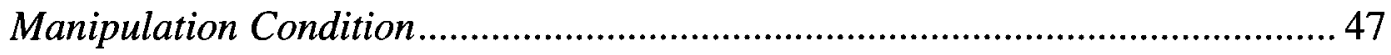

Table 9 Mean Anticipated Positive Attitudes............................................................... 50

Table 10 Positive Attitudes ANOVA Table: Disposition X Acting Condition X

Mood Manipulation Condition ................................................................. 50

Table 11 Mean Negative Affect................................................................................. 52

Table 12 NA ANOVA Table: Disposition X Acting Condition X

Manipulation Condition................................................................. 52

Table 13 Mean Anticipated Low Activation Positive Affect ........................................ 54

Table 14 Low Activation PA ANOVA Table: Disposition X Acting Condition X

Mood Manipulation Condition ........................................................... 54

Table 15 Mean Anticipated Low activation Negative Affect .......................................5 57

Table 16 Low Activation NA Table: Disposition X Acting Condition X

Mood Manipulation Condition ............................................................. 57

Table 17 Mean Ratings Positive Emotions in Social Situations ..................................... 60 
Table 18 Mean Positive Emotions in Social Situations ANOVA Table:

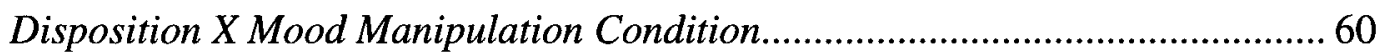

Table 19 Mean Ratings Positive Emotions in Non-Social Situations ................................ 61

Table 20 Mean Positive Emotions in Non-Social Situations ANOVA Table:

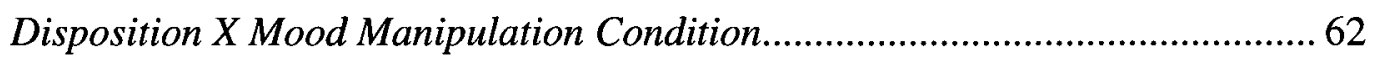

Table 21 Distribution of Responses to the Choice Task by Disposition and

Mood Manipulation Condition ............................................................................ 64 


\section{List of Figures}

Figure 1. Factors Involved in Affective Forecasting ........................................... 28

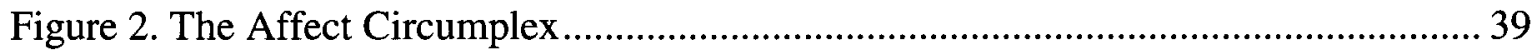

Figure 3. PA Disposition X Acting Condition Interaction Graph ............................... 49

Figure 4. Low Activation PA Disposition X Acting Condition Interaction Graph ........... 56

Figure 5. Low Activation NA Disposition X Acting Condition Interaction Graph............58

Figure 6. Low Activation NA Disposition X Acting Condition X Mood Manipulation

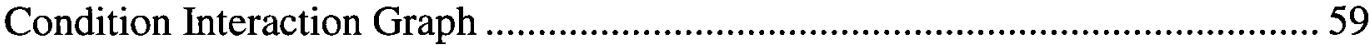

Figure 7. Affective Forecasts for Social and Non-Social Situations ......................... 63 


\section{List of Appendices}

Appendix A - Goldberg's Mini-Markers for extraversion......................................... 107

Appendix B - Mood Induction Film Clip Descriptions ............................................. 108

Appendix C - Questionnaire to Support Experiment Cover Story ............................ 109

Appendix D - Hypothetical Group Discussion Task Instructions ............................. 110

Appendix E - Hypothetical Group Discussion Affective Forecasting Questionnaire ........ 111

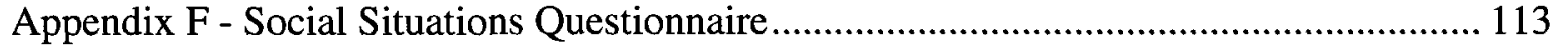

Appendix G - Imagination Questionnaire ........................................................ 114

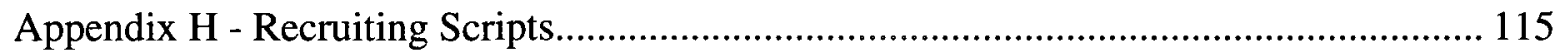

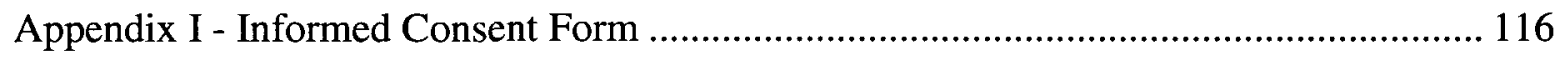

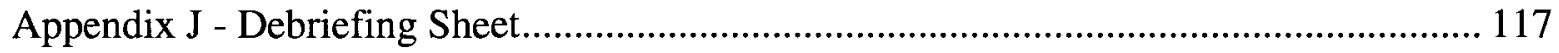




\section{THE ROLE OF PERSONALITY AND CURRENT MOOD IN PREDICTING BEHAVIOUR AND SELF-REPORTED AFFECTIVE FORECASTS FOR}

\section{SOCIAL EVENTS}

Christina M. Besner

Research has shown that trait extraversion is one of the best predictors of happiness (Diener \& Seligman, 2002) and that acting in an extraverted manner, regardless of disposition, is associated with feeling positive emotions (McNeil \& Fleeson, 2006). In light of these findings, several interesting question arise 1) why don't introverts tend to act in an extraverted manner in order to reap potential hedonic benefits and 2) under what circumstances might they be driven to do so? In order to address these questions, the current research examined trait extraversion, mood, and their interactive influence on affective forecasts (the predictions that individuals make about how they will feel in future situations) and behaviour. The overall goal of this research was to gain a better understanding of the role of affective forecasts (which may be influenced by disposition and mood) in explaining why introverts tend not to choose the extraverted behaviours that may lead to increases in well-being.

\section{Trait Extraversion}

Though often explained in a complex manner, "extraversion" and "introversion" are among the easiest psychological attributes to identify with as we have all encountered individuals who can be perfectly described by these labels. We have all come across those who are energetic, enthusiastic, outgoing, seek stimulation, are full of positive emotions, and enjoy the benefits of social facility and influence. At the other extreme, we have all encountered those who tend to be more reserved, low-key, seek less stimulation 
and have less affiliative tendencies. While introversion and extraversion represent opposite tendencies, individuals need not always be labelled strictly as either one or the other. In fact, trait extraversion may be best thought of as representing a continuum on which most people fall somewhere between being an extreme extravert or extreme introvert. Since variations in extent to which individuals display the trait of extraversion are so readily observed and make up a key component of our personalities, laymen, in their own social worlds, and psychological researchers in the laboratory, have tended to place great emphasis on this trait. Across the board, psychologists such as Jung, Eysenck, Cattell, and proponents of the Five Factor Model of Personality, have come to the consensus that the trait of extraversion is an indispensable one. Furthermore, subsequent research has demonstrated that not only is this trait indispensable in describing personalities, but it also has significant implications for some important life outcomes (Costa \& McCrae, 1980; Costa \& McCrae, 1992; DeNeve \& Cooper, 1998; Diener \& Seligman, 2002; Diener, Suh, Lucas, \& Smith, 1999).

\section{Subjective Well-being}

The science of subjective well-being (SWB, or in more common terms, happiness) focuses on how individuals evaluate the quality of their own lives in terms of both life satisfaction and levels of positive affect and negative affect (PA and NA). Thus, ratings of SWB include both a cognitive aspect and an affective aspect. The cognitive component includes judgements of satisfaction in domains such as relationships and work, whereas the affective component includes levels of positive and negative emotions and moods (Myers \& Diener, 1995). If an individual reports that they feel satisfied with their life, experience frequent PA (as described by words such as elation and joy), and 
only infrequent NA (as described by words such as worry, anger or depression), they would be labelled as having high levels of SWB (Diener, 1998; Diener et al., 1999).

As the pursuit of life satisfaction and happiness are major goals for most individuals (Diener, 1998; Diener, Suh, Smith, \& Shao, 1995), it is not at all surprising that psychologist make attempts to scientifically study SWB. In positive psychology laboratories, research is conducted in order to better understand what causes elevated levels of well-being, how affect systems function, how we process evaluations of our own happiness, what underlies human needs, and how affect influences our actions, all in the hopes of increasing our awareness of which factors could help us bolster levels of well-being (Lucas, 2008).

\section{Subjective Well-being and Personality}

Of particular interest is the role that personality traits, such as extraversion, play in influencing levels of SWB. Research has indicated the relationship between traits and SWB is quite significant as personality factors have been reported to account for as much as 39 percent of the variance in SWB (Steel, Schmidt, \& Shultz, 2008). Within the frame of the Five Factor Model of Personality (Costa \& McCrae, 1992) the traits of extraversion and agreeableness have been found to be positively associated with SWB while neuroticism is negatively associated with SWB (DeNeve \& Cooper, 1998). In particular, trait extraversion is one of the best predictors of happiness (Diener \& Seligman, 2002; Hayes \& Joseph, 2002) and research shows that, on average, extraverts report feeling more PA than introverts (Diener \& Seligman, 2002; Diener et al., 1999; Hills \& Argyle, 2001; Lucas \& Fujita, 2000). A meta-analysis conducted in this area revealed an average correlation between trait extraversion and PA of .37 (Lucas \& Fujita, 
2000). This relationship is robust as it is quite stable over time (Costa \& McCrae, 1980; Heady \& Wearing, 1989) and can be generalized across diverse populations varying by gender, age, race, and place of residence (Pavot, Diener, \& Fujita, 1990; Diener et al., 1992). Some researchers have even gone so far as to conclude that positive emotionality is the core quality of the trait of extraversion (Tellegan, 1985).

In summary, the literature on personality and SWB suggests that extraverts tend to experience more PA than introverts. It should be noted that the benefits of experiencing frequent PA have been shown many times over, with happier people experiencing more success in friendship, marriage, health, as well as in work performance and income (Lyubomirsky, King, \& Diener, 2005; Diener et al., 1999). Essentially, extraverts experience more PA, which can lead to higher levels of life satisfaction and overall SWB (Bhattacharya, Singh, Kaur, \& Neeti, 2006). In light of these findings, expressing higher levels of trait extraversion may be viewed in a favourable manner.

\section{Explaining the Link between Extraversion and Subjective Well-being}

As trait extraversion plays a role in driving psychological well-being, researchers have been motivated to better understand and explain this relationship. However, the mechanisms which lead to dispositional difference in levels of SWB are still not well understood and several possible explanations for these differences exist.

One set of possibilities suggests that personality traits affect well-being in an indirect manner (McCrae \& Costa, 1991). That is, levels of SWB are elevated in extraverts due to differences in the situations they tend to choose or the way in which they experience life events. For example, it may be that extraverts select situations which 
are more favourable to the experience of positive emotions (Pavot et al., 1990), partake more in pleasurable social situations (Watson, Clark, McIntyre, \& Hamaker, 1992), tend to derive more enjoyment from social situations, or have more satisfying social interactions than introverts (Argyle \& $\mathrm{Lu}, 1990$ ). However, this set of explanations may not fully account for the relationship between extraversion and PA as research demonstrates that extraverts tend to be happier than introverts even when they are alone (Pavot et al., 1990).

Some evidence suggests that relationship enhancing traits, such as extraversion, are closely tied to levels of SWB (DeNeve, 1999) as they promote our basic and essential need for relatedness to others (Baumeister \& Leary, 1995) which is linked to happiness levels (Myers, 1999 as cited in Ryan \& Deci, 2001). For example, Reis and colleagues (Reis, Sheldon, Gable, Roscoe, \& Ryan, 2000) demonstrated that daily fluctuations in feelings of relatedness predicted daily ratings of PA and other indicators of SWB. As sociability and social involvement are components of the trait of extraversion (Baumeister \& Leary, 1995) and as the maintenance of positive relations with others is linked to the trait of extraversion (Schmutte \& Ryff, 1997), more fulfilled needs to relate to others could explain why extraversion and SWB are associated with one another. In support of this hypothesis, research shows that, introverts who have solid social networks tend to be just as happy as extraverts (Hotard, McFatter, McWhirter, \& Stegall, 1989).

Another explanation might be that extraverts have a better person-environment fit in a society in which social interaction is essential (Diener, Larsen, \& Emmons, 1984; Pavot et al., 1990). In other words, since social interaction is demanded of individuals in our culture, it may be that extraverts have higher levels of SWB due to the fact that they 
have personalities which better coincide with our society's requirements (Pavot et al., 1990).

The temperamental view of the link between trait extraversion and SWB suggests that personality traits represent enduring dispositions that directly contribute to levels of SWB (McCrae \& Costa, 1991). In other words, the temperament of extraverts predisposes them to experience more PA than introverts leading to differences in SWB (Costa \& McCrae, 1980). While the exact nature of the proposed temperamental differences between extraverts and introverts can differ widely, all theories in this category lead to the conclusions that extraverts will generally tend to be happier than introverts, positive events will elicit greater responses from extraverts than from introverts, and that there is probably a biological reason for these differences (Robinson, Solberg, Vargas, \& Tamir, 2003).

Psychobiological explanations for why extraverts and introverts differ in terms of positive affectivity, which coincide with the temperamental view, suggest that there may be internal differences in susceptibility to PA, approach motivation, or reward sensitivity between extraverts and introverts (Carver, Sutton, \& Scheier, 2000). One popular theory, proposed early on by Gray (1971), postulates that trait extraversion levels result from differences in sensitivity to rewards and punishments. In Gray's reinforcement sensitivity theory (1987) these variations in sensitivity are attributed to the differential activation of two neurological systems: the Behavioural Activation System (which responds to signals of reward and nonpunishment) and the Behavioural Inhibition System (which responds to signals of punishment and nonreward). These two systems can be linked to both personality traits and levels of SWB (Elliot \& Thrash, 2002). For example, extraversion 
had been found to be positively associated with sensitivity to rewards (Mitchell, Kimbrel, Hundt, Cobb, Nelson-Gray, \& Lootens, 2007). As a result, extraverts are thought to have more sensitive Behaviour Activation Systems and demonstrate the approach-orientation (a disposition towards approaching situations) which can lead to potential rewards, the promotion of PA, and greater well-being (Pickering, Corr, \& Gray, 1999).

If extraverts are more sensitive to reward cues in their environment than their introverted counterparts, they should also show increased processing of positive stimuli and increased PA in response to such stimuli (Lucas, 2008). In other words, because signals of reward are the source of PA, and because extraverts are more sensitive to signals of rewards, extraverts should be predisposed to experiencing PA (Strelau, 1994, as cited in Roesch, 1999). Research conducted by Larsen and Ketelaar (1989) demonstrates that dispositional extraverts do indeed display a predisposition to experience PA. Specifically, extraverts respond more robustly than introverts when shown stimuli meant to induce a positive mood, but not when shown stimuli meant to induce a negative mood. Similarly, Gross, Sutton, and Ketelaar (1998) demonstrated that, when viewing a positive mood inducing film, extraversion was associated with both a greater tendency to experience PA and a stronger reaction to positive mood clips. Thus, Gray's suggestion that extraverts are more sensitive to positive cues may be reflected in the greater reactivity of extraverts to positive stimuli in the outlined studies.

In recent years, researchers have moved beyond theoretical psychobiological explanations for the link between extraversion and PA to examine this issue on a physiological level. Several studies have shown that extraversion is correlated with activity in areas of the brain which are dopaminergically innervated and have been shown 
to influence affect and reward processing (Depue \& Collins, 1999; Hutcherson, Goldin, Ramel, McRae, \& Gross, 2008). Additionally, research using functional magnetic resonance imaging has shown that extraverts show greater brain activation (specifically in the amygdala) in response to faces with happy expressions when compared to introverts (Canli, Sivers, Whitfield, Gotlib, \& Gabriel, 2002). Thus, research substantiates the idea that there are biological differences between extraverts and introverts which may help explain levels of SWB.

In sum, psychobiological explanations for dispositional differences in SWB, in their various forms, point to one other explanation for why extraverts tend to experience more PA. Essentially, they suggest that extraverts may be more attuned to positive stimuli, respond to the same objective stimuli with more intense positive emotions than introverts (Zelenski \& Larsen, 1999), and be prone to seeking out rewards with approachoriented behaviours.

Other temperamental theories suggest that extraverts may be prone to experiencing PA because they are able to better self-regulate their moods to maintain positive moods over time (Lischetzke \& Eid, 2006) and/or experience more emotional stability in general (Vitterso, 2001; Hills and Argyle, 2001). Indeed, research does suggest that, overall, extraverts are better able to understand and regulate their emotions when compared to introverts (Ciarrochi, Chan, \& Caputi, 2000).

It should be noted that explanations for why extraverts, in general, seem to be happier than introverts, are not mutually exclusive. It could be that numerous personality theories, taken together, account for the relationship between extraversion and SWB. Furthermore, such personality factors may combine with situational or environmental 
factors to fully explain the link between extraversion and SWB (Pavot et al., 1990). Though complex, research on this topic is critical as in working to understand the link between personality factors and SWB we may find the potential to increase levels of well-being in our society (Diener, 2000). Although it may not be feasible to significantly modify the stable aspects of an individual's personality, we may be able to increase levels of well-being by encouraging extraverted behaviours in more introverted individuals (Argyle \& Lu, 1990). In line with this, Fredrickson (2008) proposes that being more social, extraverted, and interacting with others is a potential route to increasing happiness levels. These suggestions are critical to current research.

\section{State Extraversion and Subjective Well-being}

An important issue that needs to be addressed is whether or not there is a causal link between extraverted behaviours and happiness. If changes in extraversion lead to changes in levels of PA, then it may be possible to promote well-being through behaviour change (McNeil \& Fleeson, 2006), potentially through the manipulation of personality states. A personality state, unlike a stable personality trait, describes an individual's personality in the moment (Fleeson, 2001). The notion of a personality state coincides with the density distribution approach to personality which purports that personality is determined, not necessarily by a fixed internal trait, but by the distribution of varying personality states over periods of time (Fleeson, 2001). According to this approach, extraverts can be described as such because they tend to be high on state extraversion more often over time than those who would be labelled as introverts. To the extent that personality states and personality traits share common features (and indeed, Fleeson suggests that traits and states may be somewhat isomorphic), there is the potential that 
enacting an extraverted personality state may invoke the same PA associated with the personality trait of extraversion (Fleeson, Malanos, \& Achille, 2002). In light of this, research can explore beyond why extraverts may be happier than introverts in general, to examine why individuals (extraverted or introverted) might be happier on one day, or during one hour, than they are at other times. The answer might have to do with the extent to which that person has "acted extraverted" in the moment.

Research has shown that there is considerable within-individual variation in traits levels (Heller, Komar, \& Lee, 2007) and that people differ significantly in their behaviour from moment to moment. That is, regardless of dispositional traits, individuals are likely to behave in introverted and extraverted ways over time. Throughout these variations, it has been found that individuals tend to be happier when acting extraverted then when acting introverted. For example, Fleeson et al. (2002) examined the relationship between state extraversion and happiness by having participants rate their levels of extraversion and PA five times a day over a 13 day period. The study demonstrated that momentary increases in state extraversion were accompanied by momentary increases in levels of PA. This research is important as it demonstrates that short-term, within-person variations in levels of state extraversion can be linked to online fluctuations in affect. Therefore, in addition to the evidence that stable differences in happiness levels can be attributed to differences in trait extraversion, research suggests that changes in state extraversion lead to increased PA, regardless of stable disposition.

Subsequent research by McNeil and Fleeson (2006) has demonstrated that when state extraversion is manipulated by instructing participants to temporarily act either extraverted or introverted in a group discussion task, regardless of individual disposition, 
participants report more PA when instructed to act extraverted as opposed to introverted. In their study, participants engaged in ten minute group discussions with two other individuals. In each group, one participant was instructed to act extraverted (bold, spontaneous, assertive, and talkative), one was instructed to act introverted (reserved, inhibited, timid, and quiet) and a third participant was given no instructions (forming a control group). The results demonstrated that acting extraverted, as opposed to acting introverted, led to increased reports of PA. Thus, acting in an extraverted manner, even if one is a dispositional introvert, has the potential to yield hedonic benefits and increase well-being. As such, the link between SWB and personality is likely to be at least somewhat attributable to engaging in extraverted behaviours as opposed to possessing the temperamental attributes of a dispositional extravert.

In sum, the work of Fleeson and colleagues (Fleeson et al., 2002; McNeil \& Fleeson, 2006) shows that there is a casual link between extraverted behaviours and PA. Furthermore, it suggests that well-being could potentially be increased through acting in an extraverted manner.

Since social situations may elicit more extravert-type behaviours, we might also expect that participating in such situations boosts levels of PA. In line with this, studies show that spending time in social situations is generally a pleasant experience (Lucas \& Diener, 2001) and that individuals who act in a sociable manner tend to experience more PA than others (Emmons and Diener, 1986). Furthermore, Vittengl and Holt (2000) have demonstrated that even when social situations are not self-selected (i.e. when individuals are placed into a social situation), individuals report benefiting affectively from such situations. Related research has shown that when mood is manipulated in a negative 
direction, regardless of disposition, individuals benefit affectively from participating in social interaction (Augustine \& Hemenover, 2008). In other words, affect repair is possible for both extraverts and introverts through social interaction. In addition, this experiment demonstrated that introverts tended to cope maladaptively when alone, but coped just as well as extraverts when given the chance to socially interact. Thus, not only do more social situations seem to lead to PA, but being in a social situation may encourage affect repair as well.

The described research provides support for the notion that enacting an extraverted state leads to increased positive affect and suggests that being in more social situations may lead to greater PA as well. However, it has been suggested that the causality may actually work in the reverse direction in our daily lives (Diener et al., 1992; Pavot et al. 1990). That is, it may be that positive moods lead us to feel more extraverted or behave more socially. The implications of mood states and the potential bidirectional relationship between PA and acting extraverted will be addressed later in this review.

\section{Affective Forecasting: Why don't Introverts act Extraverted more Often?}

The evidence shows that extraverts and introverts alike feel PA in situations where they act in an extraverted manner. This finding begs the question as to why extraverts tend to take advantage of this potential for mood boosts through acting in an extraverted manner while introverts may fail to do so. One potential explanation, which is especially important in the current investigation, relates to affective forecasts. An affective forecast is a prediction about the extent to which a future outcome or event will bring us positive or negative emotions. Thus, much like when meteorologists attempt to forecast future weather conditions, we regularly attempt to forecast our future emotional 
states. For example, if invited to a social gathering, we might try to forecast the emotions we would expect to result from this event. Both anticipated positive feelings (such as elation, joy, and excitement) as well as negative feelings (boredom, anxiousness, and fear) are likely to be assessed. Although this process can be undertaken explicitly, much of our forecasting may occur at an implicit level (Gilbert, Pinel, Wilson, Blumberg, \& Wheatley, 1998). Once we have forecasted our affect and developed a set of predicted emotions for an upcoming event, we can then base our decisions about this event (for example, whether or not we would like to attend the social gathering) on these anticipated emotional reactions (Wilson \& Gilbert, 2005). Thus, the emotions we expect feeling as a result of our actions can affect our decision making processes and guide the choices we make (Mellers \& McGraw, 2001).

The Decision Affect Theory (Mellers, Schwartz, Ho, \& Ritov, 1997) substantiates this view by detailing what factors we take into account when using our predicted emotions to make decisions. Specifically the theory suggests that, when we make a choice, we perform a mental calculation in which we take into account the utilities of the obtained (and unobtained) outcomes, the likelihood of the particular outcome occurring, as well as the potential disappointment that may ensue due to the differences between various outcomes. In essence, we weigh our anticipated emotions about a particular outcome by the perceived chance of that outcome occurring to calculate an average level of anticipated pleasure for each outcome (Mellers, Schwartz, \& Ritov, 1999). Then, after considering our choices, we are able to opt for the outcome that we believe is most likely to bring us the maximum amount of pleasure (Schwarz, 2000). Thus, the processes forecasting affect should be viewed as a critical one as individuals base their actions, at 
least in part, on their expectations about the affective consequences of future events (Gilbert et al., 1998; Mellers \& McGraw, 2001; Mellers et al., 1999).

However, just as meteorologists sometimes mispredict future weather conditions, individuals may mispredict their affective responses to future events. Such errors can result in suboptimal decision making (Kermer, Driver-Linn, Wilson, \& Gilbert, 2006) which could lead to a failure to profit from situations which may bring us happiness or lead us to engage in behaviours that may be detrimental to happiness levels. Indeed, research suggests that errors in affective forecasts can lead individuals to act in ways that do not optimize well-being and happiness (Gilbert \& Ebert, 2002). While not all decisions are made in the pursuit of happiness (some important goals may involve making less hedonically appealing choices), when we do make choices based on the anticipated hedonic consequences of our actions, these choices need to be rooted in unbiased affective forecasts of future emotions.

Research on affective forecasting has demonstrated that individuals tend to anticipate that their immediate reactions to emotional events will be more intense than the reactions that they actually experience. In a sequence of studies, Buehler and McFarland (2001) demonstrated that individuals overestimated both their PA in response to a pleasant event (getting a grade in university than expected) and their NA in response to an unpleasant event (getting a grade worse than expected). This "intensity bias" has been demonstrated in many other studies as well. For example, it has been shown that university professors who were denied tenure were much happier than they expected to be in response to the disappointment (Gilbert et al., 1998) and displeasure was also overestimated in women receiving undesired pregnancy test results (Mellers \& McGraw, 
2001). However, there is some evidence which demonstrates that the impact bias can be curbed. Buehler and McFarland (2001) found that when participants were encouraged to focus on relevant past experiences when forecasting affect for a future event, they made less extreme and more accurate predictions than those who focused only on the future event itself to the exclusion of past experiences.

Forecasting biases can also occur due to what Schkade and Kahneman (1998) have label the "focusing illusion". This illusion occurs when we focus our attention too much on a particular aspect of a situation and neglect to take into account other aspects. Under these circumstances the attended information is likely to be overweighed in terms of importance and the role of other aspects underweighted. For example, when asked to imagine life as a paraplegic, we may focus too much on the loss of the use of our lower extremities and neglect to take into account other significant factors which impact life satisfaction, but would not be tainted by paraplegia. Since the impact on well-being of past events (such as the involvement in a life altering accident) is reduced as we shift our attention to current events and daily preoccupations (Suh et al., 1996), we should not neglect to take such other factors into account when forecasting our affect. There is also evidence, however, that the effect of the focusing illusion can be curbed. Wilson and colleagues (Wilson, Wheatley, Meyers, Gilbert, \& Axsom, 2000) were able to demonstrate that when participants were encouraged to consider the various other events that would occur concurrently with an event for which affect was being forecasted, the focusing illusion was avoided and forecasts became less extreme and more accurate.

Ross (1989) suggested that our predictions of future affect are guided by implicit theories about how particular events tend to unfold. If such theories are misguided, biases 
in affective forecasts could result. For example, if an individual tends to view social gatherings as intensely awkward, they may overestimate the amount of NA that will result from such events and fail to consider the neutral or potentially positive emotions that could accompany the event. Additionally, it has been shown that the details of an event we imagine often differ quite significantly from the actual experience of the event (Dunning, Griffin, Milojkovic, \& Ross, 1990) and that although individuals may imagine a future event occurring in one specific manner, there are usually many ways in which the event could unfold (Buehler \& McFarland, 2001). Research conducted by Griffin, Dunning, and Ross (1990) demonstrates that, when imagining a future event, individuals do indeed tend to envision only one particular scenario and thus, most likely make one single affective forecasts for the event. However, depending on the way in which the actual event unfolds, emotional reactions could vary widely. Thus, wrongly envisioning what a situation might entail or not considering the differing ways in which situations could unfold, is another manner in which biases in affective forecasts may occur.

Finally, affective forecasts about future emotions may be influenced by our recall of past emotional states (Thomas \& Diener, 1990). Since we often use our memories about emotions during past events to make forecasts for similar future events (Wilson, Meyers, \& Gilbert, 2001), it is important that our recall of past emotions be accurate. However, research shows that individuals tend to make errors when recalling past emotions. For example, one study demonstrated that individuals tend to overestimate past emotional intensity and underestimate the frequency of PA (as compared to NA) when recalling past emotional states (Thomas \& Diener, 1990). Such errors in the recall of past 
emotions may provide an extra hurdle towards making unbiased affective forecasts in the present.

In sum, the affective forecasts we make and the theories we hold about what will bring us positive emotions and what will not are extremely important as they can give us clues as to how individuals may behave in order to increase their own levels of wellbeing (Furnham \& Cheng, 2000). Affective forecasts which relate to the extent to which individuals believe that extraverted situations and behaviours will increase happiness (Diener, 1984) are especially important in the context of the current investigation. From the research described in this paper, it is clear that happiness is associated with levels of extraversion, and that increased extraverted behaviours can lead to increased PA. However, research demonstrates that not all individuals believe that being extraverted is associated with being happy (Furnham \& Cheng, 2000). Thus, the affective forecasts we make for more extravert-type behaviours may indeed lead our actions astray.

Personality and Affective Forecasts: Individual Differences in Affective Forecasts

The current investigation was based on the idea that introverts make the hedonically suboptimal choice to engage in introverted behaviours over more extraverttype behaviours. Although the evidence suggests that introverts have the potential to reap hedonic benefits from acting extraverted (Fleeson et al., 2002; McNeil \& Fleeson, 2006), we proposed that introverts would not anticipate these hedonic benefits. In line with this, a small pilot study conducted in the Carleton University Happy Lab (Wynn \& Zelenski, 2007) suggested that introvert may indeed underestimate PA for acting extraverted to a significantly greater degree than extraverts. In investigating dispositional differences in affective forecasts in the current study, we expected that introverts would predict affect 
for extravert-type behaviours differently than extraverts, and in such a way that may lead them to be less likely to choose extraverted behaviours and situations. Essentially, a central question in the current research is what type of affective forecasts do people with differing levels of trait extraversion make for extraverted/introverted behaviours and how might differences in forecasting influence optimal decision making? However, in order to ask such a question, it is first desirable to support the assumption that individual differences in affective forecasts exist and may be related to disposition.

As already discussed when predicting future affect, various biases can influence our affective forecasts. Beitz (2005) suggests that although people in general tend to exhibit these biases, individual differences may moderate their effects and lead to differences forecasting. For example, Beitz demonstrated that levels of negative affect intensity (somewhat similar to neuroticism, this is the tendency to react to negative outcomes with low, normal or excessive negative emotions) was an adequate predictor of affective forecasts for the duration of future negative affective states. Specifically, those showing more negative affect intensity tended to overpredict the duration of future negative states to a greater degree than others. Thus, Beitz was able to demonstrate that a psychological variable (negative affect intensity) could be implicated in individuals' tendency to exhibit a greater forecasting bias. Although Beitz's research is most closely linked to psychopathology, it suggests that personality factors may also lead to individual difference in forecasting (since negative affect intensity is similar to the personality trait of neuroticism).

Mellers (2000) described that some individuals anticipate greater pleasure accompanying good outcomes/less displeasure accompanying bad outcome, while others 
may anticipate less pleasure with good outcomes/greater displease with bad outcomes. Mellers further suggests that the former group may have a tendency to approach situations, whereas the later may tend to demonstrate avoidance behaviours. These ideas relate closely to the theory of reward sensitivity and it may be that extraverts react more in line with the first description (optimistic forecasts and approach-oriented behaviours) whereas introverts react more in line with the second description (less optimistic forecasts and avoidance-oriented behaviours). In agreement with these ideas, research shows that introverts are less likely to predict positive events occurring in the future (Zelenski \& Larsen, 2002) and tend to evaluate positive future event less positively than extraverts (Uziel, 2006). Focusing more extravert-type situations in particular, the literature has shown that extraverts rate pleasant social situations more positively and anticipate feeling more PA in such situations when compared to introverts (Lucas \& Diener, 2001). Since those high in extraversion tend to anticipate that events will be more positive, it follows that they might choose to approach situations more often than introverts, and indeed, levels of extraversion correlate with decisions to approach certain situations (Starosta, 1999).

Recall that Thomas and Diener's (1990) suggested that affective forecasts about future emotions may be influenced by our memories of past emotional states. Thus, it may be that introverts and extraverts differentially recall past emotional events, leading them to make different predictions about future outcomes. To substantiate this view, Mayo (1982) found that extraversion was related to the retrieval of more positive memories. Similarly, Feldman Barrett (1997) found that extraverts tended to recall more positive emotions than they report on a momentary basis. The fact that extraverts recall 
more positive memories may explain, at least in part, why their affective forecasts tend to be more positive than those of introverts. In a similar vein, it has been proposed that since introverts are more sensitive to cues of punishments, they may have been significantly impacted by past aversive social situations (Graziano, Bernstein Feldesman, \& Rahe, 1985). Such salient memories of aversive social encounters might bias forecasts for future encounters in a negative direction and lead introverts away from choosing social events. Extraverts, by contrast, being sensitive to rewards, might have forecasts which are biased in a positive direction because of the salience of positive past social situations.

Although predictions of future affect are often based on specific memories of emotions in similar past situations, Lerner and Gonzalez (2005) suggest that the very act of calling up information from memory can influence forecasts and lead to individual differences. An important concept in their area of work is ease-of-thought-generation, that is, the ease with which an individual can generate examples of or thoughts about something. In one study by Rothman and Schwartz (1998), participants were asked to list either three factors that made them susceptible to heart disease (easy to generate list) or 8 factors (a more difficult to generate list). The authors demonstrated that when it was easier it was for participants to generate a list of risk factors for heart disease, they tended to form the implicit impression that were more vulnerable to this condition when compared to those for whom generating examples was more difficult. In the current context, dispositional differences in generating thought about acting extraverted or partaking in social situations could lead to different implicit judgements about such action and events. For example, if introverts find that it is easy to generate examples of how extravert-type situations are uncomfortable and/or extraverts find it easy to generate 
examples of how enjoyable extravert-type situations are, this could lead to differences in affective forecasts with introverts predicting less positive emotions than extraverts. Essentially, the act of calling up information from memory can bias prediction of affect and may lead to individual differences in affective forecasts.

Robinson and Clore (2002a) suggest that although people prefer to predict their future emotions based on information about the specific upcoming event, this type of information is not always available. In such cases, it is proposed that individuals rely on trait self-knowledge (Robinson and Clore, 2002b). In other words, when individuals do not have the experiential knowledge about a situation or event that would allow them to make judgements about their emotions for this event based on memory, they often use trait-related beliefs about how they tend to react in general. As an example, if an extravert doesn't know exactly how they will react to a particular extravert-type situation, they might infer their emotional reactions in a way that is consistent with trait-related beliefs about themselves, and most likely conclude they would enjoy the situation. As introverts would be acting counterdispositionally in such a situation, they might reach a very different conclusion due to their differing trait-related beliefs. Although the affect of trait self-knowledge on ratings of emotion has not been shown with regards to prospective emotions (affective forecasts), it has been shown with regards to retrospective emotions. Feldman Barrett (1997) demonstrated that extraverts' trait-related beliefs about emotion informed their retrospective judgements of emotion.

In sum, research has shown that extraverts and introverts process information differently when evaluating future events and when recalling events and emotions from memory. In a very general sense, the research suggests that extraverts tend to predict 
more positive emotions and outcomes, and recall more positive memories than introverts. The literature also provides support for the notion that extraverts forecast affect more positively for extravert-type behaviours and social situation specifically. The theoretical ideas discussed provide some insight into why these differences may exist. Overall, the literature strongly supports that idea that individual differences in affective forecasts exist and are related to disposition.

\section{Interaction between Personality and the Details of the Forecasted Situation}

As previously summarized, the current investigation was based on the idea that introverts make the hedonically suboptimal choice to engage in introverted behaviours over more extraverted behaviours because they predict affect differently than extraverts, and in such a way that may lead them away from choosing extraverted behaviours. Although the evidence suggests that extraverts forecast more positively than introverts in general and more positively for social situations, the question of how introverts and extraverts feel about introverted behaviours still remains. If extraverts forecast affect for all situations more positively than introverts, and introverts forecast affect for all situations more negatively than extraverts, there may be no reason to suspect that affective forecasts could account for differences in decisions to approach extraverted and introverted situations. However, if introverts were found to forecast affect for introverted behaviours and situations more positively than extraverts, this could explain why introverts may be inclined to choose such behaviours and situations. Thus, an important question for the current study to address is do extraverts indiscriminately forecast affect more positively, while introverts forecast less positively, or do judgements depend on the situation being evaluated? We strived to support the idea that affective expectations do 
not solely depend on disposition, but on the interplay between disposition and the details of the situation (extraverted versus introverted situations/behaviours) for which affect is being forecasted.

\section{Mood States and Affective Forecasts}

It may also be that personality traits influence affective forecasts through their influence on mood states. As already discussed, personality traits can predispose individuals to certain mood states, with extraverts experiencing more PA than introverts. In response to affect-related traits such as extraversion, Rusting (1998) proposed that mood states mediate the relationship between personality and differences in information processing. In line with this, Zelenski and Larsen (2002) suggest that since the affectrelated traits such as extraversion predict habitual mood states, and since mood states influence judgments (for a review, see Schwarz, 2000), traits such as extraversion may predict affect-congruent judgments. Given that forecasting one's affect is a cognitive, judgment based task, this process could be influenced by habitual mood states (which are linked to disposition). However, in order to explore how dispositional traits may influence affective forecasts through their influence on habitual mood states, it is first necessary to support the assumption that mood states in general can influence affective forecasts.

Broad findings in the area of mood and biases suggest that affect-related cognitive processes can have an impact on judgements with positive moods tending to positively bias judgements and negative moods tending to negatively bias judgements (Rusting, 1998). According to the affect as information model, this effect occurs because individuals mistake pre-existing feelings for feelings about the target they are judging 
(Schwartz \& Clore, 1983). In other words, it may be difficult to distinguish between preexisting emotions and our emotional responses to thinking about the object of our judgement. Alternatively, mood-congruency theory can also explain these findings. This theory is based on a network model of affect in which emotions have specific nodes in memory which are linked with other aspects of memory (Bower, 1991). When a specific node is activated, the links associated with that emotion are also activated and the information associated with that emotion becomes more accessible. Thus, when in a positive mood, positive information linked to nodes in memory for PA become more easily accessible. This greater accessibility can contribute to biasing judgments in a mood-congruent direction.

Research demonstrates that current states can indeed affect affective forecasts for future events. For example, individuals predict greater enjoyment of a next day meal when they make these predictions hungry as opposed to satiated (Gilbert et al., 2002). This research shows that individuals sometimes use their current states to make predictions about future affect, even though their current state may be irrelevant to the future affective state in question. This effect has been labelled a "projection bias" as individuals are projecting their current state into their predictions of future states (Loewenstein, O'Donoghue, \& Rabin, 2003). Although the meal study described did not focus on mood states in particular, it does demonstrate that a visceral state can influence an affective forecast for a future event and suggests the possibility that another state, such as a mood state, may impact forecasts. And indeed, research in this area has shown that positive moods lead individuals to make more positive associations with situations they imagine themselves in (Clark \& Waddell, 1981). Thus, the literature does provide some 
support for the idea that mood states influence affective forecasts in a mood-congruent manner.

Mood states may also influence the memories that we recall which, as previously discussed, can influence affective forecasts. Research suggests that individuals tend to recall mood-congruent memories (Bower, 1991; Isen, Shalker, Clark, \& Karp, 1978). Thus, we tend to recall more positive memories when in a good mood and more negative memories when in a bad mood. In line with this, Teasdale, Taylor, and Fogarty (1980) found that current mood could impact recall of past experiences, with positive moods leading to the recall of more pleasant memories. Since we often base affective forecasts on our recall of pasts event (Wilson et al., 2001), if one is better able to recall positive past experiences when in a positive mood, affective forecasts for future events are likely to become more positive as well. In other words, current mood states, through their influence on recall, could impact affective forecasts.

In their research, Lerner and Gonzalez (2005) also suggest that fleeting emotions could impact affective forecasts. This was proposed in relation to their work on ease-ofthought-generation and the emotions which may result from these thought processes. The authors propose that if, for example, an individual is considering a particular future event for which they generate largely negative thoughts, they may experience fleeting feelings of anxiousness, fear, or distress. Such feelings could then impact affective forecasts for the future events in a mood-congruent manner. Thus, current moods, in this case, brought about by internal thought processes, may influence judgements. This idea can also be linked with personality factors as it has been shown that extraverts react with more PA than introverts when imagining themselves in happy events (Larsen and Ketelaar, 1991). 
Such variations in the experience of fleeting emotions could help account for differences in the affective forecasts of extraverts and introverts.

If mood states influence affective forecasts, it follows that behavioural choices might also be influenced. Wright and Bower (1992) suggest that moods may indeed bias decision making through their influence on probability judgements. In their research it was found that those in a happy mood tend to view positive events as more probable and report lower probabilities for the occurrence of negative events. As we make decisions based both on the affect we predict in a given outcome, and the probability of attaining that outcome (Mellers et al, 1997), higher rating of probability for positive outcomes could lead to more approach behaviours.

Not only is it necessary to explore whether or not there is evidence to support the idea that mood states influence affective forecasts, but it is also of interest to explore how positive mood states effect attitudes towards extravert-type behaviours specifically. Cunningham, Steinberg, and Grev (1980) proposed that positive moods are linked to social and approach motivation which can lead to extraverted and outgoing behaviours. With this in mind, Cunningham (1988a) investigated the effects of mood states on individuals' interest in various situations. Participants who received positive mood manipulations were found to show a greater interest in social activities when compared to those who received no mood manipulation. Cunningham reported that one of the strongest mediators of the effect of mood on interest in social activity was the expectancy of positive outcomes for the event (which may be viewed as a type of affective forecast). Thus, positive moods are likely to lead to more positive affective forecasts in general, as well as for more extravert-type behaviours. 
Related research reveals other connections between positive moods and extraverted behaviours. Cunningham (1988b) demonstrated that inducing a positive mood can increase self-disclosure and lead individuals to behave more socially. Similarly, research in the Carleton University Happy Lab has indicated that, when moods are manipulated, individuals show an increased preference for social situations and feel more social when they are in a positive mood (Whelan, 2008). Thus, research shows that positive moods influence judgement, leading to greater preferences for extravert-type behaviours and situations. These changes in preferences for acting socially may be mediated by affective forecasts.

In sum, research indicates that positive moods lead individuals to make more positive judgements and affective forecasts. Additionally, the literature suggests that positive moods may have the potential to bolster affective forecasts specifically for social, extraverted, and approach-oriented behaviours.

\section{Habitual Mood States and Affective Forecasts}

Now that it has been established that mood states can influence affective forecasts, we can return to the notion of habitual mood states and their impact on forecasting. As already summarized, Zelenski and Larsen (2002) proposed that since the affect-related traits such as extraversion predict positive mood states, and since mood states influence judgments, traits such as extraversion may predict affect-congruent judgments, such as affective forecasts. In other words, since extraverts habitually experience more PA than introverts, it follows that forecasting should more often take place in a positive mood. As such, the forecasts of extraverts may be more likely to be biased in a positive direction than those of introverts. Thus, it may be that differences in 
habitual mood levels mediate the relationship between personality and differences in information processing (Rusting, 1998).

In sum, the large amount of literature related to topic demonstrates that the role of personality and mood states in predicting forecasts is a complex one. As suggested by Dodini (2006) there may be an inter-relationship between personality traits, habitual moods, affective forecasts, acutal experiences, and memories of emotion (see figure 1).

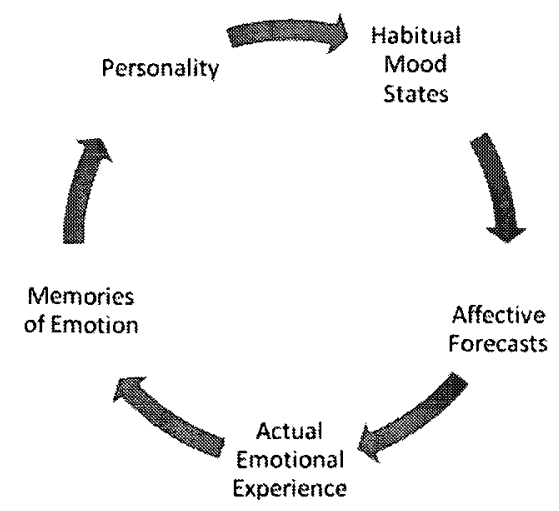

Figure 1. Factors Involved in Affective Forecasting. Based on Dodini, 2006.

\section{Changing Affective Forecasting}

If introverts truly can benefit hedonically from acting extraverted in a way comparable to extraverts, one might imagine that they would learn over time to take advantage of this in order to achieve a boost in PA. Unfortunately, research suggests that it is difficult to profit from past emotional experiences and learn from them (Wilson, Meyers, \& Gilbert, 2003). In fact, one study demonstrated that previous experience with an emotional event did not lead to any increase in the accuracy of later forecasts for this same event (Ayton, Pott, \& Elwakili, 2007). Wilson et al. (2001) suggest that in order to learn from past experiences and increase the accuracy of later forecasts, three conditions, 
which are often not met, must be satisfied. Specifically, individuals must make a conscious effort to compare past events with the future event in question, correctly choose past events that are applicable to the evaluation of the future event, and correctly recall their affect in these past events. Given limitations in our abilities to learn from past experiences, it seems possible that introverts make forecasting errors and fail to learn over time to choose the extraverted behaviours which could potentially lead to hedonic benefits. Thus, an important question to explore in this line of research is when, or under what conditions, introverts may predict enjoying extraverted behaviours and choose to act in an extraverted manner.

It has been established that, for both extraverts and introverts, acting in an extraverted manner leads to increased level of PA (McNeil \& Fleeson, 2006), but, given research on mood and judgements, might initial increases in PA lead people towards more extraverted behaviours and situations? In other words, just as acting extraverted may lead to increased PA, PA may lead individuals to be more inclined to act extraverted and/or partake in social situations. This would suggest a bidirectional relationship between PA and acting extraverted. When mood is elevated individuals may make more positive affective forecasts and therefore be more inclined to choose extravert-type activities and behaviours. If, in particular, introverts are less optimistic about the degree to which they will enjoy acting extraverted/being social (as the reviewed literature suggests they may be), inducing a positive mood could boost their outlook on such behaviours. If affective forecasts do indeed become more positive for introverts after a mood boost, introverts may then become more inclined to choose extravert-type behaviours and situations, and thus, profit from the potential hedonic benefits of doing so. 
Tamir and Robinson (2007) proposed that positive mood states lead individuals to become more sensitive to reward cues in their environmental and inform approachrelated decisions. This suggestion is closely linked to temperamental theories of personality which propose that extraverts are more approach-oriented and sensitive to rewards. In essence, it may be that transient positive mood states, which mimic the habitual mood state of extraverts, lead individuals to be more inclined to act as extraverts naturally do. As such, introverts in a positive mood may forecast affect more positively for extravert-type situations and be more inclined to choose such situations. The current study explores this proposed effect.

\section{Predictions and Aims of the Current Investigation}

A primary goal of the current investigation was to explore the relationship between personality and affective forecasts. Once again, this research was based on the idea introverts make the hedonically suboptimal choice to engage in introverted behaviours over more extravert-type behaviours. While the evidence suggests that introverts have the potential to reap hedonic benefits from engaging in extraverted behaviours, we suggest that introverts will not anticipate these hedonic benefits and forecast affect for such extraverted behaviours differently than extraverts. In the current investigation affective forecasts and attitudes towards acting in an extraverted manner or introverted manner in a group discussion were collected. These affective forecasts and attitudes allowed for the examination of dispositional differences in forecasts for extraverted and introverted behaviours. We predicted, a priori, that introverts would forecast less PA, less positive attitudes towards the discussion, and/or more NA for acting extraverted when compared to extraverts. In other words, we predicted that introverts 
would make affective forecasts which would make them less likely, when compared to extraverts, to choose extraverted behaviours. Since the literature shows that introverts and extraverts respond in comparably positive ways to acting extraverted (McNeil \& Fleeson, 2006), any dispositional differences in predictions for acting extraverted may represent errors in affective forecasting. In addition, we predicted that introverts would forecast more PA, more positive attitudes towards the discussion, and/or less NA for acting introverted when compared to extraverts. Thus, we predicted that introverts would make affective forecasts which would make them more likely, when compared to extraverts, to choose introverted behaviours.

Going beyond examining differences in affective forecasts, this study also investigated the role that current mood may play in predicting affective forecasts for acting extraverted/introverted. As previously outlined, there may be a bidirectional relationship between PA and acting extraverted. In the current investigation, film clips were used to induce positive or neutral moods. We predicted that disposition and mood manipulation condition would interact to predict affective forecasts for acting extraverted and introverted. Specifically we predicted that introverts, who may generally make less positive forecasts about acting extraverted and/or more positive forecasts for acting introverted, would forecast affect more positively for acting extraverted after a mood boost. The most intriguing finding may be if introverts in a positive mood manipulation condition "catch up" to dispositional extraverts (in the neutral mood manipulation condition) in terms of their affective forecasts for acting extraverted. If, after a mood boost, introverts are found to make affective forecasts more similar to those of extraverts, 
they may in turn behave more like extraverts and potentially profit from the hedonic benefits of acting extraverted when in a positive mood.

In light of the previously noted findings that introverts anticipate feeling less PA in social situations (Lucas \& Diener, 2001) and that positive moods lead to greater interest in social activities (Cunningham, 1988b) the current study also strove to investigate how disposition and mood may interact to influence affective forecasts for everyday social and non-social situations (situations more commonly experienced than "acting extraverted/introverted" in a group discussion). We predicted that, introverts, who may generally make less positive judgments for social situations (and potentially, more positive judgment about non-social situations) when compared to extraverts, would forecast affect more positively for social situations after a mood boost. Once again, the most intriguing finding may be if introverts in a positive mood manipulation condition "catch up" to dispositional extraverts (in the neutral mood manipulation condition) in terms of their affective forecasts of positive emotions for social situations. If, after a mood boost, introverts are found to make affective forecasts more similar to those of extraverts, they may in turn behave more like extraverts and potentially profit from choosing more social situations (which may encourage extraverted behaviours) over nonsocial ones.

Finally, the present study examined if mood boost could not only change affective forecasts for future extraverted behaviours, but also affect an actual choice for participating in a future event. Since individuals use their anticipated emotions as guides to choices (Mellers et al., 1997) and if anticipated emotions are modified through the mood manipulation, it follows that real world decisions about future extraverted 
behaviours should be influenced by the mood boost. The current investigation included a behavioural choice (in which participants chose between waiting a few minutes in social situation or waiting alone) and can thus examine if affective forecasts may account for the relationship between personality or mood and behaviour. It has been demonstrated introverts spend more time alone when compared to extraverts (Mehl, Gosling, \& Pennebaker, 2006) and that positive moods cause an increased desire for social-situations (Cunningham, 1988). Thus, we predicted that introverts, who may show a preference for being alone, will show a greater preference for a social situation (waiting with others) as a consequence of the mood boosts (this change being mediated by positively biased affective forecasts). We also predicted that disposition and mood would interact such that when comparing dispositional introverts in the positive mood condition to dispositional extraverts in the neutral mood condition dispositional introverts would "catch up" to dispositional extraverts and choose to wait with others to a similar degree after the mood boost.

To explore these predictions, participants in the study were classified as either extreme dispositional extraverts or extreme dispositional introverts through personality testing. In order to induce the desired mood states, participants were randomly assigned to experience either a positive mood induction (experimental condition) or a neutral mood induction (control condition) before completing any questionnaires. Participants then forecasted affect and attitudes for either acting introverted or acting extraverted (again, randomly assigned) in a hypothetical group discussion. They also rated various social and non-social events and completed a behavioural choice task in which they made a choice between waiting alone or with others. 
Method

\section{Participants}

Carleton University students were recruited through e-mails and phone calls to participate in the study in exchange for course credit or payment of 10 dollars. All students selected to participate had completed Carleton's mass testing questionnaire set which included a measure of extraversion (Goldberg's Mini-Markers for Extraversion) to allow for pre-selection of participants based on this trait and the creation of extreme groups. Originally, we recruited participants who had trait extraversion scores in the top $25 \%$ or bottom $25 \%$, however, as recruiting unfolded, it was determined that not enough subjects were choosing to participate in the study to gain a large enough sample when drawing only from this pool. Thus, the pool was expanded to include those in the top and bottom $30 \%$ of trait extraversion scores. Trait extraversion scores of those who participated in the study were over 4.75 (extreme extraverts) or under 4.00 (extreme introverts).

Of the original 108 participants (59 female, 42 male), seven participants were excluded from the study because the mood manipulation did not work in the manner expected (for example, in debriefing some participants indicated that they found the neutral mood manipulation to be very positive) or because the participant had serious suspicions that their mood was being manipulated in the study. Thus, the final sample size was 101 participants. Table 1 illustrates the number of participants in each group. 
Table 1

Number of Participants in each Condition Group

$\underline{\text { Dispositional Extraverts } \quad \text { Dispositional Introverts }}$

$\underline{\text { Act Ext. }} \quad \underline{\text { Act Int. }} \quad \underline{\text { Act Ext. }} \quad \underline{\text { Act Int. }}$ Mood Totals

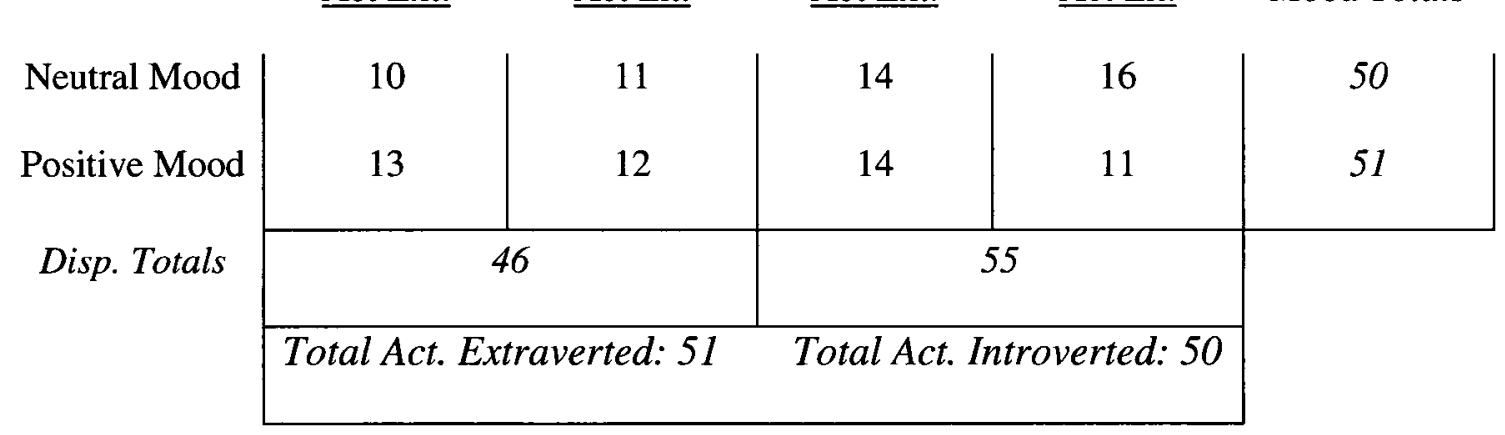

Materials

Goldberg's Mini-Markers for Extraversion. In order to attain a measure of extraversion prior to each participant entering the lab, Goldberg's Mini-Markers for Extraversion (Saucier, 1994) was included in Carleton University's mass testing questionnaire set. This trusted measure generally produces Cronbach's alpha coefficients above .78 (Saucier, 1994). The eight items on this measure used in the calculation of trait extraversion were: bold, energetic, extraverted, talkative, quiet, bashful, shy, and withdrawn (the last 4 items were reversed scored). See appendix A for the full MiniMarkers questionnaire.

Mood Manipulation. In order to induce a positive mood (for those in the experimental condition) or a neutral mood (for those in the control condition), two film clips of equal length (approximately 11 minutes) were used. The positive clip featured a moment of personal triumph from the movie "Akeelah and the Bee" (Atchison, 2006) and 
the neutral clip featured a roundtable discussion of the work of literature "Beowulf" (Harryson, 2006). For detailed descriptions of the film clips, see appendix B.

These two film clips have been used in the Carleton University Happy Lab and have been shown to have a significant effect on mood. Previous testing on the clips (using ANOVA and Tukey's Honestly Significant Difference, as there were three conditions being examined when pre-testing was conducted, $\mathrm{N}=99$ ) revealed that the positive film produced more PA than the neutral film (also notable is that participants rated the positive film as being significantly more pleasant than the neutral film). Appropriately, NA did not differ between the two films. See Table 2 for means and standard deviations by condition.

Table 2

Comparison of Affect by Mood Condition

\begin{tabular}{lllll} 
& \multicolumn{4}{c}{ Condition } \\
\cline { 2 - 5 } Affect & \multicolumn{2}{c}{ Positive } & \multicolumn{2}{c}{ Control } \\
\cline { 2 - 5 } Positive Affect & $4.78_{\mathrm{a}}$ & 0.98 & $3.37_{\mathrm{b}}$ & 0.94 \\
Negative Affect & $2.03_{\mathrm{a}}$ & 0.95 & $2.18_{\mathrm{a}}$ & 0.92 \\
Pleasantness & $5.70_{\mathrm{a}}$ & 0.95 & $4.88_{\mathrm{b}}$ & 0.85
\end{tabular}

Note: means with different subscripts are different at least at the $p<.05$ level

It was ideal that participants did not regard the viewing of the film as a mood manipulation procedure, as such, a cover story was used and participants were told they were participating in a study on "Film and Personality" which examines "how people with different personality types react to the same situations or events". After viewing the 
film, in order to support the cover story that the film clip is an integral part of the study, participants were asked to answer a few questions about the film. This filler questionnaire can be viewed in Appendix C.

Hypothetical Group Discussion Task. The situation detailed in the Hypothetical Group Discussion Task, which is the scenario for which participants forecast affect, mirrors the one used by McNeil and Fleeson (2006). In Fleeson's task, participants were asked to act extraverted or introverted during a group discussion task in which he/she and a group of two others had 10 minutes to decide which pieces of equipment would be the most and least important to have if caught in a winter storm. In the current investigation, participants did not complete the actual group discussion, but were asked to imagine acting extraverted (in the acting extraverted condition) or introverted (in the acting introverted condition) in the described group discussion. Specifically, participants were either instructed to imagine acting "bold, talkative, energetic, active, assertive, and adventurous" or "reserved, quiet, lethargic, passive, compliant, and unadventurous" during the group discussion. The complete instructions for the Hypothetical Group Discussion Task can be viewed in Appendix D.

The study measured only affective forecasts and no online ratings of affect were attained since participants did not actually complete the group discussion task. Due to the evidence in the literature which documents that introverts and extraverts alike experience PA to a comparable degree when acting extraverted (McNiel \& Fleeson, 2006; Wynn \& Zelenski, 2007), we feel confident in assuming that, if we were to run participants through the group discussion task, no differences in experienced affect between introverts and extraverts would exist. Since no differences in experienced affect would be 
anticipated, any differences in forecasted affect between introverts and extraverts will be viewed as representing differential predictions for the same outcome. Any differences in forecasted affect which may present themselves can be interpreted in order to draw conclusions about the forecasting of introverts and extraverts.

Hypothetical Group Discussion Affective Forecasting Questionnaire. After reading the description of the hypothetical group discussion task, participants in the study proceeded to fill out a questionnaire about how they would anticipate feeling in the described situation. This questionnaire measured each participant's self-reported affective forecasts and anticipated positive attitudes towards the hypothetical discussion.

Participants rated their agreement, using a 7-point Likert scale, with four statements measuring predicted positive attitudes towards the discussion: I think the discussion will be enjoyable, I will have moments of fun during the discussion, I think I will like the other members of the discussion, and, I think the other members of the discussion will like me. Cronbach's alpha for this portion of the measure was .88. Additionally, participants were asked to indicate, using a 7-point Likert scale, the degree to which they would anticipate feeling certain emotions during the discussion using an adapted version of the PANAS (Watson \& Clark, 1994). The measure was slightly adapted such that the ratings given to the 24 words in this portion of the questionnaire provide a measure of forecasted PA and NA for the group discussion. As an example, the acting extraverted version of the Hypothetical Group Discussion Affective Forecasting Questionnaire can be viewed in Appendix E. 
Scoring of the hypothetical Group Discussion Questionnaire

While there are numerous ways in which to explore differences in feelings, the current study draws on the circumplex model of affect (Larsen \& Diener, 1992, see figure 2). This model conceptualises affect using two separate dimensions, arousal and pleasantness. The pleasant dimension runs along the horizontal axis and the arousal dimension runs along the vertical axis. Examples of emotion terms which coincide with the various affective states are shown at each extreme.

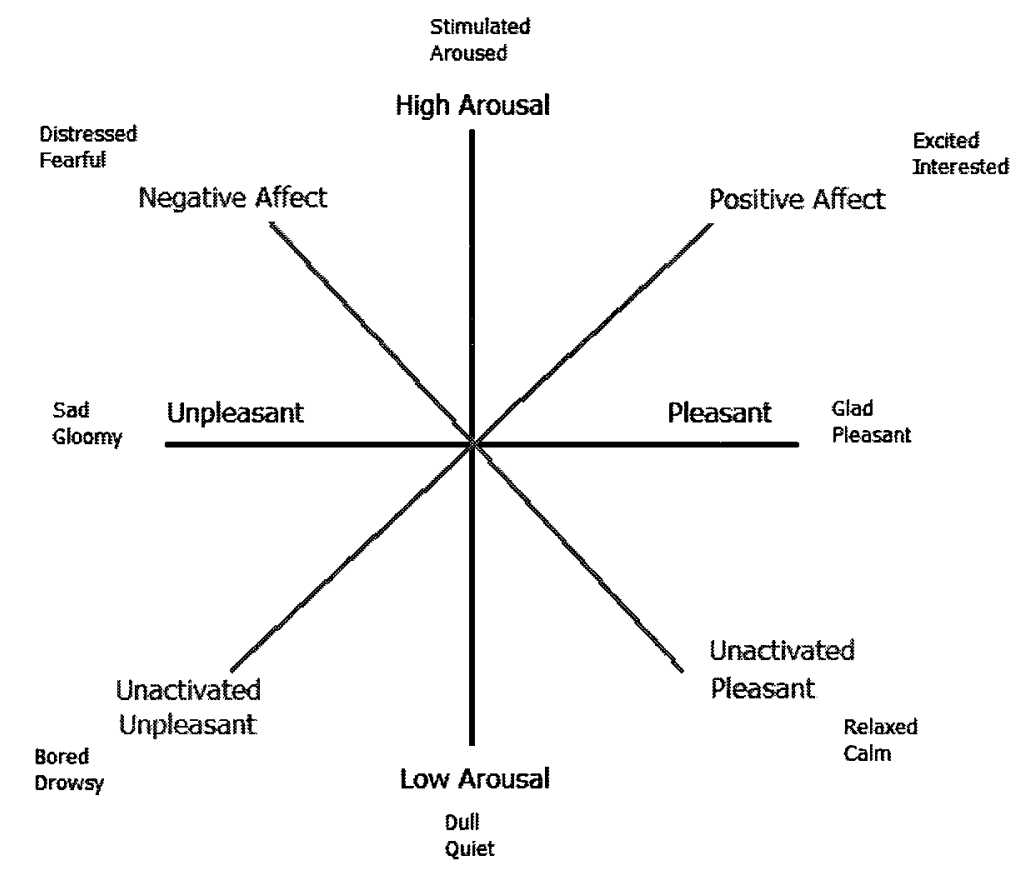

Figure 2. The Affect Circumplex (based on Larsen \& Diener, 1992)

In the current examination, a large focus is placed PA and NA. These two dimensions of affect are examined separately as there is much support for their independence (Emmons \& Diener, 1985). PA includes emotions which are high arousal as well as pleasant and NA includes emotions which are high arousal and unpleasant. In the Hypothetical Group Discussion Affective Forecasting Questionnaire participants were 
asked to rate the degree to which they would expect to feel strong, alert, active, interested, and excited during the group discussion. A mean score on these five terms was used to measure anticipated PA (Cronbach's alpha .95). Similarly, participants were asked to rate to what degree they would expect to feel irritable, upset, nervous, fearful, hostile, distressed, and jittery during the group discussion. A mean score on these 7 terms was used to measure anticipated NA (Cronbach's alpha .84).

The modified PANAS also allowed for the examination of affect subscales and can thus examine low activation PA and NA. While PA and NA feature high activation/high arousal items such as "elated" or "nervous", low activation PA and NA feature lower activation/arousal terms such as "calm" or "bored". These terms still capture aspects of pleasant/unpleasant feelings, but without the high arousal implied in measures of PA and NA. Mean scores on the items relaxed, calm and quiet were used to calculate low activation PA. However, Cronbach's alpha for this subset of items was quite low at .42 , potentially due to the fact that only three items were included in the measure. Mean scores on the items bored, idle and dull were used to calculate low activation NA (Cronbach's alpha .90).

Social Situations Questionnaire. In the Social Situation Questionnaire (based on Whelan, 2008) participants rated, using a 7-point Likert scale, how much they would anticipate feeling positive emotions in various situations, both social and non-social (for example, "Going to a museum with a small group of friends" and "Going to the beach to suntan by yourself."). This questionnaire provides a measure of the anticipated positive emotions for different situations varying in the degree to which they are social and represent balanced levels of pleasantness (since pleasantness has been a confound in 
previous measures as social situations have been shown to be viewed as moderately more pleasant than non-social situations, Whelan, 2008). The 10 items used to measure anticipated positive emotions in social situations (Cronbach's alpha of .72) and 10 items were used to measure anticipated positive emotions in non-social situations (Cronbach's alpha of .77). The complete measure can be viewed in Appendix F

Imagination Questionnaire. There was some concern that systematic differences in the ability to imagine future events and feelings would affect the results of this study. This concern is legitimate as it has been demonstrated that levels of trait extraversion do indeed impact the use of mental imagery, with introverts experiencing more vivid mental imagery than extraverts (Gralton, Hayes, \& Richardson, 1979). Since this study required participants to forecast how they would feel in hypothetical situations, it was important to explore how differences in the ability to imagine and mentally simulate these events might affect affective forecasts. As there was no imagination questionnaire found in the literature that seemed to capture the type of imagination used in the study, a measure was created. Using a 7-point Likert scare participants rated their agreement with 12 statements. Questions about imagination in general were included ("I have a good imagination"), as were questions about the ability to use mental imagery ("When I imagine things, I am able to see a vivid image in my mind") and questions related specifically to imaging affect ("It is easy for me to imagine how I will feel in response to future events"). The questionnaire had a Cronbach's alpha of .90 and can be viewed in Appendix G.

Choice Task. Finally, participants were asked to make an actual behavioural choice as opposed to a forecast of affect. Towards the end of the experiment, participants 
were told that they would need to wait a few minutes while the experimenter prepared a final task for them to complete. It was explained to each participant that he/she could either wait alone (opting for a non-social situation), or wait with other participants who were supposedly also currently in the lab (opting for a social situation). The asking order of this question was counterbalanced (would you like to wait alone/with others versus with others/alone). Each participant's response to this question was recorded.

\section{Procedure}

Participants were invited, via email or phone (scripts can be viewed in Appendix H) to take part in a study on "Film and Personality" which, they were told, examines how people with different personality types react to the same situations or events. Before each participant arrived at the lab, they were randomly assigned to an acting condition (acting introverted versus acting extraverted) and mood manipulation condition (the computer upon which the videos were viewed randomly assigned participants to the positive mood condition or neutral mood condition). As a control, the experimenter conducting the study was unaware of both the trait extraversion score of the participant and the mood manipulation condition.

Upon entering the lab, participants were asked to read and sign an informed consent form (which can be viewed in Appendix I). Once this had been completed, participants were shown the appropriate mood manipulation film clip (positive or neutral) on a computer with headphones. Next, the participants completed the filler task to support the experiment's cover story in which they were asked several questions about the film they had just viewed. Then, participants were given the instructions for the appropriate version of the Hypothetical Group Discussion Task (acting extraverted or 
acting introverted). Once the instructions for this task had been read and understood, participants completed the Hypothetical Group Discussion Affective Forecasting Questionnaire in which they forecasted their affect and attitudes for the imagined group discussion. Next, participants completed the Social Situations Questionnaire. Finally, participants were asked to complete the choice task in which they made an actual choice about whether they would like to wait for a few minutes with other participants or alone (opting for a social or non-social choice). After the participants had made this choice, the experiment was complete.

Upon completing the study, participants were verbally debriefed, had the deception explained to them, were given a debriefing sheet (which can be viewed in Appendix J), and thanked for their participation.

Results

\section{Imagination Questionnaire}

The imagination questionnaire was created in order to address concerns over differences in the ability to picture and mentally simulate events. A $2 \times 2 \times 2$ ANOVA (disposition by acting condition by mood manipulation condition) was conducted to determine if mean scores for the imagination questionnaire differed by condition group. No main effect of disposition, $\mathrm{F}(1,93)=1.94$, partial $\eta^{2}=.020, p=.17$, or mood condition, $\mathrm{F}(1,93)=2.09$, partial $\eta^{2}=.02, p=.15$, was found, and no interaction was present, $\mathrm{F}(1,93)=.70$, partial $\eta^{2}=.007, p=.70$. As neither disposition nor mood was found to be systematically related to self-reported imagination ability, more confidence was gained in assuming that differences in imagination ability would not influence further analyses. However, a significant main effect of acting condition was found, 
$\mathrm{F}(1,93)=5.03$, partial $\eta^{2}=.05, p=.03$, with those instructed to act extraverted reporting greater imagination ability $(M=5.46, S D=.80)$ than those instructed to act introverted $(M=5.07, S D=.92)$. Due to this link between imagination scores and acting condition, imagination was used as a covariate in subsequent ANOVA analyses. However, the results of the analyses were not seriously impacted by using imagination as a covariate. That is, the nature of the conclusions drawn from the study remain the same, with or without the use of imagination as a covariate. Results are therefore reported without the covariate for ease of presentation.

\section{Dispositional Differences in Forecasts for Extraverted/Introverted Behaviours}

We predicted that introverts would forecast affect differently than extraverts, and in such a way that might lead them away from choosing extraverted behaviours and towards introverted behaviours. As an initial step in analysis, affective forecasts from participants in the neutral condition $(\mathrm{N}=51)$ were examined using t-tests. These tests allowed for the examination of how anticipated reactions to acting extraverted and introverted may differ by disposition, regardless of any mood manipulations. Mean forecasts (by disposition and acting condition) of predicted PA, positive attitudes towards the discussion and NA can be viewed in tables 3,4 and 5 respectively.

Table 3

Mean Predicted Positive Affect (neutral mood manipulation only)

\begin{tabular}{crrr}
\hline & \multicolumn{2}{c}{ Extraverts } & \multicolumn{2}{c}{ Introverts } \\
\hline$M$ & $S D$ & $M$ & $S D$
\end{tabular}

\begin{tabular}{lllll}
\hline Act Extraverted & 6.26 & .60 & 5.37 & 1.17 \\
Act Introverted & 2.84 & 1.41 & 2.51 & 1.07 \\
\hline
\end{tabular}


Table 4

Mean Predicted Positive Attitudes (neutral mood manipulation only)

\begin{tabular}{cccc}
\hline & Extraverts & \multicolumn{2}{c}{ Introverts } \\
\hline$M$ & $S D$ & $M$ & $S D$
\end{tabular}

\begin{tabular}{lllll}
\hline Act Extraverted & 5.70 & .93 & 5.03 & 1.03 \\
Act Introverted & 3.68 & 1.06 & 3.11 & 1.13 \\
\hline
\end{tabular}

Table 5

Mean Predicted Negative Affect (neutral mood manipulation only)

\begin{tabular}{lrrrc}
\cline { 2 - 5 } & \multicolumn{2}{c}{ Extraverts } & \multicolumn{2}{c}{ Introverts } \\
\cline { 2 - 5 } & $M$ & $S D$ & $M$ & $S D$ \\
\hline Act Extraverted & 1.87 & .66 & 2.78 & .84 \\
Act Introverted & 2.92 & .95 & 3.05 & 1.28 \\
\hline
\end{tabular}

It was predicted, a priori, that for acting extraverted, introverts would forecast less PA, predict holding less positive attitudes towards the discussion, and/or predict more NA when compared to extraverts. There was a significant difference in predicted PA, $\mathrm{t}(22)=2.20, \mathrm{p}=.04$, with introverts forecasting less PA $(\mathrm{M}=5.37, \mathrm{SD}=1.17)$ than extraverts $(M=6.26, S D=.60)$. No significant differences in predicted attitudes towards the discussion were found, $\mathrm{t}(22)=1.62, \mathrm{p}=.12$. However, similar to PA, there was a significant difference for predicted $\mathrm{NA}, \mathrm{t}(22)=-2.82, \mathrm{p}=.01$ with introverts predicting more NA $(\mathrm{M}=2.78, \mathrm{SD}=.84)$ than extraverts $(\mathrm{M}=1.87, \mathrm{SD}=.66)$. These t-tests provide some initial support for dispositional differences in affective forecasts for acting extraverted. 
For the acting introverted condition, it was predicted, a priori, that introverts would forecast more PA, more positive attitudes towards the discussion, and/or less NA when compared to extraverts. However, there were no significant difference in group means for extraverts and introverts for either predicted PA, $\mathrm{t}(25)=.68, \mathrm{p}=.50$, positive attitudes towards the discussion, $\mathrm{t}(25)=1.33, p=.20$, or NA, $\mathrm{t}(25)=-.29, p=.78$.

In sum, while for acting extraverted, introverts anticipated experiencing less PA and more NA when compared to extraverts, no differences in forecasted affect were found for acting introverted. These finding only partially support our predictions.

\section{2x2x2 ANOVA: Main Dependant Variables of Interest}

In the previous section, data from the neutral condition was examined to explore how extraverts and introverts forecasts emotions for acting extraverted/introverted without the influence of a positive mood manipulation. Subsequent ANOVAs take into account all three factors in the experiment, that is, disposition, acting condition, and mood manipulation condition, in order to address our prediction that disposition and mood interact to predict affective forecasts for each dependant variable (PA, positive attitudes, and NA). Affective Forecasts for Positive Affect

A 2x2x2 ANOVA (disposition by acting condition by mood manipulation condition) was conducted to search for mean differences in predicted PA. A table of means and an ANOVA table can be viewed in tables 6 and 7 respectively. 
Table 6

Mean Anticipated Positive Affect

\begin{tabular}{|c|c|c|c|c|c|c|c|c|c|}
\hline & \multicolumn{4}{|c|}{ Dispositional Extraverts } & \multicolumn{4}{|c|}{$\underline{\text { Dispositional Introverts }}$} & \multirow[b]{3}{*}{ Totals } \\
\hline & \multicolumn{2}{|c|}{ Act Ext. } & \multicolumn{2}{|c|}{$\underline{\text { Act Int. }}$} & \multicolumn{2}{|c|}{ Act Ext. } & \multicolumn{2}{|c|}{ Act Int. } & \\
\hline & $M$ & $S D$ & $M$ & $S D$ & $M$ & $S D$ & $M$ & $S D$ & \\
\hline Neutral & 6.26 & .60 & 2.84 & 1.41 & 5.37 & 1.17 & 2.51 & 1.06 & $4.10 S D=1.93$ \\
\hline Positive & 5.89 & .49 & 2.41 & 1.00 & 5.20 & .97 & 2.51 & .83 & $4.12 S D=1.77$ \\
\hline \multirow[t]{3}{*}{ Totals } & \multicolumn{4}{|c|}{$4.33 S D=1.97$} & \multicolumn{4}{|c|}{$3.93 S D=1.72$} & \\
\hline & \multicolumn{2}{|c|}{$6.05 S D=.56$} & \multicolumn{2}{|c|}{$2.61 S D=1.21$} & \multicolumn{2}{|c|}{$5.29 S D=1.06$} & \multicolumn{2}{|c|}{$2.51 S D=.96$} & \\
\hline & \multicolumn{4}{|c|}{ Total Act. Ext: $5.63 S D=.94$} & \multicolumn{4}{|c|}{ Total Act. Int: $2.56 \quad S D=1.07$} & \\
\hline
\end{tabular}

Table 7

PA ANOVA Table: Disposition X Acting Condition X Mood Manipulation Condition

\begin{tabular}{lrrrrrr}
\hline Source & $S S$ & $d f$ & $M S$ & $F$ & $p$ & Partial $\eta^{2}$ \\
\hline Disposition & 5.07 & 1 & 5.07 & 5.17 & .03 & .05 \\
Acting & 239.38 & 1 & 239.38 & 244.07 & $<.001$ & .72 \\
Mood & 1.43 & 1 & 1.43 & 1.46 & .23 & .01 \\
Disp * Acting & 2.81 & 1 & 2.81 & 2.87 & .09 & .03 \\
Disp * Mood & .58 & 1 & .58 & .59 & .44 & .006 \\
Acting * Mood & .02 & 1 & .02 & .02 & .89 & $<.001$ \\
Disp*Acting* Mood & .07 & 1 & .07 & .08 & .78 & $<.001$ \\
Error & 91.21 & 93 & .98 & & & \\
\hline
\end{tabular}


ANOVA results revealed a significant main effect of disposition, $F(1,93)=5.17$, partial $\eta^{2}=.05, p=.03$, with dispositional extraverts $(M=4.44, S D=1.97)$ predicting more PA than dispositional introverts $(M=3.92, S D=1.72)$. There was also a significant main effect of acting condition, $\mathrm{F}(1,93)=244.07$, partial $\eta^{2}=.72, p<.001$, with those instructed to act extraverted $(M=5.63, S D=.94)$ predicting more PA than those instructed to act introverted $(M=2.56, S D=1.07)$. There was no main effect of mood manipulation condition, $\mathrm{F}(1,93)=1.46$, partial $\eta^{2}=.01, p=.23$, indicating that participants did not tend to predict experiencing more PA during the group discussion when in a good mood when compared to a neutral mood.

The only significance for the two-way interactions in the ANOVA was a marginally significant interaction between disposition and acting condition, $F(1,93)=$ 2.87, partial $\eta^{2}=.03, p=.09$ (see figure 3). Simple effects contrasts revealed that although there were no significant differences in mean ratings of anticipated PA for acting introverted, $\mathrm{F}(1,97)=1.65$, partial $\eta^{2}=.02, p=.20$, there was a marginally significant difference for acting extraverted, $\mathrm{F}(1,97)=2.85$, partial $\eta^{2}=.03, p=.10$ with extraverts predicting more PA $(M=6.05, S D=.56)$ than introverts $(M=5.29, S D=$ 1.06). Simple effect contrasts for acting condition revealed that both introverts $(F(1,97)=$ 109.59, partial $\left.\eta^{2}=.53, p=<.001\right)$ and extraverts $\left(\mathrm{F}(1,97)=144.22\right.$, partial $\eta^{2}=.59, p=$ <.001) predict significantly more PA for acting extraverted than for acting introverted. 


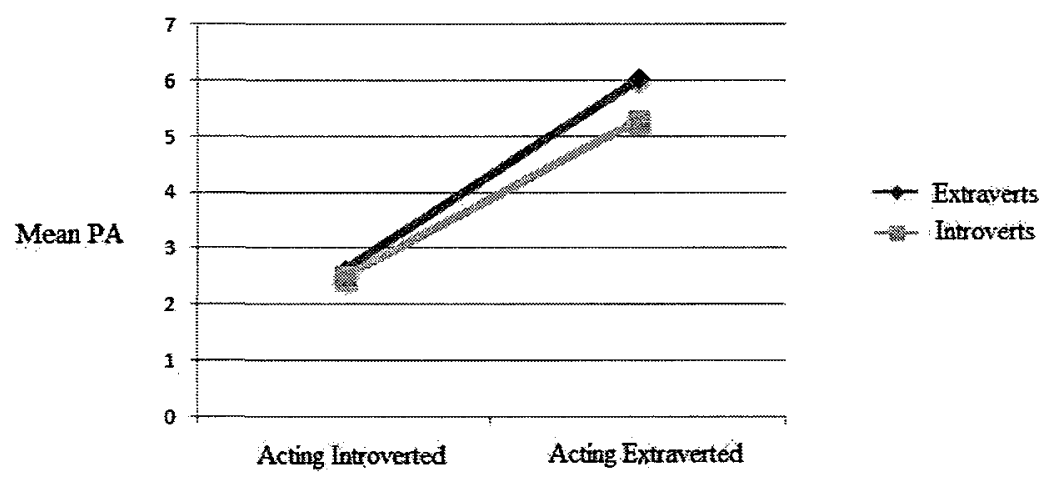

Figure 3. PA Disposition X Acting Condition Interaction Graph

There was no significant 3-way interaction between disposition, acting condition and mood manipulation condition, $\mathrm{F}(1,93)=.08$, partial $\eta^{2}<.001, p=.78$. Thus, no support was provided for mood states and disposition interacting to predict affective forecasts for acting introverted and extraverted. In other words, mood states did not affect introverts' and extraverts' forecasts for acting extraverted/introverted differently. Positive Attitudes towards Acting Introverted and Acting Extraverted

A $2 \times 2 \times 2$ ANOVA (disposition by acting condition by mood manipulation condition) was conducted to search for mean differences in anticipated positive attitudes towards the imagined group discussion. A table of means and ANOVA table can be viewed in tables 9 and 10 respectively. 
Table 9

Mean Anticipated Positive Attitudes

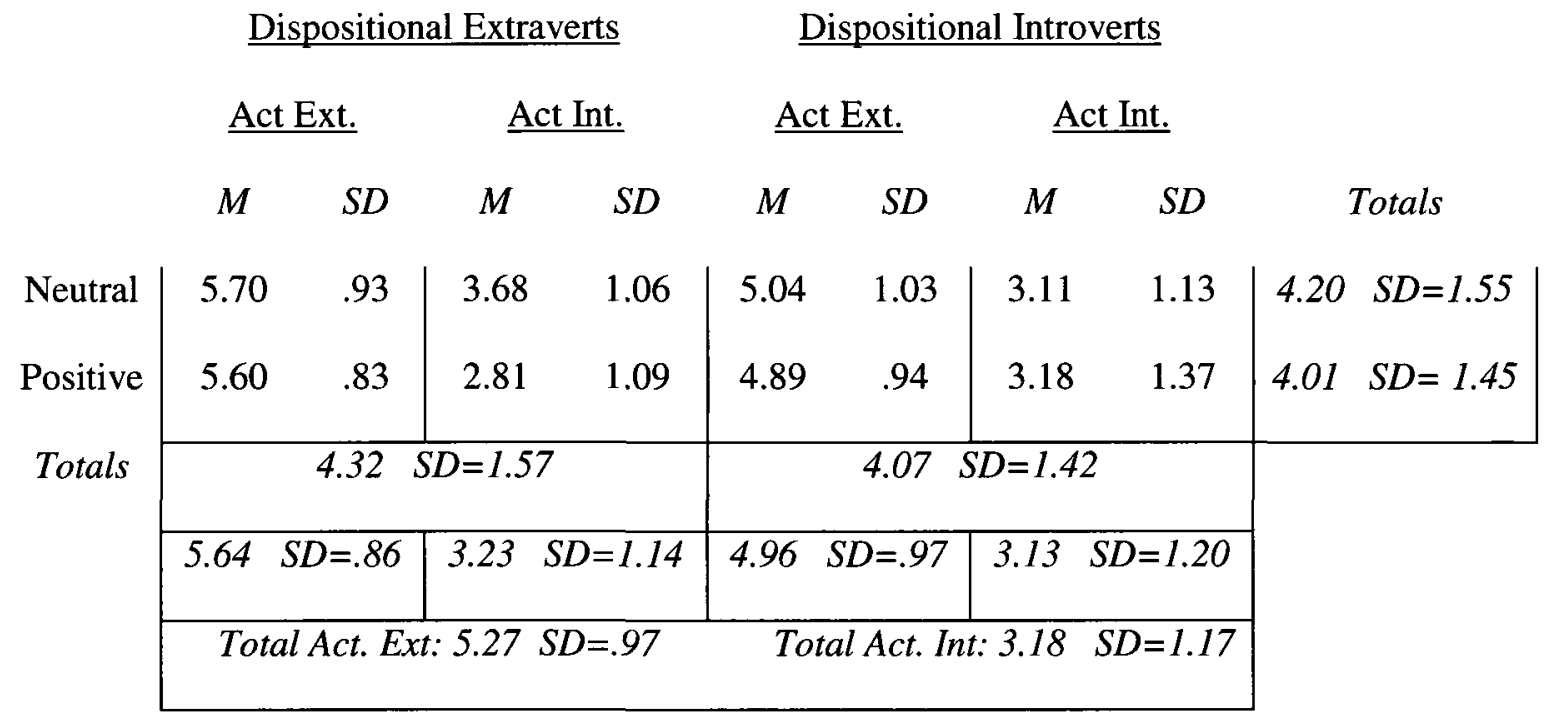

Table 10

Positive Attitudes ANOVA Table: Disposition X Acting Condition X Mood Manipulation Condition

\begin{tabular}{lrrrrrr}
\hline Source & $S S$ & $d f$ & $M S$ & $F$ & $p$ & Partial $\eta^{2}$ \\
\hline Disposition & 3.81 & 1 & 3.81 & 3.42 & .07 & .04 \\
Acting & 110.00 & 1 & 110.00 & 98.82 & $<.001$ & .52 \\
Mood & 1.68 & 1 & 1.68 & 1.51 & .22 & .02 \\
Disp * Acting & 2.09 & 1 & 2.09 & 1.88 & .17 & .02 \\
Disp * Mood & 1.26 & 1 & 1.26 & 1.13 & .29 & .01 \\
Acting * Mood & .47 & 1 & .47 & .42 & .52 & .004 \\
Disp*Acting* Mood & 1.49 & 1 & 1.49 & 1.34 & .25 & .01 \\
Error & 103.52 & 93 & 1.11 & & & \\
\hline
\end{tabular}


The analysis revealed a significant main effect of acting condition, $F(1,93)=$ 98.82, partial $\eta^{2}=.52, p<.001$, with those instructed to act extraverted $(M=5.27, S D=$ .97) predicting more positive attitudes towards the discussion than those instructed to act introverted $(M=3.18, S D=1.17)$. In addition, a marginally significant main effect of disposition was found, $\mathrm{F}(1,93)=3.42$, partial $\eta^{2}=.04, p=.07$, with dispositional extraverts $(M=4.43, S D=1.57)$ predicting more positive attitudes towards the discussion than dispositional introverts $(M=4.07, S D=1.42)$. There was no significant main effect of mood manipulation condition, $\mathrm{F}(1,93)=1.51$, partial $\eta^{2}=.02, p=.22$, indicating that participants did not tend to predict having more positive attitudes towards a group discussion when in a good mood when compared to a neutral mood.

There were no significant two-way interactions. There was also no significant three-way interaction between disposition, acting condition and mood manipulation condition, $\mathrm{F}(1,93)=1.34$, partial $\eta^{2}=.01, p=.25$. Thus, mood states and disposition did not seem to interact to predict affective forecasts for acting extraverted and introverted. Affective Forecasts for Negative Affect

A $2 \times 2 \times 2$ ANOVA (disposition by acting condition by mood manipulation condition) was conducted to search for mean differences in predicted NA. A table of means and ANOVA table can be viewed in tables 11 and 12 respectively. 
Table 11

Mean Negative Affect

\begin{tabular}{|c|c|c|c|c|c|c|c|c|c|}
\hline & & position & 1 Extray & & $\underline{\text { Dis }}$ & osition & al Intro & & \\
\hline & $\underline{\mathrm{Ac}}$ & Ext. & $\underline{\mathrm{Ac}}$ & & $\underline{\text { Act }}$ & & & & \\
\hline & $M$ & $S D$ & $M$ & $S D$ & $M$ & $S D$ & $M$ & $S D$ & Totals \\
\hline Neutral & 1.87 & .66 & 2.92 & .95 & 2.77 & .84 & 3.05 & 1.28 & $2.71 S D=1.06$ \\
\hline Positive & 2.34 & 1.39 & 3.55 & 1.59 & 3.18 & .74 & 3.71 & 1.12 & $3.17 S D=1.32$ \\
\hline Totals & & $2.69 \mathrm{~S}$ & $=1.35$ & & & .15 & $D=1.0$ & & \\
\hline & 2.14 & $\mathrm{D}=1.13$ & 3.25 & $=1.33$ & 2.96 & $=.80$ & 3.32 & $=1.24$ & \\
\hline & Total & Ext: 2 & $8 S D$ & & otal A & $n t: 3.2$ & $9 S$ & & \\
\hline
\end{tabular}

Table 12

NA ANOVA Table: Disposition X Acting Condition X Mood Manipulation Condition

\begin{tabular}{lrrrrrr}
\hline Source & $S S$ & $d f$ & $M S$ & $F$ & $p$ & Partial $\eta^{2}$ \\
\hline Disposition & 6.36 & 1 & 6.36 & 5.01 & .03 & .05 \\
Acting & 14.47 & 1 & 14.47 & 11.40 & .001 & .11 \\
Mood & 7.12 & 1 & 7.12 & 5.61 & .02 & .06 \\
Disp * Acting & 3.18 & 1 & 3.18 & 2.51 & .12 & .03 \\
Disp * Mood & .002 & 1 & .002 & .001 & .97 & $<.001$ \\
Acting * Mood & .27 & 1 & .27 & .21 & .65 & .002 \\
Disp*Acting* Mood & .02 & 1 & .02 & .01 & .91 & $<.001$ \\
Error & 116.77 & 93 & 1.27 & & & \\
\hline
\end{tabular}


The analysis revealed a significant main effect of disposition, $F(1,93)=5.01$, partial $\eta^{2}=.05, p=.03$, with introverts $(M=3.15, S D=1.05)$ predicting more NA than extraverts $(M=2.69, S D=1.35)$. There was also a significant main effect of acting condition, $\mathrm{F}(1,93)=11.40$, partial $\eta^{2}=.11, p=001$, with those instructed to act introverted $(M=3.29, S D=1.27)$ predicting more NA when compared to those instructed to act extraverted $(M=2.58, S D=1.05)$. Additionally, there was a significant main effect of mood manipulation condition, $\mathrm{F}(1,93)=5.61$, partial $\eta^{2}=.06, p=.02$, with, surprisingly, those who viewed the neutral film $(M=2.71, S D=1.06)$ predicting less NA than those who viewed the positive film $(M=3.17, S D=1.32)$.

There were no significant two-way interactions. There was also no significant three-way interaction between disposition, acting condition and mood manipulation condition, $\mathrm{F}(1,93)=.01$, partial $\eta^{2}<.001, p=.91$. Thus, once again, mood states did not seem to interact with disposition to predict affective forecasts for acting extraverted and introverted.

2x2x2 ANOVA: Affective Forecasts of Low Activation Positive and Negative Affect A $2 \times 2 \times 2$ ANOVA (disposition by acting condition by mood manipulation condition) was conducted to search for mean differences in low activation PA. A table of means and an ANOVA table can be viewed in tables 13 and 14 respectively. 
Table 13

Mean Anticipated Low Activation Positive Affect

\begin{tabular}{|c|c|c|c|c|c|c|c|c|c|}
\hline & \multicolumn{4}{|c|}{ Dispositional Extraverts } & \multicolumn{4}{|c|}{ Dispositional Introverts } & \multirow[b]{3}{*}{ Totals } \\
\hline & \multicolumn{2}{|c|}{ Act Ext. } & \multicolumn{2}{|c|}{ Act Int. } & \multicolumn{2}{|c|}{ Act Ext. } & \multicolumn{2}{|c|}{ Act Int. } & \\
\hline & $M$ & $S D$ & $M$ & $S D$ & $M$ & $S D$ & $M$ & $S D$ & \\
\hline Neutral & 2.90 & 1.18 & 4.67 & .87 & 3.52 & 1.07 & 4.50 & 7.72 & $4.04 S D=1.51$ \\
\hline \multirow{4}{*}{$\begin{array}{c}\text { Positive } \\
\text { Totals }\end{array}$} & 2.51 & 1.01 & 4.58 & 1.04 & 3.29 & 1.06 & 4.45 & .95 & $3.65 S D=1.31$ \\
\hline & \multicolumn{4}{|c|}{$3.65 S D=1.40$} & \multicolumn{4}{|c|}{$3.93 S D=1.35$} & \\
\hline & \multicolumn{2}{|c|}{$2.68 S D=1.08$} & \multicolumn{2}{|c|}{$4.62 S D=.94$} & \multicolumn{2}{|c|}{$3.40 \quad S D=1.05$} & \multicolumn{2}{|c|}{$4.48 \quad S D=1.43$} & \\
\hline & \multicolumn{4}{|c|}{ Total Act. Ext: $3.07 S D=1.11$} & \multicolumn{4}{|c|}{ Total Act. Int:4.55 $S D=1.22$} & \\
\hline
\end{tabular}

Table 14

Low Activation PA ANOVA Table: Disposition X Acting Condition X Mood Manipulation Condition

\begin{tabular}{lrrrrrr}
\hline Source & $S S$ & $d f$ & $M S$ & $F$ & $p$ & Partial $\eta^{2}$ \\
\hline Disposition & 1.87 & 1 & 1.87 & 1.37 & .24 & .02 \\
Acting & 55.28 & 1 & 55.28 & 40.54 & $<.001$ & .30 \\
Mood & .88 & 1 & .88 & .64 & .42 & .007 \\
Disp * Acting & 4.42 & 1 & 4.42 & 3.24 & .08 & .03 \\
Disp * Mood & .05 & 1 & .05 & .04 & .84 & $<.001$ \\
Acting * Mood & .38 & 1 & .38 & .28 & .60 & .003 \\
Disp*Acting* Mood & .02 & 1 & .02 & .01 & .91 & $<.001$ \\
Error & 126.81 & 93 & 1.36 & & & \\
\hline
\end{tabular}


As the assumption of homogeneity of variance was not met, Levene's test of equality of variances $F(7,93)=2.50, p=.02$, a more stringent alpha level of .01 was used. The ANOVA revealed a significant main effect of acting condition, $F(1,93)=$ 40.54, partial $\eta^{2}=.30, p<.001$, with participants predicting more low activation PA for acting introverted $(M=4.55, S D=1.22)$ than for acting extraverted $(M=3.07, S D=$ 1.11). No other main effects were significant.

There was a marginally significant two-way interaction between disposition and acting condition, $\mathrm{F}(1,93)=3.24$, partial $\eta^{2}=.03, p=.08$ (see figure 4 ). Simple effects contrasts revealed that both extraverts, $\mathrm{F}(1,97)=32.84$, partial $\eta^{2}=.25, p<.001$, and introverts, $\mathrm{F}(1,97)=11.96$, partial $\eta^{2}=.11, p=.001$, anticipated feeling significantly more low activation PA while acting introverted when compared to acting extraverted. Furthermore, although there were no significant differences in mean ratings of anticipated low activation PA for acting introverted, $\mathrm{F}(1,97)=<.001$, partial $\eta^{2}=<.001, p=.95$, there was a marginally significant difference for acting extraverted, $F(1,97)=3.20$, partial $\eta^{2}=.03, p=.08$ with introverts predicting more low activation PA $(M=3.40, S D$ $=1.05)$ than extraverts $(M=2.68, S D=1.08)$. 


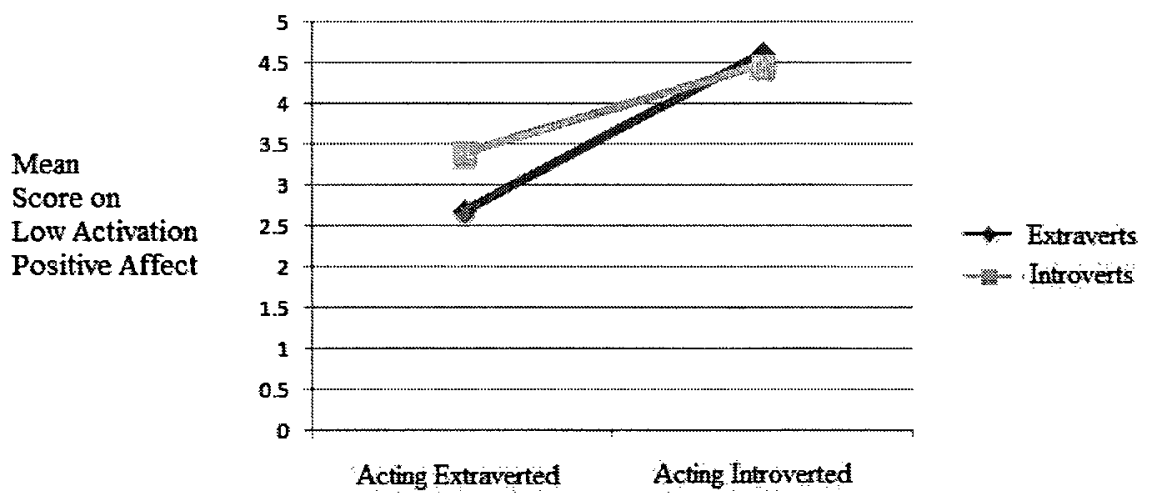

Figure 4. Low Activation PA Disposition X Acting Condition Interaction Graph

No other interactions were significant. The three-way interaction was also not significant, $\mathrm{F}(1,93)=.01$, partial $\eta^{2}<.001, p=.91$, indicating that disposition, acting condition, and mood manipulation condition did not interact to predict ratings of low activation PA.

A separate $2 \times 2 \times 2$ ANOVA (disposition by acting condition by mood manipulation condition) was conducted to search for mean differences in low activation NA. A table of means and an ANOVA table can be viewed in tables 15 and 16 respectively. 
Table 15

Mean Anticipated Low Activation Negative Affect

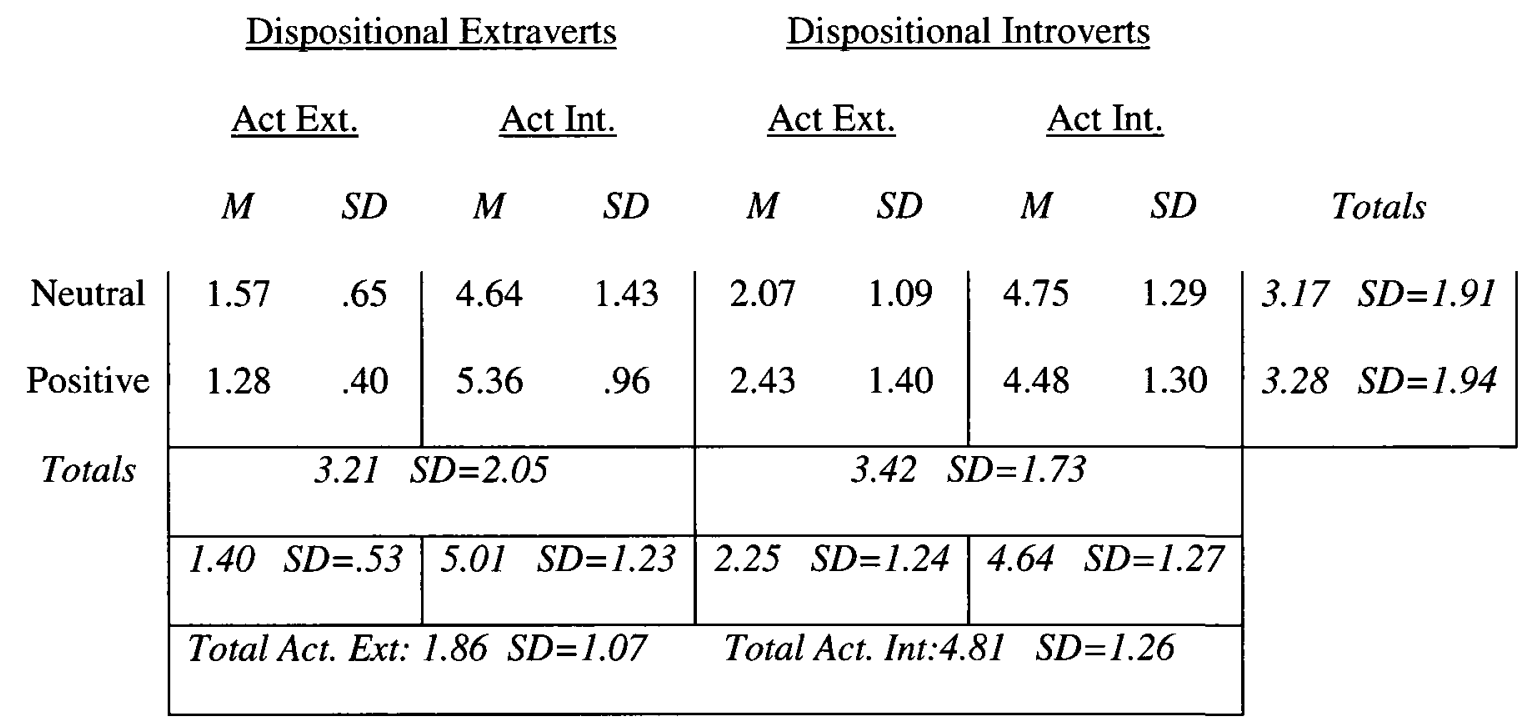

Table 16

Low Activation NA Table: Disposition X Acting Condition X Mood Manipulation Condition

\begin{tabular}{lrrrrrr}
\hline Source & $S S$ & $d f$ & $M S$ & $F$ & $p$ & Partial $\eta^{2}$ \\
\hline Disposition & 1.22 & 1 & 1.22 & .96 & .33 & .01 \\
Acting & 218.12 & 1 & 218.12 & 170.86 & $<.001$ & .65 \\
Mood & .44 & 1 & .44 & .34 & .56 & .004 \\
Disp * Acting & 9.00 & 1 & 9.00 & 7.05 & .01 & .07 \\
Disp * Mood & .19 & 1 & .19 & .15 & .70 & .002 \\
Acting * Mood & .23 & 1 & .23 & .18 & .67 & .002 \\
Disp*Acting* Mood & 4.11 & 1 & 4.11 & 3.22 & .08 & .03 \\
Error & 118.73 & 93 & 1.28 & & & \\
\hline
\end{tabular}


As the assumption of homogeneity of variance was not met, Levene's test of equality of variances $F(7,93)=.2 .75, p=.01$, a more stringent alpha level of .01 was used. The analysis revealed a significant main effect of acting condition, $F(1,93)=$ 170.86, partial $\eta^{2}=.65, p<.001$, with participants reporting more low activation NA for acting introverted $(M=4.81, S D=1.26)$ when compared to acting extraverted $(M=1.86$, $S D=1.07)$. No other significant main effects were found.

There was also a significant two-way interaction between disposition and acting condition, $\mathrm{F}(1,93)=9.00$, partial $\eta^{2}=.07, p=.01$ (see figure 5). Simple effects contrasts revealed that for both extraverts and introverts, predictions of low activation NA were higher for acting introverted, $\mathrm{F}(1,93)=117.58$, partial $\eta^{2}=.55, p<.001$, than for acting extraverted, $\mathrm{F}(1,93)=61.55$, partial $\eta^{2}=.39, p<.001$. Furthermore, although there were no significant differences in mean ratings of anticipated low activation NA for acting introverted, $\mathrm{F}(1,97)=.17$, partial $\eta^{2}=.001, p=.68$, there was a marginally significant difference for acting extraverted, $\mathrm{F}(1,97)=3.04$, partial $\eta^{2}=.03, p=.08$, with introverts predicting more low activation NA $(M=2.25, S D=1.24)$ than extraverts $(M=1.40, S D$ $=.53$ ). No other two-way interactions were significant.

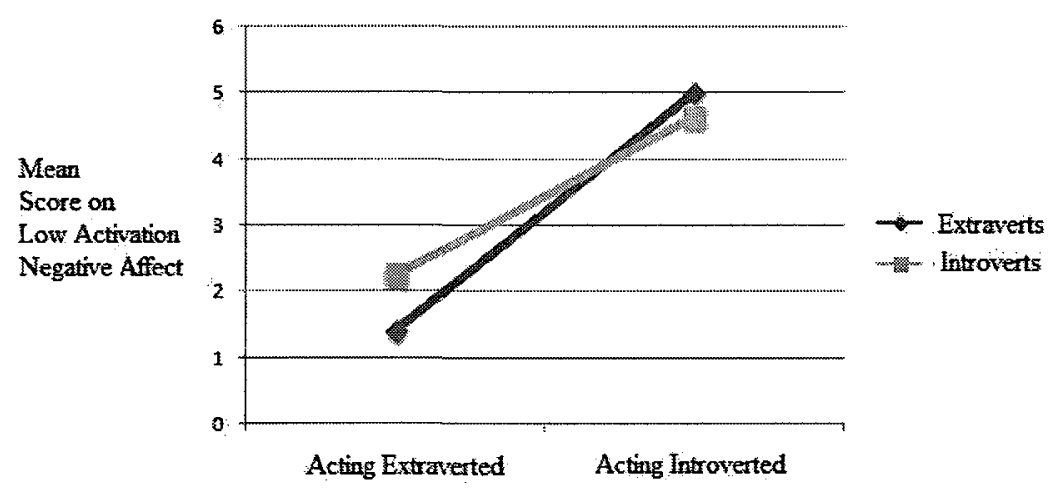

Figure 5. Low Activation NA Disposition X Acting Condition Interaction Graph 
The three-way interaction was marginally significant, $\mathrm{F}(1,93)=3.22$, partial $\eta^{2}=$ $.03, p=.08$. The interaction is quiet subtle, but indicates disposition, acting condition, and mood manipulation condition did interact in some way to predict ratings of low activation NA (see figure 6). In sum, while this portion of the analysis revealed some effects of mood they were not in the direction which would have been expected.

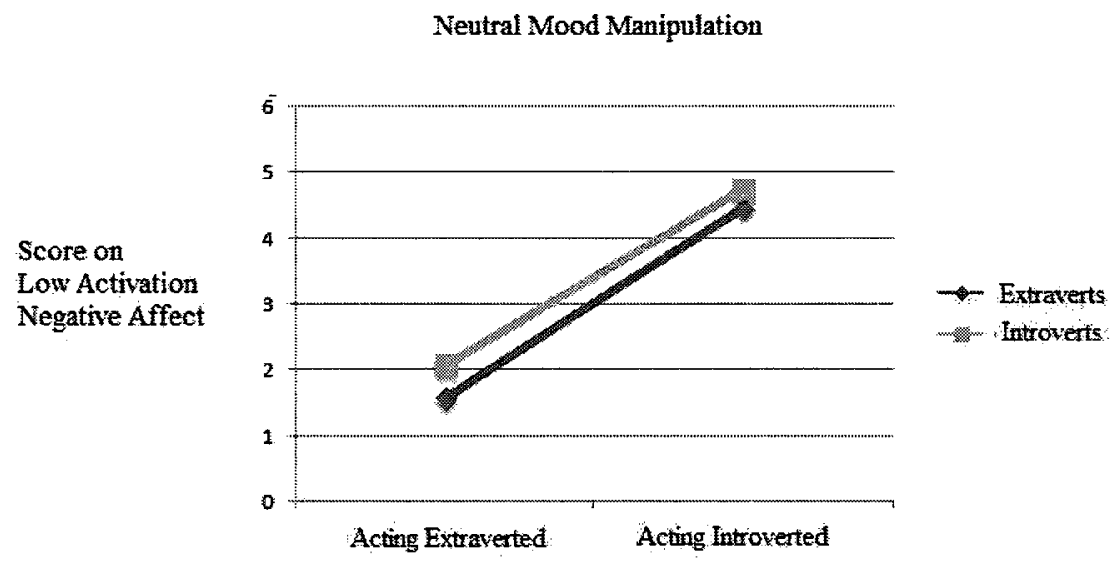

Positive Mood Manipulation

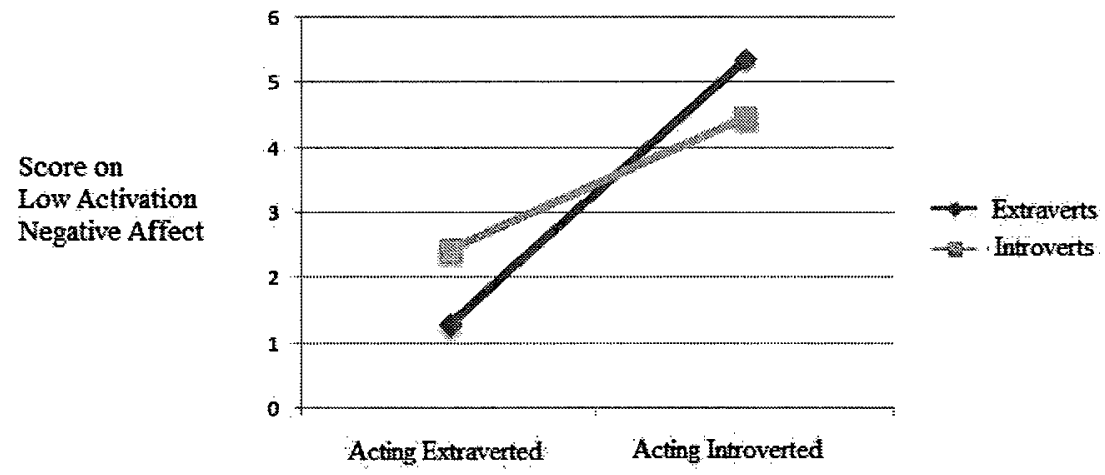

Figure 6. Low Activation NA Disposition X Acting Condition X Mood Manipulation Condition Interaction Graph 


\section{Affective Forecasts for Social and Non-Social Situations}

The Social Situations Questionnaire was included in order to search for differences in predicted positive emotions for social versus non-social situations. First, a 2x2 ANOVA (disposition by mood manipulation condition) was conducted to search for group differences in ratings of anticipated positive emotions in social situations. A table of means and an ANOVA table can be viewed in tables 17 and 18 respectively

Table 17

Mean Ratings Positive Emotions in Social Situations

\begin{tabular}{l|cc|cc|cc|}
\multicolumn{1}{c}{} & \multicolumn{2}{c}{ Extraverts } & \multicolumn{2}{c}{ Introverts } \\
\multicolumn{1}{c}{$M$} & $S D$ & $M$ & $S D$ & Total \\
Neutral & 5.26 & .81 & 4.88 & .69 & 5.03 & $S D=.70$ \\
Positive & 5.19 & .57 & 4.88 & .80 & 5.04 & $S D=.75$ \\
Total & 5.22 & $S D=.68$ & 4.88 & $S D=.73$ & & \\
\cline { 2 - 6 } & & & & &
\end{tabular}

Table 18

Mean Positive Emotions in Social Situations ANOVA Table: Disposition X Mood Manipulation Condition

\begin{tabular}{lrrrrrr}
\hline Source & $S S$ & $d f$ & $M S$ & $F$ & $p$ & Partial $\eta^{2}$ \\
\hline Disposition & 2.99 & 1 & 2.99 & 5.85 & .02 & .06 \\
Mood & .04 & 1 & .04 & .07 & .79 & .001 \\
Disp * Mood & .03 & 1 & .03 & .06 & .81 & .001 \\
Error & 49.65 & 97 & .51 & & & \\
\hline
\end{tabular}


A significant main effect of disposition was found, $\mathrm{F}(1,97)=5.85$, partial $\eta^{2}=$ $.06, p=.02$, with extraverts $(M=5.22, S D=.68)$ predicting more positive emotions in social situations than introverts $(M=4.88, S D=.73)$. No significant main effect of mood was demonstrated, $\mathrm{F}(1,97)=.07$, partial $\eta^{2}=.001, p=.79$. The interaction was also not significant, $\mathrm{F}(1,97)=.06$, partial $\eta^{2}=.001, p=.81$. Thus, again, it was not shown that disposition and mood interact to predict affective forecasts for social situations.

A separate $2 \times 2$ ANOVA (disposition by mood manipulation condition) was conducted to search for group differences in ratings of anticipated positive emotions for non-social situations. A table of means and an ANOVA table can be viewed in tables 19 and 20 respectively.

Table 19

Mean Ratings Positive Emotions in Non-Social Situations

\begin{tabular}{|c|c|c|c|c|c|}
\hline & \multicolumn{2}{|c|}{$\underline{\text { Extraverts }}$} & \multicolumn{2}{|c|}{ Introverts } & \multirow[b]{2}{*}{ Total } \\
\hline & $M$ & $S D$ & $M$ & $S D$ & \\
\hline Neutral & 4.26 & .80 & 4.54 & .93 & $4.43 S D=.82$ \\
\hline Positive & 4.41 & .91 & 4.69 & .68 & $4.55 S D=.81$ \\
\hline Total & 4.34 & $=86$ & 4.61 & $=.82$ & \\
\hline
\end{tabular}


Table 20

Mean Positive Emotions in Non-Social Situations ANOVA Table: Disposition X Mood Manipulation Condition

\begin{tabular}{lrrrrrr}
\hline Source & $S S$ & $d f$ & $M S$ & $F$ & $p$ & Partial $\eta^{2}$ \\
\hline Disposition & 1.91 & 1 & 1.91 & 2.68 & .11 & .03 \\
Mood & .55 & 1 & .55 & .78 & .38 & .008 \\
Disp * Mood & $<.001$ & 1 & $<.001$ & $<.001$ & .99 & $<.001$ \\
Error & 68.93 & 97 & .71 & & & \\
\hline
\end{tabular}

A main effect of disposition, approaching marginal significance, was found, $\mathrm{F}(1,97)=2.68$, partial $\eta^{2}=.03, p=.11$, with introverts $(M=4.61, S D=.82)$ predicting more positive emotions in non-social situations when compared to extraverts $(M=4.34$, $S D=.86)$. There was however, no significant main effect of mood, $\mathrm{F}(1,97)=.78$, partial $\eta^{2}=.008, p=.38$. The interaction was also not significant, $\mathrm{F}(1,97)=<.001$, partial $\eta^{2}=$ $<.001, p=.99$. Thus, it was not demonstrated that disposition and mood interact to predict affective forecasts for non-social situations.

In sum, the analysis revealed that disposition affects predictions of positive emotions in social and non-social situations, with introverts predicting less positive emotions in social situations and tending to forecast more positive emotions in non-social situations when compared to extraverts (these means are illustrated in figure 7). However, again, no effect of mood was demonstrated. 


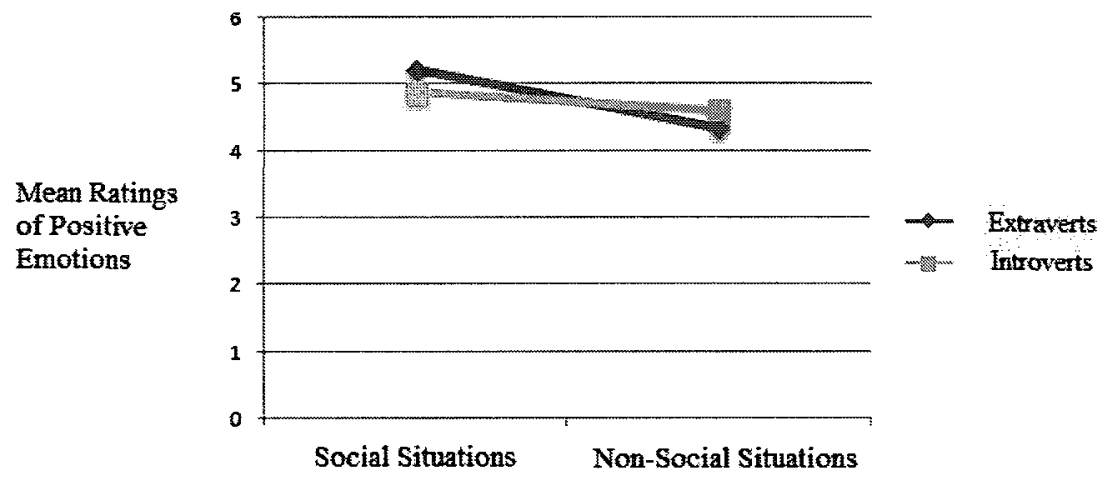

Figure 7. Affective Forecasts for Social and Non-Social Situations

\section{Extraverted Behaviours: Choice Task}

In the final portion of the study, participants made a choice as to whether they would like to wait alone (opting for a non-social situation) or with others (opting for a social situation). Unfortunately, this aspect of the study was not especially successful. Twenty-nine participants were not included in the analysis because they refused to give an answer to the question or they offered an inappropriate answer. An additional 11 participants were not included in the analysis for this portion of the study because they seriously suspected that this final question about waiting alone or with others was a part of the experiment. The final participants count for this portion of the study was 44 .

Table 21 shows responses to the choice task question by disposition and mood manipulation condition. The first general observation that can be made is that overwhelmingly, individuals choose to wait with others as opposed to alone (10 participants in total choose to wait alone compared to 34 who choose to wait with others). 
Table 21

Distribution of Responses to the Choice Task by Disposition and Mood Manipulation Condition

\begin{tabular}{|c|c|c|c|c|}
\hline & & Alone & With Others & \\
\hline \multirow[t]{2}{*}{ Extraverts } & \multirow{2}{*}{$\begin{array}{l}\text { Neutral Mood } \\
\text { Positive Mood }\end{array}$} & $\begin{array}{c}1 \\
\text { Expected Count: } 1.6\end{array}$ & $\begin{array}{c}\mathbf{6} \\
\text { Expected Count: } 5.4\end{array}$ & Total $=7$ \\
\hline & & $\begin{array}{c}\mathbf{2} \\
\text { Expected Count: } 2.5\end{array}$ & $\stackrel{9}{\text { Expected Count: } 8.5}$ & Total $=11$ \\
\hline \multirow[t]{3}{*}{ Introverts } & \multirow{2}{*}{$\begin{array}{l}\text { Neutral Mood } \\
\text { Positive Mood }\end{array}$} & $\begin{array}{c}\mathbf{5} \\
\text { Expected Count: } 3.4\end{array}$ & $\begin{array}{c}\mathbf{1 0} \\
\text { Expected Count: } 11.6\end{array}$ & \multirow{2}{*}{$\begin{array}{l}\text { Total }=15 \\
\text { Total }=11\end{array}$} \\
\hline & & $\begin{array}{c}\mathbf{2} \\
\text { Expected Count: } 2.5\end{array}$ & $\begin{array}{c}9 \\
\text { Expected Count: } 8.5\end{array}$ & \\
\hline & & Total $=10$ & Total $=34$ & \\
\hline
\end{tabular}

As table 21 illustrates, the observed and expected values are very similar in each condition cell. Chi-Squared analysis revealed that there were no significant differences in response rates for choosing to wait alone versus with other people between condition groups, $\chi 2(8, \mathrm{~N}=44)=1.50, \mathrm{p}<.68$. That is, extraverts and introverts, in both positive and neutral moods, responded similarly to the choice task question. Thus, our prediction that introverts would show a greater preference for the non-social situation, but be more inclined to choose the social situation after a mood boost (this change being mediated by positively biased affective forecasts) was not supported.

\section{Discussion}

The main goal of the current investigation was to explore the relationship between personality, mood, and affective forecasts/behaviour. The results demonstrated that, when compared to extraverts, introverts make less optimistic predictions about acting in an extraverted way and predict less positive emotions in social situations, providing some support for dispositional difference in affective forecasts (as not all dispositional differences examined were significant). Such differences in forecasts may account, at 
least in part, for why introverts may not choose extraverted behaviours/social situations to the same degree as extraverts. In current investigation, we also strove to show that affective forecasts could be modified through the manipulation of mood states. However, support for this idea was not attained as mood (particularly the widely used dimensions of PA and NA) generally did not seem to affect affective forecasts or interact with disposition to predict affective forecasts. Finally, we were unable to demonstrate that mood states may lead to changes in real world behaviours as we did not find that introverts demonstrated a preference for being alone or that they show a greater preference for a social situation as a consequence of a mood boost.

\section{Main Effects of Interest}

Although the main purpose of the study was to examine interactions between disposition, acting condition, and mood, some interesting main effects were noted. We demonstrated that introverts, in general, tend to predict less PA, more NA, and expect to hold less positive attitudes (although the finding for attitudes was only marginally significant) towards the group discussion when compared to extraverts. This is in line with past research, which has shown that introverts imagine future events to be less positive (Uziel, 2006) and expect to feel less positive emotions in future events when compared to extraverts (Lucas \& Diener, 2001). However, such differences in forecasts may represent affective forecast errors as experiences of affect in similar situations may or may not differ for introverts and extraverts. Results also showed that, in general, individuals expect to experience more PA, less NA and hold more positive attitudes towards the discussion when imagining acting extraverted when compared to acting introverted. Thus, as a whole, participants tended to view acting extraverted as a more 
favourable choice than acting introverted. These affective forecasts suggest that, as a whole, participants understand that acting extraverted should lead to more positive emotions than acting introverted (as shown by McNeil \& Fleeson, 2006).

When examining other types of affect, we found that participants predicted experiencing significantly more low activation PA while acting introverted when compared to acting extraverted (recall, however, that the alpha level for this measure was quite low). Thus, in contrast to PA, which is associated with acting extraverted, individuals anticipate that low activation PA will result from acting introverted. In other words, while individuals don't seem to anticipate feeling more high arousal positive emotions when acting introverted as opposed to extraverted, they do expect to feel more calmly contented. Overall these results suggest that acting introverted may be associated with a different type of positive emotions and that those who aim to feel relaxed and calm, may choose introverted behaviours over more extraverted ones. While McNeil \& Fleeson (2006) demonstrated that participants report more PA when instructed to act extraverted as opposed to introverted, their study did not examine low activation PA. If low activation emotions were included in such a study, we may find that although individuals report experiencing more PA while acting extraverted, they may report more low activation PA for acting introverted. In such a case, the hedonic benefits of acting extraverted or introverted may depend on individual preferences for emotional states. It is a distinct possibility that introverts prefer to feel calmly contented over feeling more highly activated positive emotions. In line with this idea, Rusting and Larsen (1994) demonstrated that individuals varying in levels of extraversion do differ in terms of the types of moods they prefer. Their study showed that although all individuals enjoy 
positive moods, extraversion was correlated with the desire for more activated or aroused positive mood states. Since measures of PA are composed of terms which represent high arousal emotions (such as, for example feeling "excited"), it may be that measures of PA do not represent the types of positive moods which introverts enjoy most. If introverts do indeed enjoy low activation PA states, this could explain why they may choose introverted behaviours over more extraverted ones. It is of note however, that our results also showed that acting introverted was associated with predicting higher levels of low activation NA. Thus, although participants, as a whole, predict feeling more calmly contented while acting introverted, they also expect to experience more feelings related to boredom.

\section{Disposition and Affective Forecasting}

McNeil \& Fleeson (2006) demonstrated that when state extraversion is manipulated by instructing participants to temporarily act either extraverted or introverted in a group discussion task, regardless of individual dispositions, participants report more PA when instructed to act extraverted as opposed to introverted. In the current investigation, we postulated that introverts would not expect to profit hedonically from acting extraverted and would therefore forecast affect differently than extraverts, and in such a way that might make them less likely to choose extraverted behaviours. The results of the initial t-tests demonstrated that, when mood is not manipulated, introverts anticipate experiencing less PA and more NA while acting extraverted when compared to extraverts. There was also a non-significant trend for introverts to forecast less positive attitudes towards acting extraverted. In light of the literature on affective forecasting which suggests that we use our anticipated emotions as guides to choices (Wilson \& 
Gilbert, 2005; Mellers, Schwartz, Ho, \& Ritov, 1997), we may wish to conclude that these differences in anticipated emotions account, at least in part, for why introverts may not choose extraverted behaviours and situations more often. In other words, the fact that introverts are less optimistic in their predictions about how they expect to feel while acting extraverted may help explain why introverts may not act as extraverts do regularly. Of course, these dispositional differences/trends likely represent errors in affective forecasting, as research has shown that individuals of both dispositions react in an equally positive manner to acting extraverted. In sum, our prediction that introverts would make affective forecasts for acting extraverted which might make them less likely, when compared to extraverts, to choose extraverted behaviours, was largely supported.

Although we anticipated that there would be dispositional differences in affective forecasts for acting introverted as well, no support for such differences was found. Therefore, our prediction that introverts would forecast affect differently then extraverts for acting introverted, and in such a way that might make them more likely to choose introverted behaviours, was not supported. This null finding, however, may still be viewed in a somewhat favourable manner as it helps provide support for situational details accounting for how extraverts and introverts anticipate reacting emotionally. If it had been found that extraverted tended to respond with more PA and less NA regardless of the situation being considered, the conclusion drawn above would not be especially powerful as an overall tendency to be more optimistic about affective outcomes would have been demonstrated. This type of overall optimism would be likely to lead extraverts to approach all situations (both extraverted and introverted) more often than introverts. However, because extraverts predict more PA and less NA in one situation (acting 
extraverted), but not another (acting introverted), more confidence is gained in our conclusions about dispositional differences in affective forecasts for acting extraverted, potentially accounting for difference in behaviour as extraverts should be more motivated than introverts to choose extraverted behaviours, but not introverted ones.

It should be noted that, once again, both extraverts and introverts seem to forecast affect more positively for the acting extraverted condition when compared to the acting introverted condition. In other words, the data suggests that individuals of both dispositions should be inclined to choose extraverted behaviours over introverted ones, though extraverts may have somewhat more motivation than introverts to do so. Thus, it would seem that potential errors in forecasts may be subtle and reflect a difference in magnitude of predicted affect, as opposed to direction. Essentially, introverts do not appear to be "wrong" about affect for acting extraverted (as they seem to predict liking extraverted more than acting introverted), they are just not as optimistic as extraverts about the affect they might feel in such situations. Such differences, though subtle, may still help account for why extraverts may choose to act in an extraverted manner and introverts may not.

Dispositional differences in affective forecasts were also considered by way of the two-way interactions between acting condition and disposition in the overall 3-way ANOVAs. These interactions mirror the initial neutral condition t-tests, however, they include all participants, both those who had their mood manipulated in a positive direction and those who did not. We view the t-tests as solid initial analyses as they isolate the effect of disposition from mood, however the two-way interactions are worth considering as well. In examining this data we found more support for dispositional 
differences in how extraverts and introverts feel about acting extraverted. In line with the results from the t-tests, marginally significant ANOVA results revealed that introverts predict less PA for acting extraverted than extraverts do, but make similar forecasts of PA for acting introverted. These results, again, suggest that the affective forecasts made by introverts may indeed make them less likely than extraverts to choose extraverted behaviours. However, since results showed that individuals of both dispositions feel similarly about acting introverted, and both predict significantly more PA for acting extraverted when compared to acting introverted, the data, again, suggests that all individuals should be inclined to choose extraverted behaviours over introverted ones, though extraverts may have somewhat more motivation than introverts to do so (since they predict more PA for acting extraverted than introverts). Although not significant, the trends in the data also suggest that introverts tend to predict less positive attitudes and more NA for acting extraverted when compared to extraverts, but, once again, their predictions of NA and attitudes for acting introverted were similar to those of extraverts.

This study also examined affective forecasts for social and non-social situations. Results showed that introverts expect to experience significantly less positive emotions in social situations when compared to extraverts and there was a trend (approaching marginal significance) for introverts to forecast more positive affect for non-social situations. These findings suggest that affective expectations may play a role in guiding introverts towards choosing non-social/less extraverted situations and extraverts towards choosing social/more extraverted situations. Once again, these differences could represent forecasting errors as introverts may, or may not, react as extraverts do in response to social/non-social situations (whereas Fleeson's research demonstrates that PA 
is higher for both introverts and extraverts when acting extraverted (2006), no comparable studies have examined experienced affect in social versus non-social situations).

When examining the interplay between disposition and affective forecasts for low activation affective terms it was found that, although there were no dispositional differences in ratings of anticipated low activation PA for acting introverted, introverts predicted more low activation PA than extraverts for acting extraverted (marginally significant finding). In other words, introverts feel they will be more relaxed and calm while acting extraverted than extraverts. This finding seems somewhat counterintuitive as acting in an extraverted manner would not have been expected to be rated as especially calming for introverts. Counter to what might have been expected, this finding suggests an affective expectation that might lead introverts towards acting extraverted (if they are motivated to feel low activation PA). Additionally, although there were no significant dispositional differences in ratings of anticipated low activation NA for acting introverted, there was a marginally significant difference for acting extraverted, with introverts predicting more low activation NA than extraverts. Hence, introverts may expect to experience more feelings related to boredom while acting extraverted than extraverts do. Once again, such a finding is unexpected as it suggests an affective response that might lead introverts towards acting extraverted. As no research examining actual experiences of low activation emotions while acting introverted/extraverted has been conducted, future studies should investigate these emotions in the acting extraverted/introverted scenario. Conducting such research would allow us to better understand low activation PA and NA and their role in acting introverted/extraverted. 
In sum, though not a perfect match (as significance levels vary), the findings/trends of the t-test and two-way interactions in the ANOVA largely coincide and suggest that introverts, when compared to extraverts, may be less motivated to choose extraverted behaviours as they have a tendency to forecast affect about such behaviours less positively. Additionally, the data from affective forecasts of social and non-social situations also suggests that, when compared to extraverts, introverts may be more motivated to choose non-social situations over social ones as they forecast affect less positively for social situations and may forecast more positively for non-social situations. Hence, as predicted, in many cases, disposition and the details of the situation have an interactive effect of affective forecasts. Furthermore, these differences in affective forecasts may explain, at least in part, why extraverts may take advantage of acting extraverted and partaking in social situations (and potentially reap the hedonic benefits of doing so), while introverts may not. Finally, our investigation of low activation PA and NA revealed somewhat counterintuitive findings and further research in this area should be considered.

\section{Disposition, Mood, and Affective Forecasting}

We included mood manipulations in the current investigation in order to determine whether or not disposition and mood have an interactive influence on affective forecasts. Unfortunately, we were not able to show that disposition, acting condition and mood manipulation condition interact to predict affective forecasts for acting extraverted and introverted in the expected manner. We predicted that introverts, who we thought would forecasts affect less positively for acting extraverted/social situations, might, after a mood boost, forecast affect about acting extraverted/being social more optimistically. 
If, after a mood boost, introverts made affective forecasts more similar to those of extraverts (whose mood had not been manipulated), we thought that introverts may in turn behave more like extraverts and potentially profit from the hedonic benefits of acting extraverted/socially. However, we were also not able to show support for any predicted effect of mood or an interaction between disposition and mood on affective forecasts. These findings are not in line with the idea that positive moods lead individuals to make more positive associations with situations they imagine themselves in (Clark \& Waddell, 1981) and do not seem consistent with reports that positive moods lead to greater interest in social activities (Cunningham, 1988b).

Though, for the most part, the mood manipulation was not shown to have any significant effect on affective forecasts, in the case of NA, an effect was found but it was not in the anticipated direction as participants anticipated feeling more NA (across acting conditions) after a positive mood boost. This odd finding could be due to the fact the emotionally neutral film clip featured what was essentially a group discussion about the work of literature "Beowulf". It may be that those who viewed this film felt less inclined to predict NA in their own hypothetical group discussion as they had just viewed a film featuring a discussion in which contributors did not appear to be experiencing negative emotions. While the positive mood inducing film also featured elements of social interaction, this interaction did not include any type of group discussion. In future experiments using mood manipulations and the given affective forecasting task, another neutral film in which no discussion is featured should be considered. In choosing another video, predictions of affect with regards to the group discussion should not be biased. 
One marginally significant interaction between disposition, acting condition and mood was noted. However, the interaction did not suggest that positive moods change attitudes towards acting introverted or acting extraverted in such a way that might lead introverts to choose extraverted behaviours more often (as in both mood states, and in both acting conditions, introverts expect to experience very similar levels of low activation NA). While this type of three-way interaction was important to the current study, the demonstrated interaction, being so subtle, does little to inform how moods and disposition may interact to determine affective forecasts, and potentially, behaviours.

It is difficult to determine why we were unable to demonstrate the anticipated interaction between mood and disposition on affective forecasts for acting extraverted/introverted or for social/non-social situations. Even without considering personality factors, based on the literature which suggests that judgements tend to be biased in a mood-congruent manner (Rusting, 1998), we might have expected the mood manipulation to bias judgements in a positive direction. Although it is possible that the mood manipulation did not influence mood states, this seems unlikely given the significant effect that the positive film clip has been shown to have on mood states in past research (as noted in the methods section). However, since online reports of affect were not collected in this study (as we did not want to arouse suspicions about the mood manipulation by measuring mood states), we cannot determine whether or not the mood manipulation was successful in altering mood states. It may be that although mood states were modified by the film, the effect did not last long enough to affect the questionnaires. Since participants watched the film, answered a short questionnaire about the film, and 
then engaged in imagining the group discussion, the effects of the mood manipulation may have worn off before any of the main questionnaires were answered.

If we assume that the mood manipulation did modify mood states and these mood states lasted over a long enough period of time, questions are raised about the ability of our measures to detect the changes in affective forecasts which may have resulted as a consequence of altered moods. The social situations questionnaire in particular was quite brief and merely asked participants to indicate the degree to which they anticipated feeling, quite simply, "positive emotions" in the given situations. Therefore, this measure may not have succeeded in detecting the influence of mood states on affective forecasts. In future research, we would consider allotting more time for this measure in order to give participants a chance to rate their feeling about social and non-social situations more precisely (perhaps through measuring predicted PA, NA, as well as low activation PA and NA). We would also consider expanding the PANAS measure to potentially measure predicted emotion more comprehensively and hopefully, detect any changes in predicted emotion which might occur. However, in the end, it may be that, contrary to what was predicted, a change in mood state does not have the potential to change affective forecasts for future events.

\section{Affective Forecasts and Behavioural Choices}

This portion of the study was designed to explore if mood boosts could affect an actual choice for participating in a future social or non-social event. We expected that since individuals use their predicted emotions as guides to choice (Mellers et al., 1997) and anticipated emotions may be modified through the mood manipulation, it would follow that real world decisions about future extraverted behaviours should be influenced 
by a mood boost. In light of the finding that introverts spend more time alone when compared to extraverts (Mehl, Gosling, \& Pennebaker, 2006) and that positive moods cause an increased desire for social-situations (Cunningham, 1988b) we predicted that introverts, who may show an increased preference for the non-social situation, would show a greater preference for the social situation as a consequence of the mood boosts (potentially leading them to respond more similarly to dispositional extraverts whose mood had not been manipulated). However, our results did not demonstrate that introverts preferred the non-social situation, or a change in preferences through a mood boost. Overall, the results did not coincide with Cunningham's findings that positive moods cause an increased desire for social-situations as participants in general did not tend to opt for social situations more often when in a positive mood.

It is of note that this portion of the study was quite severely limited as numerous participants were excluded from analysis. First of all, many participants refused to give an answer to the question as to whether they would like to wait alone or with others. That is, despite numerous prompts to attain an answer, many participants continued to assert that they had no preference as to where they would like to wait. As the participants were told they would be waiting "for a few minutes" they may have viewed this choice as being an insignificant one, explaining their lack of preference. Alternatively, participants may have wanted to appear particular about their waiting location, and as such, choose not respond. Other participants were excluded from analysis because they gave an inappropriate answer to the question, such as indicating a preference to wait in the closest room available or to make a call in the hallway. In addition, numerous participants were excluded from analysis because they were suspicions that the choice task question was a 
part of the experiment. Due to these issues, the sample size for the portion of the study was much smaller than desirable. Another limitation to this portion of the study was that most participants chose to wait with other people as opposed to alone. The straightforward interpretation of this result is that participants, both introverted and extraverted, were drawn towards the more social option of waiting with others. Although it may be that participants in general preferred the social situation, we suspect that participants may have viewed waiting alone as request for special treatment and waiting with others as the easier or less particular choice. In other words, it may be that participants choose to wait with others more frequently due to reasons other than the "socialness" of the situation. Even though the experimenter was careful to ask the question in such a way which suggested that either option was completely acceptable, social desirability may have been a major factor in this portion of the experiment.

Hopefully, in further experiments, the procedure for this choice task can be modified in such a way that it will encourage all participants to answer the question appropriately and with less suspicion. Changing the task completely is another option, however, previous studies in the Carleton University Happy Lab have shown that other methods can have their limitations as well. For example, in one study, participants were asked whether they would like to work alone, or with others on a task. In contrast to what happened in the current study, most participants choose to be alone, potentially because they felt it would be easier/faster to work on the task alone as opposed to working with others. While perfecting a behavioural choice task may not be easy, these tasks are an essential part of this type of research as they help to uncover whether or not self-report data translates into actual real-world behaviours. 


\section{Overall Findings}

In sum, two main questions were considered in the current research. First of all, do introverts and extraverts differ in their affective forecasts for introverted and extraverted behaviours and situations? Overall, the results show that introverts anticipate feeling less positively about acting extraverted (by anticipating less PA and more NA when compared to extraverts), whereas individuals of both dispositions feel similarly about acting introverted. When considering social situations we found that introverts anticipate feeling less positive emotions in social situations when compared to extraverts and there was a trend which suggested that introverts may forecast more positive emotions in non-social situations. Such differences in forecasts may account, at least in part, for why introverts do not choose extraverted behaviours and situations more often. There were also dispositional differences in affective expectations for low activation PA and NA (though these differences were challenging to interpret and some were only marginally significant). Overall, the answer to this first question is yes, the current research has demonstrated dispositional differences in how introverts and extraverts forecast affect, at least for acting extraverted/social situations. The second question we considered was how might mood states affect the affective forecasts and behaviours of introverts and extraverts? We were, however, unable to show that mood states impact affective forecasts (at least not in the predicted manner) or behaviours. While we expected that positive mood states might lead introverted individuals to hold more positive affective expectations for acting extraverted/social situations as well as change real-world social behaviours, we were unable to demonstrate these effects. 
Overall, the findings suggest that both introverts and extraverts should be inclined to choose extraverted behaviours over introverted ones (as individuals of both dispositions tend to make more positive predictions about acting extraverted than acting introverted). Thus, once again, differences in affective forecasts may be viewed as subtle, as they reflect differences in magnitude as opposed to direction. However, results suggest that extraverts should be more motivated to choose extraverted behaviours/social situations than introverts, as their affective forecasts tend to be more positive. Other important findings suggest that individuals predict different types of emotion for acting introverted (such as experiencing more low activation PA, but also more and low activation NA) when compared to acting extraverted (which is associated with PA). Therefore, choices to engage in introverted behaviours over extraverted ones may depend on the affective preferences of the individual.

\section{Limitations}

Although several limitations of the current investigation have been addressed throughout the discussion, other limitations should be noted as well.

The sample used in the current investigation may be considered limited as it consisted primarily of first year students at Carleton University. While this is typical of many studies in psychology and it is not expected that this limitation affected our findings, it would have been desirable to collect a sample of participants which was more representative of the general population. Additionally, the fact that the study made use primarily of self-report questionnaires is another drawback as social desirability could have affected the participants' responses. As already discussed, it is thought that social 
desirability was a major factor in explaining why the choice task portion of the experiment did not yield favourable outcomes.

The study is also limited due to the fact that random assignment to the experimental conditions was not perfect. Toward the end of the study, the condition groups were rather uneven (with more participants in some conditions than others), therefore the probability of each participant ending up in one combination of conditions versus others was adjusted so that more individuals would be assigned to the conditions which were lacking in participants. Thus, in the end, not all participants had the same chance of being assigned to any of the condition groups. Additionally, the final number of participants assigned to each condition was not equal. In ANOVA analysis, orthogonality is lost for main effects and lower order interaction is lost when sample sizes within groups are uneven and the values of the marginal means become somewhat ambiguous (Tabachnick \& Fidell, 2007). In order to deal with overlapping variance, experimenters can choose to assign priority to one IV over others (allowing this IV to take the portion of the variance which overlaps). However, since there was no compelling reason to assign priority, the unweighted approach was used and overlapping variance went unanalysed in the ANOVAs, as recommended by Tabachnick and Fidell (2007). Therefore, default SPSS output for marginal means and standard deviations were reported in the analysis section.

A theoretical limitation of the study may relate to the treatment of behaviour as either introverted or extraverted. Although we view the personality trait of extraversion as being a continuous trait (where one need not be either a strict introvert or extravert), in the current study, behaviours were treated as dichotomous. In other words, we described 
behaviours as either introverted or extraverted, without considering the possibility of behaviours which might be in between these two poles. It may be that while introverts shy away from very extraverted behaviours (such as the "acting extraverted" behaviour described in the current study), they may choose to act somewhat extraverted and potentially benefit hedonically from choosing such behaviours as well. Future research should explore affective forecasts and experiences of affect for acting extraverted to varying degrees.

\section{Imagination Ability}

Another potential limitation of the study may be the affect of imagination ability. When examining self-reported imagination ability we found that those instructed to imagine acting extraverted reported significantly higher levels of imagination ability than those instructed to imagine acting introverted. This finding was surprising as the imagination questionnaire related to imagination ability in general (i.e. a trait) as opposed to the ability to imagine one particular scenario (such as acting extraverted or introverted in a group discussion task). This finding may represent a failure of random assignment, or it could be that the hypothetical group discussion task, in which participants are asked to imagine a scenario, biased responses to the imagination questionnaire. For example, if those asked to imagine acting extraverted found this task easier, as perhaps acting extraverted in a social scenario seems more intuitive or socially acceptable, this could explain why participants subsequently reported greater imagination ability. In the same way, if those who imagined acting introverted found the imagination task more difficult, this may explain reports of poorer imagination ability. In future studies, we would consider administering an imagination questionnaire prior to having participants imagine 
the group discussion. By conducting the study in the manner, we would ensure that selfreports of imagination ability are not biased by a prior imagination task. We could also consider asking participants directly about how easily they were able to imagine the group discussion scenario, in order to see if differences in the ability to imagine acting extraverted/introverted in the given scenario actually exist.

Unfortunately, the link between acting condition and self-reported imagination ability presented a potential confound for this study. Specifically, if individuals were able to imagine acting extraverted in the described situation more vividly or with more ease than imagining acting introverted, the main effects found for acting condition throughout the study may have been due to differences in imagination ability. In other words, if individuals were able to better imagine acting extraverted, they may have predicted more positive emotions/attitudes for the scenario because of this. However, through the use of imagination as a covariate in the various ANCOVA analyses, it was established that the nature of the conclusions drawn from the study were not modified by taking imagination ability into account. Unfortunately, however, no such control was used in the case of the t-tests.

It is also of note that the imagination scale used was a newly created measure, therefore it is not yet known whether or not this measure can provide truly valid information on imagination ability. In light of this, it is difficult to draw conclusions with respect to the role of imagination ability in affective forecasting. An interesting topic for future research would be to explore measures of imagination ability more closely in order to discover exactly what affect imagination has on affective forecasts.

Forecasting Accuracy 
While this research explored dispositional differences in affective forecasts, it did not examine the accuracy of these predictions. Since research has shown that introverts and extraverts react in an equally positive manner to acting extraverted (McNeil \& Fleeson, 2006) and our research shows that introverts and extraverts make differential predictions for this event, some errors in forecasting must have occurred. However, since the acting extraverted/introverted scenarios were not actually experienced by the participants, we have no way of knowing whose forecasts were accurate, and whose may have been misguided. Our predictions suggested that introverts may misforecast affect, as we proposed that introverts would not anticipate the PA associated with acting extraverted. This prediction seemed to make intuitive sense as, despite the fact that individuals of all dispositions experience similar levels of PA while acting extraverted, introverts may choose such behaviours less often. Support for this prediction was also provided by pilot research which suggested that, for acting extraverted, introverts underestimate PA (i.e. expect to experience less PA than they actually do while acting extraverted) to a greater degree than extraverts (Wynn and Zelenski, 2007). Still, it should be noted that introverts are not necessarily the ones who mispredict affect. It could also be that extraverts tend to overpredict PA for acting extraverted, driving them to choose such behaviours more regularly. Introverts, by contrast, may make forecasts for these events that are less biased in a positive direction, and potentially more accurate. However, we may consider that the most important thing is not the accuracy of forecasts, but ultimately, choosing the outcome which will lead to the most positive emotions. In other words, even if extraverts are overly optimistic in their predictions, if these forecast leads them to choose one behaviour which will lead to more PA (acting extraverted), over 
another behaviour which will lead to less PA (acting introverted), the erroneous forecast need not necessarily be viewed as maladaptive. In conducting this study we had hoped it would provide a basis for future research on the accuracy of affective forecasts by showing that introverts and extraverts do indeed differ in their affective forecasts as well as that mood states affect forecasting and behaviours (although this second goal was not achieved). Future research should explore the degree to which the affective forecasts of extraverts and introverts are accurate, and whether or not mood manipulations have the potential to promote accuracy.

\section{Theoretical Considerations}

\section{The Happy Introvert}

In an early piece by Thorpe (1941) two important questions were posed: "What is wrong with introversion?" and "Must we all be extraverts?" These are extremely pertinent questions with regard to the current research. Although we believe that introverts may benefit hedonically from acting extraverted, we cannot neglect the fact that introversion may have its own benefits. As Thorpe suggests, when we characterize introverts as lonely, maladjusted, and emotionally unstable, we portray them as being rather ineffectual individuals. Thorpe reminds us that introverts may be quietly content scholars, revel in the joys of less active or outgoing pass times, and nevertheless be effective social participants when the situation demands it of them. Along the same lines, Hills and Argyle (1999) refer back to thinkers such as Aristotle and Epicurus who held views of happiness which emphasised a quiet and peaceful existence and propose that many introverted individuals today find happiness in much the same ways. As suggested by our findings on low activation PA, it may be that those driven towards feeling calmly 
contented (over highly activated states of PA) will choose introverted behaviours over more extraverted ones and benefit from this choice.

Thorpe (1941) also prompts us to consider that "a man is more than the sum of his personality test" (p.103). Similarly, more recent authors have suggested that although traits are important, relying on trait constructs exclusively to explain SWB is not advisable (Diener, 1996). In support of this Hills and Argyle (1999) found that some introverts were nearly identical to extraverts in terms of their preference for solitude, participation in introspective activities, and relationships. Their study demonstrated that the happiness levels of their participants were more closely tied to variables related to self-esteem and fulfilment rather than to levels of trait extraversion. Therefore, although we should examine trait extraversion and give serious consideration to how it may impact life outcomes and SWB, the ultimate determination of happiness will not depend solely on trait extraversion levels, or on levels of any trait.

In sum, the current research need not suggest that there is something inherently wrong with introverts or that we must all become extraverts. It merely provides a suggestion that when introverts realise the prospective value of acting in an extraverted manner, they may become driven to work towards the goal of choosing more extraverted behaviours in order to reap potential hedonic benefits. Even Thorpe, who wrote so passionately about the positive side of introversion, suggested that introverted individuals can make changes for the better by examining how they live their lives and act socially.

\section{Authenticity and Being True to Traits}

Some authors suggest that when pursuing happiness we need to be genuine, authentic, and true to ourselves (Kets de Vries, 2000). Trait theory would suggest that to 
be true to one's self is to act in accordance with one's inborn traits (Sheldon, Ryan, Rawsthorne \& Ilardi, 1997) and some authors strongly support the notion of being true to personality traits (McGregor, McAdams, \& Little, 2005). However, depending on the context of the situations we find ourselves in, we may act more or less in accordance with our "true selves". For example, when the situation calls for acting extraverted, an introvert may depart from their normal and/or preferred behaviours and present themselves in a different way. Some research shows that situations which allow us to be authentic lead to better health and well-being while situations which require us to depart from our authentic selves lead to distress (Sheldon, Ryan, \& Reis, 1996; Ryan, Sheldon, Kasser, \& Deci, 1996, as cited in Sheldon, Ryan, Rawsthorne \& Ilardi, 1997). One study on five-factor personality traits, demonstrated that SWB was related to measures of selfconsistency and psychological authenticity (Sheldon, Ryan, Rawsthorne \& Ilardi, 1997). The authors concluded that being true to one's self is important in discussions of SWB. Similarly, the behaviour concordance model (Moskowitz \& Cote, 1995) proposes that acting in concordance with traits leads to more PA than acting out of character. In related research, Roberts and Donahue (1994) demonstrated that the satisfaction an individual experiences when playing a certain role is linked to the degree to which the behaviour the individual enacts is similar to their self-reported traits. Applying this model to the current context, we might expect introverts to experience more PA when engaging in behaviours congruent with introversion and less PA when acting extraverted. However, as the heavily cited study by McNeil \& Fleeson (2006) has demonstrated, regardless of individual dispositions, participants report more PA when acting extraverted as opposed to introverted. Thus, it may be that although acting out of character is 
generally not preferred, when there is the potentially to reap hedonic benefits from acting counterdispositionally, the scales may tip towards compromising authenticity to experience a mood boost.

However, some theorists suggest that acting counterdispositionally need not be regarded as being "untrue" to one's self as authenticity may be defined as experiences that are internally guided and brought about through one's own choices (Sheldon, Ryan, Rawsthorne \& Ilardi, 1997). When viewed in this manner, if individuals make a choice to behave counterdispositionally, perhaps because they anticipate PA resulting from their choice, the behaviour may be viewed as authentic. In fact, it has been suggested that the more choice people have in their roles and the more they identify with them, the better they are enabled to enact these roles (Sheldon, Ryan, Rawsthorne \& Ilardi, 1997). Thus, if we make the choice to act extraverted and are able to identify with the role, being more outgoing and social may come naturally.

In sum, there are arguments in the literature for being true to one's inborn traits and tendencies which speak against the ideas presented in the current research. However, the literature suggests that there is still potential for individuals to reap hedonic benefits through acting extraverted, especially if introverts are internally motivated to do so. The Goal of Happiness and Changing Levels of Happiness

While many studies, such as the current one, strive to explore ways in which wellbring might be optimised, the idea that we can increase levels of SWB does not go without question and the literature seems to reveal little about how we can actually change levels of well-being (Lyubomirsky, Sheldon and Schkade, 2005). Since research shows that levels of happiness moderately heritable (Tellegan, Lykken, Bouchard, 
Wilcox, Segal, \& Rich, 1988) and very stable over time (Eid \& Diener, 2004), some question whether or not levels of SWB can be increased more than temporarily. However, other authors argue that there is promise to modify levels of happiness more than temporarily (Seligman, Steen, Park, \& Peterson, 2005). Lyubomirsky, Sheldon, and Schkade (2005) suggest that while genetic influences are a factor in determining wellbeing, another important factor is relevant activities. In line with this, it has been proposed that encouraging extraverted activities, such as being social and interacting with others, may indeed be a viable route to increasing levels of well-being (Argyle and Lu, 1990; Fredrickson, 2008). Similarly, Fordyce (1983) identified spending more time socializing and developing a more social and extraverted personality as potential ways to increase SWB. And indeed, in his research on happiness interventions, Fordyce found that being more social was one of the most helpful strategies for increasing happiness. In line with the ideas presented in the current research, Fordyce's work suggests that enacting extravert-type behaviours may indeed be a way in which individuals can increase their levels of well-being.

While changing our behaviours may be a viable route towards increase happiness levels, Lyubomirsky, Sheldon, and Schkade (2005) point out that engaging in activities to increase happiness levels requires initiative and effort. Not only do these requirements impact our ability to engage in activity to begin with (i.e. can you commit to enacting extraverted behaviours and finding extraverted/social situation to partake in?), but also implied is the concept of ego-depletion. Acting out of character may be regarded as an act of self-regulation and, as Muraven and Baumeister (2000) suggest, our capacity to selfregulate is limited. For example, research has shown that acting in a counternormative 
manner leads to impaired self-regulation in later instances, suggesting that effortful selfpresentation uses up self-regulatory resources (Vohs, Baumeister, and Ciarocco, 2005). In other words, acting out of character may fatigue our self-regulatory resources and take a toll on our ability to self-regulate in future situations. Hence, there may be longer-term costs associated with acting extraverted in order to reap hedonic benefits in the moment.

In sum, acting counterdispositionally in order to achieve a mood boost may have both drawbacks and hedonic benefits. Ongoing research will help us to disentangle these pros and cons in order to better understand how extraverted behaviours may or may not promote long-term well-being.

\section{Conclusions}

While laymen and psychologists alike may use the terms "introversion" and "extraversion" liberally, the psychological underpinnings and implications of this personality trait are still not comprehensively understood. Research findings in the area of "acting extraverted" suggest that individuals experience more PA when they act like dispositional extraverts as opposed to dispositional introverts (Fleeson, Malanos, \& Achille, 2002; McNeil \& Fleeson, 2006). Such findings suggest that individuals may have a degree of control over their levels of well-being by modifying their own behaviours and that clinical interventions to encourage individuals to act extraverted are indeed a possibility. However, if introverts tend to make errors in affective forecasts for situations that require or encourage extraverted behaviours, they will likely be less inclined to choose such situations. Thus, an initial step to guiding introverts towards acting extraverted may need to include correcting potentially misguided forecasts about extraverted behaviours. Our research suggests that indeed, introverts do predict affect 
differently than extraverts, and in such a way that might lead them to be less likely than extraverts to choose extraverted situations and behaviours as well as social situations. While we attempted to show that mood states affect affective forecasts and may lead introverts to forecast affect more positively for acting extraverted/being social, we fell short of supporting these ideas. We also failed to show that mood states may, through their affect on affective forecasts, change real world behaviours. Future research should re-examine the affect of mood on affective forecasts and behaviours, in order to determine if the potential exists to modify affective forecasts through mood manipulations. Future studies might also explore alternative ways to modify affective forecasts, such as having participants focus on a past event in which they acted extraverted/introverted in order help curb forecasting biases. Finally, although we stand behind the notion that extraverted behaviours have the potential to benefit individual of all dispositions hedonically, this research suggests that introverted behaviours may also result in positive feelings, such as feeling calm and relaxed (but also potentially feeling related to boredom). Therefore, fondness for extraverted over introverted behaviours and situations may depend on individual preferences for emotional states. It may be that activated states of PA do not represent the types of positive moods which introverts tend to enjoy. 


\section{References}

Argyle, M., \& Lu, L. (1990). Happiness and social skills. Personality and Individual Differences, 11, 1255-1261.

Atchison, D. (Writer/Director). (2006). Akeelah and the bee [Movie Picture]. United States: Spelling Bee Productions Inc.

Augustine, A. A. \& Hemenover, S. H. (2008). Extraversion and the consequences of social interaction on affect repair. Personality and Individual Differences, 44, $1151-1161$.

Ayton, P., Pott, A., \& Elwakili, N. (2007). Affecting forecasting: Why can't people predict their emotions? Thinking \& Reasoning, 13, 62-80.

Bagozzi, R. P., Dholakia, U. M., \& Basuroy, S. (2003). How effortful decisions get enacted: The motivating role of decision processes, desires, and anticipated emotions. Journal of Behavioral Decision Making, 16, 273-295.

Baumeister, R., \& Leary, M. R. (1995). The need to belong: Desire for interpersonal attachments as a fundamental human motivation. Psychological Bulletin, 117, 497-529.

Beitz, K. (2005). The relationship between emotional reactivity, affect intensity, and affect liability and the ability to predict affective consequence for self and others (Doctoral dissertation, University of Nevada, 2005). Retrieved from ProQuest Dissertations \& Theses. (UMI Microfiber 3209129)

Bhattacharya, T., Singh,V., Kaur, R., \& Neeti, R. (2006). Judgements of subjective wellbeing: Influences of personality and affect. National Academy of Psychology, 51, 132-138. 
Bower, G. H. (1991). Mood congruity of social judgments. In J. P. Forgas (Ed.), Emotion and Social Judgment (pp. 31-35). Oxford: Pergamon Press.

Buehler, R., \& McFarland, C. (2001). Intensity bias in affective forecasting: The role of temporal focus. Personality and Social Psychology Bulletin, 27, 1480-1493.

Canli, T., Sivers, H., Whitfield, S. L., Gotlib, I. H., \& Gabriel, J. D. E. (2002). Amygdala responses to happy faces as a function of extraversion. Science, 296, 2191.

Carver, C. S., Sutton, S. K., \& Scheier, M. F. (2000). Action, emotion and personality: Emerging conceptual integration. Personality and Social Psychology Bulletin, 26, 741-751.

Ciarrochi, J. V., Chan, A. Y. C., \& Caputi, P. (2000). A critical evaluation of the emotional intelligence construct. Personality and Individual Differences, 28, 539-561.

Clark , M. S., \& Waddell, B. A. (1981). Effects of moods on thoughts about helping, attraction and information acquisition. Social Psychology Quarterly, 46, 31-35.

Costa, P. T., \& McCrae, R. R. (1980). Influence of extraversion and neuroticism on subjective well-being: Happy and unhappy people. Journal of Personality and Social Psychology, 38, 668-678.

Costa, P. T., \& McCrae, R. R. (1992). The five-factor model of personality and its relevance to personality disorders. Journal of Personality Disorders, 6, 343-359.

Costa, P. T., \& McCrae, R. R. (1994). The stability of personality: Observation and evaluations. Current Directions in Psychological Science, 3, 173-175.

Cunningham, M. R. (1988a). What do you do when you're happy or blue? Mood, expectancies, and behavioral interest. Motivation and Emotion, 12, 309-331. 
Cunningham, M. R. (1988b). Does happiness mean friendliness? Induced mood and heterosexual self-disclosure. Personality and social psychology Bulletin, 14, 283297.

Cunningham, M. R., Steinberg, J., \& Grev, R. (1980). Wanting to and having to help: Separate motivations for positive mood and guilt-induced helping. Journal of Personality and Social Psychology, 38, 181-192.

DeNeve, K. M. (1999). Happy as an extraverted clam? The role of personality in subjective well-being. Current Directions in Psychological Science, 8, 141-144.

DeNeve, K. M., \& Cooper, H. (1998). The happy personality: A meta-analysis of 137 personality traits and subjective well-being. Psychological Bulletin, 124, 197-229.

Depue, R.A., Collins, P.F. (1999). Neurobiology of the structure of personality: Dopamine, facilitation of incentive motivation, and extraversion. Behavioral and Brain Sciences, 22, 491-569.

Diener, E. (1984). Subjective well-being. Psychological Bulletin, 95, 542-575.

Diener, E. (1996). Traits can be powerful, but are not enough: Lessons from subjective well-being. Journal of research in personality, 30, 389-399.

Diener, E. (1998). Subjective well-being and personality. In D. F. Barone, M. Hersen, \& V. B. Van Hasselt (Eds), Advanced Personality (pp. 311-334). NY: Plenum Press.

Diener, E. (2000). Subjective well-being: The science of happiness and a proposal for a national index. American Psychologist, 55, 34-43.

Diener, E., \& Emmons, R. (1985). The independence of positive and negative affect. Journal of Personality and Social Psychology, 47, 1105-1117. 
Diener, E., Larsen, R. (1984). Temporal stability and cross-situational consistency of effective, behavioral and cognitive responses. Journal of Personality and Social Psychology, 47, 580-592.

Diener, E., Larsen, R., \& Emmons, R. (1984). Person x situation interactions: Choice of situations and congruence response models. Journal of Personality and Social Psychology, 47, 580-592.

Diener, E., \& Lucas, R. E. (1999). Personality and subjective well-being. In D. Kahneman, E. Diener, \&, N. Schwarz (Eds.), Well-being: The foundations of hedonistic psychology (pp. 213-229). NY: Russell Sage Foundation.

Diener, E., Sandvik, E., Pavot, W., Fujita, F. (1992). Extraversion and subjective wellbeing in a U.S. national probability sample. Journal of Research in Personality, $26,205-215$.

Diener, E., \& Seligman, M. E. P. (2002). Very happy people. Psychological Science, $13,81-84$.

Diener, E., Suh, E. M., Lucas, R. E., \& Smith, H. L. (1999). Subjective well-being: Three decades of progress. Psychological Bulletin, 125, 276-302.

Diener, E., Suh, E. M., Smith, H., \& Shao, L. (1995). National differences in reported well-being: Why do they occur? Social Indicators Research, 34, 7-32.

Dodini, A. J. (2006). Effects of personality and mood on the forecast, experience and memory of emotional events (Doctoral dissertation, The Catholic University of America, 2006). Retrieved from ProQuest Dissertations \& Theses. (UMI Microfiber 3239348) 
Dunn, E. W., Biesanz, J. C., Human, L. J., \& Finn, S. (2007). Misunderstanding the affective consequences of everyday social interactions: The hidden benefits of putting one's best face forward. Journal of Personality and Social Psychology, 92, 990-1005.

Dunn, E. W., Brackett, M. A, Ashton-James, C., Schneiderman, E., \& Salovey, P. (2007). On emotionally intelligent time travel: Individual differences in affective forecasting ability. Personality and Social Psychology Bulletin, 33, 85-93.

Dunning, D., Griffin, D. W., Milojkovic, J., \& Ross, L. (1990). The overconfidence effect in social prediction. Journal of Personality and Social Psychology, 58, 568-581.

Eid, M., \& Diener, E. (2004). Global judgments of subjective well-being: Situational variability and long-term stability. Social Indicators Research, 65, 245-277.

Elliot, A. J., \& Thrash, T. M. (2002). Approach-avoidance motivation in personality: Approach and avoidance temperaments and goals. Journal of Personality and Social Psychology, 82, 804-818.

Emmons, R. A., \& Diener, E. (1985). Personality correlates of subjective well-being. Personality and Social Psychology Bulletin, 11, 89-97.

Emmons, R. A., \& Diener, E. (1986). Influence of impulsivity and sociability on subjective well-being. Journal of Personality and Social Psychology, 50, 12111215.

Feldman Barrett, L. (1997). The relationships among momentary emotion experience, personality descriptions, and retrospective ratings of emotion. Personality and Social Psychology Bulletin, 23, 1100-1110. 
Fleeson, W. (2001). Toward a structure and process integrated view of personality: Traits as density distributions of states. Journal of Personality and Social Psychology, $80,1011-1027$.

Fleeson, W., Malanos, A. B., Achille, N. (2002). An intraindividual approach to the relationship between extraversion and positive affect: Is acting extraverted as "good" as being extraverted? Journal of Personality and Social Psychology, 83, $1409-1422$.

Fordyce, M. W. (1983). A program to increase happiness: Further studies. Journal of Counselling Psychology, 30, 483-498.

Fredrickson, B. L. (2008). Promoting positive affect. In M. Eid \& R. J. Larson, (Eds.), The Science of Subjective Well-Being (pp. 449-468). NY: Guilford Press.

Friedman, E. T., Schwartz, R. M., \& Haaga, D. A. F. (2002). Are the very happy too happy? Journal of Happiness Studies, 3, 355-372.

Furnham, A., \& Cheng, H. (2000). Lay theories of happiness. Journal of Happiness Studies, 1, 227-246.

Gilbert, D. T., \& Ebert, J. E. J. (2002). Decisions and revisions: The affective forecasting of changeable outcomes. Journal of Personality and Social Psychology, 82, 503-514.

Gilbert, D. T., Wilson, T. D., Pinel, E. C., Blumberg, S. J., \& Wheatley, T. P. (1998). Immune neglect: A source of durability bias in affective forecasting. Journal of Personality and Social Psychology, 75, 617-638.

Gralton, M. A., Hayes, Y. A., \& Richardson, J. T. E. (1979). Introversion-extraversion and mental imagery. Journal of Mental Imagery, 3, 1-10. 
Gray, J. A. (1971). The psychophysiological basis of introversion-extraversion. Behaviour Research and Therapy, 8, 249-266.

Gray, J. A. (1987). Perspectives on anxiety and impulsivity: A commentary. Journal of Research in Personality, 21, 493-509.

Graziano, W., Bernstein Feldesman, A., \& Rahe, D. F. (1985). Extraversion, social cognition, and the salience of aversiveness in social situations. Journal of Personality and Social Psychology, 47, 971-980.

Griffin, D. W., Dunning, D., \& Ross, L. (1990). The role of construal processes in overconfident predictions about the self and others. Journal of Personality and Social Psychology, 59, 1128-1139.

Gross, J. J., Sutton, S. K., \& Ketelaar, T. V. (1998). Relations between affect and personality: Support for the affect-level and affective-reactivity views. Personality and Social Psychology Bulletin, 24, 279-288.

Harryson, M. (Director). (2006). Beowulf: performed by Benjamin Bagby [Movie Picture]. Sweden: Charles Morrow Productions.

Hayes, N., \& Josheph, S. (2003). Big 5 correlates of three measures of subjective wellbeing. Personality and Individual Differences, 34, 723-727.

Heady, B., \& Wearing, A. (1989). Personality, life events, and subjective well-being: Towards a dynamic equilibrium model. Journal of Personality and Social Psychology, 57, 731-739.

Heller, D., Komar, J., \& Lee, W. B. (2007). The dynamics of state, goals, and well-being. Personality and Social Psychology Bulletin, 33, 898-910. 
Hills, P., \& Argyle, M. (2001). Happiness, introversion-extraversion and happy introverts. Personality and Individual Differences, 30, 595-608.

Hotard, S. R., McFatter, R. M., McWhirter, R. M., \& Stegall, M. E. (1989). Interactive effects of extraversion, neuroticism, and social relationships on subjective wellbeing. Journal of Personality and Social Psychology, 57, 321 -331.

Hutcherson, C. A., Goldin, P. R., Ramel, W., McRae, K., \& Gross, J. J. (2008). Attention and emotion influence the relationship between extraversion and neural response. SCAN, 3, 71-79.

Isen, A.M., Shalker , T. E., Clark, M., \& Karp, L. (1978). Affect, accessibility of material In memory, and behaviour: A cognitive loop? Journal of Personality and Social Psychology, 36, 1-12.

Kermer, D. A., Driver-Linn, E., Wilson, T. D., \& Gilbert, D. T. (2006). Loss aversion in affective forecasting errors. Psychological Science, 17, 649-653.

Kets de Vries, M. (2000). The business graduation speech: Reflections on happiness. European Management Journal, 18, 302-311.

Larsen, R. J., \& Diener, E. (1992). Promises and problems with the circumplex model of emotion. In M. S. Clark (Ed.), Review of personality and social psychology, No 13. Thousand Oaks: CA. Sage Publications.

Larsen, R. J., \& Ketelaar, T. (1989). Extraversion, neuroticism, and susceptibility to positive and negative mood induction procedures. Personality and Individual Differences, 12, 1221-1228.

Larsen, R.J., Ketelaar, T. (1991). Personality and susceptibility to positive and negative emotional states. Journal of Personality and Social Psychology, 61, 132-40. 
Lerner, J. S., \& Gonzalez, R. M. (2005). Forecasting one's future based on fleeting subjective experiences. Personality and Social Psychology Bulletin, 31, 454-466.

Lischetzke, T., \& Eid, M. (2006). Why extraverts are happier than introverts: The role of mood regulation. Journal of Personality, 74, 1127-1161.

Loewenstein, G., O'Donoghue, T., \& Rabin, M. (2003) Projection bias in predicting future utility. The Quarterly Journal of Economics, 118, 1209-1248.

Lucas, R. E. (2008). Personality and subjective well-being. In M. Eid \& R. J. Larson (Eds.), The Science of Subjective Well-Being (pp. 171-194). NY: Guilford Press.

Lucas, R. E., \& Diener, E. (2001). Understanding extraverts' enjoyment of social situations: The importance of pleasantness. Journal of Personality and Social Psychology, 81, 343-356.

Lucas, R. E., \& Fujita, F. (2000). Factors influencing the relation between extraversion and pleasant affect. Journal of Personality and Social Psychology, 6, 1039-1056.

Lyubomirsky, S., King, L., \& Diener, E. (2005). The benefits of frequent positive affect: Does happiness lead to success? Psychological Bulletin, 131, 803-855.

Lyubomirsky, S., Sheldon, K.M., \& Schkade, D. (2005). Pursuing happiness: The architecture of sustainable change. Review of General Psychology, 9, 111-131.

Mayo, P. R. (1982). Personality traits and the retrieval of positive and negative memories. Personality and Individual Differences, 4, 465-471.

McCrae, R. R., \& Costa, P. T. (1991). Adding liebe und arbeit: The full five-factor model and well-being. Personality and Social Psychology Bulletin, 17, 227-232. 
McGregor, I., McAdams, D. P., \& Little, B. R. (2005). Personal projects, life stories, and happiness: On being true to traits. Journal of Research in Personality, 40, $551-572$.

McNeil, J. M., \& Fleeson, W. (2006). The casual effects of extraversion of positive affect and neuroticism on negative affect: Manipulating state extraversion and state neuroticism in an experimental approach. Journal of Research in Personality, 40, 529-550.

Mehl, M. R., Gosling, S. D., \& Pennebaker, J. W. (2006). Personality in its natural habitat: Manifestations and implicit fold theories of personality in daily life. Journal of Personality and Social Psychology, 90, 862-877.

Mellers, B. A. (2000). Choice and relative pleasure of consequences. Psychological Bulletin, 120, 910-924.

Mellers, B. A., \& McGraw, A. P. (2001). Anticipated emotions as guides to choices. Current Psychological Science, 10, 210-214.

Mellers, B. A., Schwartz, A., Ho, K., \& Ritov, I. (1997). Decision affect theory: Emotional reactions to the outcomes of risky options. Psychological Science, 8, $423-429$.

Mellers, B. A., \& Schwartz, A., \& Ritov, I. (1999). Emotion-based choice. Journal of Experimental Psychology, 128, 332-345.

Mitchell, J. T., Kimbrel, N. A., Hundt, N. E., Cobb, A. R., Nelson-Gray, R. O, \& Lootens, C. M. (2007). An analysis of reinforcement sensitivity theory and the Five-Factor Model. European Journal of Personality, 21, 869-887. 
Moskowitz, D. S. \& Cote, S. (1995). Do interpersonal traits predict affect? A comparison of three models. Journal of Personality and Social Psychology, 69, 915-924.

Muraven, M., \& Baumeister, R. F. (2000). Self-regulation and depletion of limited resources: Does self-control resemble a muscle? Psychological Bulletin, 126, 247-259.

Myers, D. G., \& Diener, E. (1995). Who is happy? Psychological Science, 6, 10-19.

Oishi, S., Diener, E., Lucas, R. E. (2007). The optimum level of well-being: Can people be too happy? Perspectives on Psychological Science, 2, 346-360.

Pavot, W., Diener, E., \& Fujita, F. (1990). Extraversion and happiness. Personality and Individual Differences, 11, 1299-1306.

Pickering, A. D., Corr, P. J., \& Gray, J. A. (1999). Interactions and reinforcement sensitivity theory: A theoretical analysis of Rusting and Larsen (1997). Personality and Individual Differences, 26, 357-365.

Reis, H. T, Sheldon, K. M, Gable, S. L., Roscoe, J., \& Ryan, R. M. (2000). Daily wellbeing: The role of autonomy, competence, and relatedness. Personality and Social Psychology Bulletin, 26, 419-35.

Roberts, B. W., \& Donahue, E. M. (1994). One personality, multiple selves: Integrating personality and social roles. Journal of Personality, 62, 199-218.

Robinson, M. D., \& Clore, G. L. (2002a). Belief and feeling: Evidence for an accessibility model of emotional self-report. Psychological Bulletin, 128, 934-960. 
Robinson, M. D., \& Clore, G. L. (2002b). Episodic and semantic knowledge in emotional self-report: Evidence for two judgment processes. Journal of Personality and Social Psychology, 83, 198-215.

Robinson, M. D., Solberg, E. C., Vargas, P. T., \& Tamir, M. (2003). Trait as default: Subjective well-being and the distinction between neutral and positive events. Journal of Personality and Social Psychology, 85, 517-527.

Roesch, S. C. (1999). Modelling the direct and indirect effects of positive emotional and cognitive traits and states on social judgement. Cognition and Emotions, 13, $387-418$.

Ross, M. (1989). Relation of implicit theories to the construction of personal histories. Psychological Review, 96, 341-357.

Rothman, A. J., \& Schwarz, N. (1998). Constructing perceptions of vulnerability: Personal relevance and the use of experiential information in health judgments. Personality and Social Psychology Bulletin, 24, 1053-1064.

Rusting, C. L. (1998). Personality, mood, and cognitive processing of emotional information: Three conceptual frameworks. Psychological Bulletin, 124, 165-196.

Rusting, C. L. (1999). Interactive effects of personality and mood on emotion-congruent memory and judgement. Journal of Personality and Social Psychology, 77, 1073-1086.

Rusting, C. L., \& Larsen, R. J. (1994). Moods as sources of stimulation: relationships between personality and desired mood states. Personality and Individual Differences, 18, 321-32. 
Ryan, R. M., \& Deci, E. L., (2001). On happiness and human potentials: A review of research on eudaimonic well-being. Annual Review of Psychology, 52, 141-166.

Saucier, G. (1994). Mini-markers: A brief version of Goldberg's unipolar big five markers. Journal of Personality Assessment, 63, 506-516.

Schkade, D. A., \& Kahneman, D. (1998). Does living in California make people happy? A focusing illusion in judgments of life satisfaction. Psychological Science, 9, $340-346$.

Schmutte, P. S., \& Ryff, C. D. (1997). Personality and well-being: Reexamining methods and meanings. Journal of Personality and Social Psychology, 73, 549-559.

Schwarz, N. (2000). Emotion, cognition and decision making. Cognition and Emotion, $14,433-440$.

Schwarz, N., \& Clore, G. L. (1983). Mood, misattribution, and judgements of well-being. Informative and directive functions of affective states. Journal of Personality and Social Psychology, 45, 513-523.

Seligman, M. E. P., Steen, T. A., Park, N. \& Peterson, C. (2005). Positive psychology progress: Empirical validation of interventions. American Psychologist, 60, 410-421.

Sheldon, K. M., Ryan, R. M., Rawsthorne, L. J., \& Ilardi, B. (1997). Trait self and true self: Cross-role variation in the Big-Five Personality Traits and its relations with psychological authenticity and subjective well-being. American Psychological Association, 73, 1380-1393. 
Starosta, J. J. (1999). The effects of mood and personality on decisions about social contact. (Doctoral dissertation, Temple University, 1999). Retrieved from ProQuest Dissertations \& Theses. (UMI Microfiber 9955860).

Steel, P., Schmidt, J., \& Shultz, J. (2008). Refining the relationship between personality and subjective well-being. Psychological Bulletin, 134, 138-161.

Suh, E., Diener, E., \& Fujita, F. (1996). Events and subjective well-being: Only recent events matter. Journal of Personality and Social Psychology, 70, 1091-1102.

Tabachnick, B. G., \& Fidell, L. S. (2007). Experimental Designs Using ANOVA. Belmont, CA: Thomson.

Tamir, M., \& Robinson, M. D. (2007). The happy spotlight: Positive moods and selective attention to rewarding information. Personality and Social Psychology Bulletin, $33,1124-1136$.

Teasdale, J. D., Taylor R., \& Fogarty S. J. (1980). Effects of induced elation-depression on the accessibility of memories of happy and unhappy experiences. Behavioral Research Therapy, 18, 339-346.

Tellegen, A. (1985). Structures of mood and personality and their relevance to assessing anxiety, with an emphasis on self-report. In A. H. Tuma \& J. D. Maser (Eds.), Anxiety and the Anxiety Disorders (pp. 681-706). Hillsdale, NJ: Erlbaum.

Tellegan, A., Lykken, D. T., Bouchard, T. J., Wilcox, K. J., Segal, N. L.,\& Rich, S. (1988). Personality similarity in twins reared apart and together. Journal of Personality and Social Psychology, 54, 1031-1039.

Thomas D. L., \& Diener, E. (1990). Memory accuracy in the recall of emotions. Personality Processes and Individual Differences, 59, 291-297. 
Thorpe, L. P. (1941). What about introversion? In L. P. Thorpe and J. N. Holliday (Eds.). Personality and life: A practical guide to personality improvement (pp. 99-121). NY: Longmans, Green and Co.

Uziel, L. (2006). The extraverted and the neurotic glasses are of different colors. Personality and Individual Differences, 41, 745-754.

Vittengl, J. R., \& Holt, C. S. (2000). Getting acquainted: The relationship of selfdisclosure and social attraction to positive affect. Journal of Social and Personal Relationships, 17, 53-66.

Vitterso, J. (2001). Personality traits and subject well-being: Emotional stability, not extraversion, is probably the important predictor. Personality and Individual Differences, 31, 903-914.

Vohs, K. D., Baumeister, R. F., \& Ciarocco, N. J. (2005). Self-regulation and selfpresentation: Regulatory resource depletion impairs impression management and effortful self-presentation depletes regulatory resources. Journal of Personality and Social Psychology, 88, 632-657.

Watson, D., \& Clark, L. A. (1994). The PANAS-X: Manual for the positive and negative affect schedule-expanded form. The University of Iowa.

Watson, D., Clark, L. A., McIntyre, C. W., \& Hamaker, S. (1992). Affect, personality, and social activity. Journal of Personality and Social Psychology, 63, 1011-1025.

Whelan, D. C. (2008). The impact of positive moods on situations preferences and feeling social. Unpublished manuscript, Carleton University.

Wilson, T. D., \& Gilbert, D. T. (2005). Affective forecasting: Knowing what to want. American Psychological Society, 14, 131-134. 
Wilson, T. D., Meyers, J., \& Gilbert, D. T. (2001). Lessons from the past: Do people learn from emotional experience that emotional reactions are short lived? Personality and Social Psychology Bulletin, 27, 1648-1661.

Wilson, T. D., Meyers, J., \& Gilbert, D. T. (2001). “How happy was I anyway?” A retreospective impact bias. Social Cognition, 21, 421-446.

Wilson, T. D., Wheatley, T. P., Meyers, J. M., Gilbert, D. T., \& Axsom, D. (2000). Focalism: A source of durability bias in affective forecasting. Journal of Personality and Social Psychology, 78, 821-836.

Wright, W. E., \& Bower, G. H. (1992). Mood effects on subjective probability assessment. Organizational Behavior and Human Decision Processes, 52, 276291.

Wynn, J., \& Zelenski, J. M. (2007). Errors in affective forecasting: Are they influence by state extraversion and disposition? Unpublished manuscript, Carleton University.

Zelenski, J. M., \& Larsen, R. J. (1999). Susceptibility to affect: A comparison of three personality taxonomies. Journal of Personality, 67, 761-791.

Zelenski, J. M., \& Larsen, R. J. (2002). Predicting the future: How affect-related personality traits influence likelihood of judgments of future events. Personality and Social Psychology Bulletin, 28, 1000-1010. 


\section{Appendix A \\ Goldberg's Mini-Markers for Extraversion (Saucier, 1994) \\ HOW ACCURATELY CAN YOU DESCRIBE YOURSELF?}

Please use this list of common human traits to describe yourself as accurately as possible. Describe yourself as you see yourself at the present time, not as you wish to be in the future. Describe yourself as you are generally or typically, as compared with other persons you know of the same sex and of roughly your same age. Before each trait, please write a number indicating how accurately that trait describes you, using the following rating scale:

Not At

All

1
Somewhat

\section{4}

2
3

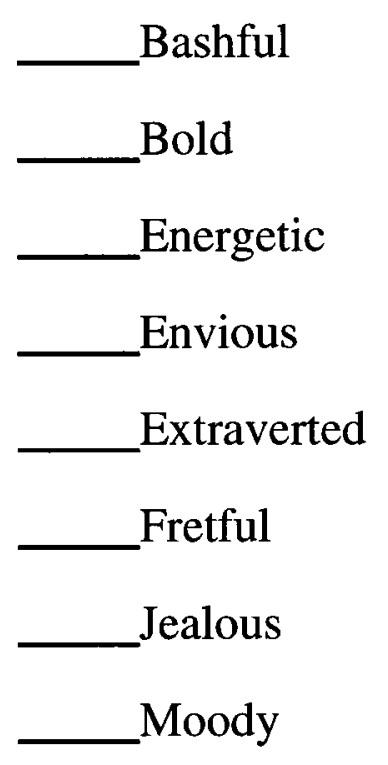

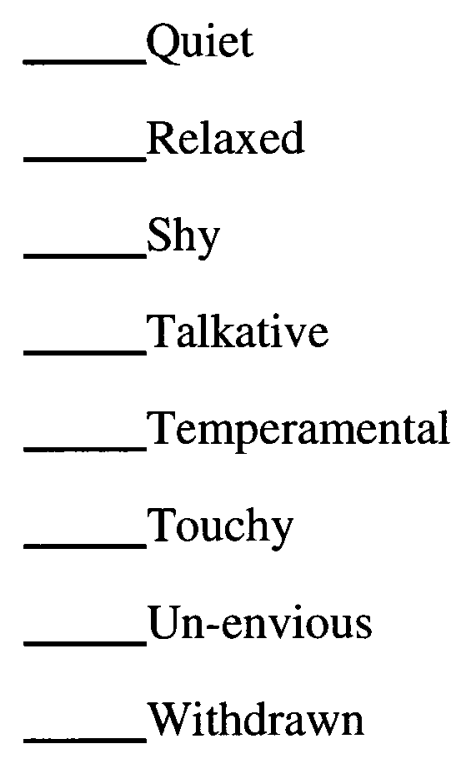




\section{Appendix B \\ Mood Induction Film Clip Descriptions}

"Akeelah and the Bee" positive mood film clip:

An 11 minute clip from the movie "Akeelah and the Bee". The film is an inspirational drama about an eleven-year-old girl from south Los Angeles who competes in the Scripps National Spelling Bee. She creates history in co-winning the event and in turn unites her neighbourhood. Viewers are uplifted and inspirited by this amazing girl.

"Beowulf" neutral mood film clip:

This video clips is of four men having a discussion about the work of writing "Beowulf". The 11 minute roundtable discussion covers such topics as:

- What is the nature of this work of writing?

- The differences between reading the text and seeing it performed.

- A short discussion of the history and mysteries of the text (When was it written? By whom?)

- A short reading from the text is also included. 
Appendix C

Questionnaire to Support Experimental Cover Story

Film and Personality

For each of the 6 items listed below, please rate how descriptive each statement is of you using the scale from 1 to 5 as shown below:

$\begin{array}{ccccc}\begin{array}{c}\text { Disagree } \\ \text { strongly }\end{array} & \begin{array}{c}\text { Disagree a } \\ \text { little }\end{array} & \begin{array}{c}\text { Neither agree } \\ \text { nor disagree }\end{array} & \text { Agree a little } & \begin{array}{c}\text { Agree strongly } \\ 1\end{array} \\ 2 & 3 & 4 & 5\end{array}$

1. __ I enjoyed what I just watched.

3. __ I found this movie or movie clip boring.

4. __ I identified with a character(s) in this movie or movie clip.

5. __ I'm sure I have seen this movie before today.

6. I__ I would recommend to a friend to watch this movie or movie clip. 


\author{
Appendix D \\ Hypothetical Group Discussion Task Instructions
}

\title{
Hypothetical Group Discussion (Acting Extraverted)
}

Imagine that you will be participating in a group discussion. Imagine that in this discussion you will have 10 minutes to decide, as a group, which pieces of equipment would be the least and most important to have if stranded in a winter storm. You will be asked to come to an agreement with your group about how these pieces of equipment should be rank-ordered.

Additionally, imagine that, during this discussion, you are asked to act in a particular way. You will need to try your best to act in that way throughout the discussion.

Specifically, imagine that you were asked to be bold, talkative, energetic, active, assertive, and adventurous. During the entire discussion, you will need to try to act in these ways.

Even though this may not be the way you normally act - imagine that you will act in these ways as much as possible during the entire discussion.

\section{Hypothetical Group Discussion (Acting Introverted)}

Imagine that you will be participating in a group discussion. Imagine that in this discussion you will have 10 minutes to decide, as a group, which pieces of equipment would be the least and most important to have if stranded in a winter storm. You will be asked to come to an agreement with your group about how these pieces of equipment should be rank-ordered.

Additionally, imagine that, during this discussion, you are asked to act in a particular way. You will need to try your best to act in that way throughout the discussion.

Specifically, imagine that you were asked to be reserved, quiet, lethargic, passive, compliant, and unadventurous. During the entire discussion, you will need to try to act in these ways.

Even though this may not be the way you normally act - imagine that you will act in these ways as much as possible during the entire discussion. 


\section{Appendix E \\ Hypothetical Group Discussion Affective Forecasting Questionnaire (Extraversion Version)}

Take a moment to consider the situation you have just imagined and your instructions for it. Remember that you were asked to imagine taking part in a group discussion in which you would act bold, talkative, energetic, active, assertive, and adventurous.

Please anticipate the thoughts and feelings you would have during the discussion, and indicate this below.

Please indicate your agreement with the following statements:

Strongly

Disagree

1

2

Neither Agree

Strongly

nor Disagree

Agree

4

5

6

7

1. I think the discussion will be enjoyable.

2 I will have moments of fun during the discussion.

3 I think I will like the other members of the discussion.

4 I think the other members of the discussion will like me. 
Please indicate how you think you would feel while participating in the discussion.

\section{Very slightly or not at all}

1
Moderately

3

2

Strong

Irritable

Alert

Upset

Active

Nervous

Embarrassed

Pleased

Stimulated

Unhappy

Bored

Drowsy

Calm

Fearful

\begin{tabular}{l} 
Strong \\
Irritable \\
Alert \\
Upset \\
Active \\
\\
Nervous \\
Embarrassed \\
Pleased \\
Stimulated \\
\hline Unhappy \\
Bored \\
Drowsy \\
Calm \\
Fearful
\end{tabular}

4

5

6

Extremely

or a lot

7

\begin{tabular}{l} 
Dull \\
Excited \\
Hostile \\
Jittery \\
Interested \\
Sad \\
\hline Worried \\
Relaxed \\
Distressed \\
Quiet \\
Idle \\
Happy \\
Full of Energy \\
Self-Conscious
\end{tabular}




\section{Appendix F \\ Social Situations Questionnaire (Modified from Whelan, 2008)}

Please list to what degree you feel you would experience positive emotions in the following situations.

Very slightly or not at all 1
Moderately

3

4

5

6

Extremely

or a lot

7

1. Playing a team sport (such as soccer, baseball, volleyball, etc).

2. Doing laundry by yourself.

3. Taking photos of nature (flowers, plants, etc).

4. Participating in a group discussion in class.

5. Working with classmates on a group project.

6. Curling up with a good book.

7. Going to a museum with a small group of friends

8. Looking out at the stars on a clear summer evening.

9. Participating in a University club (martial arts, canoeing, intramurals, etc).

10. Starting a road trip with two of your closest friends.

11. Going to a BBQ.

12. Watching your favorite TV show by yourself.

13. Going to the beach to suntan by yourself.

14. Taking a long shower after a good workout.

15. Going to a small local fair with family.

16. Sleeping in and relaxing after a busy week.

17. Attending a "networking" event for your department.

18. Reading for an upcoming class in the library.

19. Making lunch in a quiet kitchen, alone.

20. Riding in a car with a bunch of friends listening to music.

21 . Browsing in a bookstore by yourself.

22. Relaxing in a hot tub listening to the water.

23. Going out for coffee with an old friend.

24. Going for a walk by yourself.

25. Attending a wine and cheese event.

26. Playing solitaire.

27. Going to the market with a friend to get fresh fruits and vegetables.

28. Talking with 3 strangers while in an elevator together. 


\author{
Appendix G \\ Imagination Questionnaire
}

\title{
Please indicate your agreement with the following statements:
}

\begin{tabular}{ccccccc} 
Strongly & \multicolumn{3}{c}{$\begin{array}{c}\text { Neither Agree } \\
\text { nor Disagree }\end{array}$} \\
$\begin{array}{c}\text { Disagree } \\
1\end{array}$ & 2 & 3 & 4 & 5 & 6 & 7
\end{tabular}

1. I have a good imagination.

2. When someone describes a scene to me, I can easily picture it in my mind.

3. I find it difficult to imagine how I will feel in future situations.

4. I often imagine myself feeling things that I am likely to experience later.

5. When I imagine things, I am able to see a vivid image in my mind.

6. I rarely imagine myself in situations before I experience them.

7. I use my imagination often.

8. It is easy for me to imagine how I will feel in response to future events.

9. I find it difficult to imagine scenes in my mind

10. When I use my imagination, I can picture scenes quite accurately.

11. I find it difficult to picture myself in future events.

12. When I imagine myself doing something, the images and feelings I experience are usually close to real life outcomes. 


\author{
Appendix $\mathrm{H}$ \\ Recruiting Scripts
}

\title{
Email Text
}

Still looking to participate in a research study in order to get credit for your psychology course??

You participated in mass testing for the introductory psychology class at the start of the school year, and now is your chance to get the rest of your extra credit for your psychology class before the term ends. We are currently conducting a study called "Film and Personality". The purpose of the study is to examine how people with different personality types react to the same hypothetical situation. The study will take less than 30 minutes to complete and you will receive half a credit towards your $4 \%$ extra marks in your psychology class or $10 \$$.

We have the following testing times available in the coming weeks:

\section{List times slots available}

If you are interested in participating in this study, you can log onto the SONA system and sign up on your own at:

http://carleton.sona-systems.com/default.asp

If you choose to participate in the "film and personality study" you need the password to sign up online. The password is: signmeup. If you have trouble signing, feel free to email and let me know when you would like to participate in the study.

Thank you very much for considering our study! Your participation is extremely valuable and very much appreciated.

\section{Phone Script}

$\mathrm{Hi}$, this is calling from the department of psychology at Carleton University.

We are currently running a study in the CUHL lab and looking for participants. The study is called "Film and Personality". The purpose of the study is to examine how people with different personality types react to the same hypothetical situation. The study will take less than 30 minutes to complete and you will receive half a credit towards your $4 \%$ extra marks in your psychology class, or $10 \$$.

Would you be interested in participating in this study?

We have the following testing times available in the coming weeks:

List times slots available

If Yes: Thank you very much for signing up for our study! Your participation is extremely valuable and very much appreciated.

If No: Thanks so much for you time. Have a nice day. 


\author{
Appendix I \\ Informed Consent Form
}

The purpose of an informed consent is to insure that you understand the purpose of the study and the nature of your involvement. The informed consent must provide sufficient information such that you have the opportunity to determine whether you wish to participate in the study.

Present study: Film and Personality

Research personnel. The following people are involved in this research project and may be contacted at any time: Dr. John Zelenski (Faculty Sponsor, 520-2600 ext. 1609), or Christina Besner (email: cbesner@connect.carleton.ca). Should you have any ethical or other concerns about this study then please contact Dr. Avi Parush, Chair, Carleton University Ethics Committee for Psychological Research, (520-2600, ext. 6026) or Dr. Anne Bowker (Chair, Dept. of Psychology, 520-2600, ext. 2648).

Purpose. The purpose of this study is to examine how people with different personality types react to the same situations or events. For this experiment film clips will be utilized as the stimulus.

Task requirements. Participants will be asked to view a brief clip and complete a questionnaire about a hypothetical situation.

Duration and locale. The experimental session will last about 30 minutes and you will receive $0.5 \%$ increase in your final grade of PSYC 1001 or PSYC 1002 for participating. Testing will take place at Carleton University.

Potential risk/discomfort. There is no anticipated risk or discomfort involved in this study.

Anonymity/confidentiality. The data collected in this experiment are strictly confidential. All data are coded such that your name is not associated with the data.

Right to withdraw. You may withdraw from the study at any time without academic penalty. You may also choose to skip (i.e., not answer) questions you find objectionable for any reason without penalty.

\title{
Signatures
}

I have read the above form and understand the conditions of my participation. My participation in this study is voluntary, and if for any reason, at any time, I wish to leave the experiment I may do so without having to give an explanation and with no penalty whatsoever. Furthermore, I am also aware that the data gathered in this study are confidential and anonymous with respect to my personal identity. My signature indicates that I agree to participate in the study.

Participant's Name: Participant's Signature:

Researcher's Name: Researcher's Signature:

Date 


\author{
Appendix J \\ Debriefing Sheet
}

What are we trying to learn in this research \& why is it important to scientists/the general public? This project examines how moods affect our choices to join social situations. Participants were shown either a happy or neutral film or film clip. Then we assessed how people think they would feel in a social situation after being put in a positive mood versus a neutral mood. Research has found that when people participate in social situations they report more/higher levels of positive moods. Extraverts have been found to have higher levels of positive emotions and have been found to participate in social situations more frequently than introverts.

This research is examining if the decision to participate in social situations may be partially due to individuals' moods during the decision making process (i.e., which came first, the positive mood and then the social situation or vice-versa). If, when people are in a good mood, they predict they will enjoy social situations more, they may be more inclined to decide to participate in social situations.

Personality may also play a role in this research. Introverts tend to report that they will not enjoy social situations as much as extroverts report they will enjoy them. However, it turns out that both introverts and extroverts tend to enjoy some social situations equally. It may be that, while introverts sometimes don't predict they will enjoy social situations, they may predict enjoying them more if they are in a positive mood.

\title{
What are our hypotheses and predictions?
}

We predict that people in a good mood (i.e., those who watched a happy movie clip) will report that they would enjoy the hypothetical social situation more than those in a neutral mood. Also, we predict that introverts will "catch up" to extroverts in their predictions about liking a social situation. Thus, while introverts in a neutral mood may report that they would like the social situation less than extroverts, we think that introverts in a positive mood should report that they would like the social situation just as much as extroverts.

\section{Right to withdraw data.}

The data collected in this study are kept confidential. You have the right to indicate that you do not wish your data to be used in this study. If you indicate this is your choice, all measures you completed will be destroyed but you will still receive your $0.5 \%$ increase in grade or $10 \$$.

\section{Where can I learn more?}

You may want to look at the following articles for more information of affective forecasting and personality

Wilson, T.D., \& Gilbert, D.T. (2005). Affective forecasting: Knowing what to want. Current Directions in Psychological Science, 14, 131-134.

Zelenski, J.M., \& Larsen, R.J. (2002). Predicting the future: How affect-related personality traits influence likelihood judgments of future events. Personality and Social Psychology Bulletin, 28, 1000-1010.

Is there anything I can do if I found this experiment to be emotionally upsetting?

Yes. Please feel free to contact the Carleton University Health and Counselling Services at 520-6674, or the Distress Centre of Ottawa and Region at 238-3311.

\section{What if I have questions later?}

If you have any remaining concerns, questions, or comments about the experiment please feel free to email Christina Besner at cbesner@connect.carleton.ca, or speak to Dr. John Zelenski (520-2600 $\mathrm{x} 1609$ ). If you have any ethical concerns you can also discuss them Dr. Avi Parush, Chair, Carleton University Ethics Committee for Psychological Research, (520-2600, ext. 6026) or Dr. Anne Bowker (Chair, Dept. of Psychology, 520-2600, ext. 2648). 